\title{
Numerical modeling of deformations caused by carbon dioxide sequestration in coal seams
}

\author{
Xiaochao Tang \\ West Virginia University
}

Follow this and additional works at: https://researchrepository.wvu.edu/etd

\section{Recommended Citation}

Tang, Xiaochao, "Numerical modeling of deformations caused by carbon dioxide sequestration in coal seams" (2006). Graduate Theses, Dissertations, and Problem Reports. 4275.

https://researchrepository.wvu.edu/etd/4275

This Thesis is protected by copyright and/or related rights. It has been brought to you by the The Research Repository @ WVU with permission from the rights-holder(s). You are free to use this Thesis in any way that is permitted by the copyright and related rights legislation that applies to your use. For other uses you must obtain permission from the rights-holder(s) directly, unless additional rights are indicated by a Creative Commons license in the record and/ or on the work itself. This Thesis has been accepted for inclusion in WVU Graduate Theses, Dissertations, and Problem Reports collection by an authorized administrator of The Research Repository @ WVU. For more information, please contact researchrepository@mail.wvu.edu. 


\title{
Numerical Modeling of Deformations Caused by Carbon Dioxide Sequestration in Coal Seams
}

\author{
Xiaochao Tang \\ Thesis submitted to \\ College of Engineering and Mineral Resources \\ at West Virginia University \\ in partial fulfillment of the requirements \\ for the degree of \\ Master of Science \\ in \\ Civil Engineering \\ Hema J. Siriwardane, Ph.D., Chair \\ Thomas H. Wilson, Ph.D. \\ Roger C. Viadero, Ph.D. \\ Department of Civil and Environmental Engineering \\ Morgantown, West Virginia \\ 2006
}

Keywords: Carbon Sequestration, Coal Seam, FEM Analysis, Deformation 


\section{ABSTRACT \\ Numerical Modeling of Deformations Caused by Carbon Dioxide Sequestration in Coal Seams}

Xiaochao Tang

Atmospheric concentrations of $\mathrm{CO}_{2}$, as the most prevalent greenhouse gas, have been dramatically increased due to the anthropogenic emission mainly from fuel combustion. Geologic sequestration of $\mathrm{CO}_{2}$ in coal seams is an attractive choice to mitigate global $\mathrm{CO}_{2}$ emissions and its consequences. It can also provide secondary benefits such as enhanced coalbed methane production.

Three coal sites from Appalachian basin and Black Warrior basin were selected to numerically study the effects of $\mathrm{CO}_{2}$ injection in coal seams on overburden deformations. Finite element method was used for the analysis of overburden response. The analysis consisted of two phases $-\mathrm{CO}_{2}$ injection and pore pressure dissipation after the termination of injection. The selected sites have differential geologic characters. The distribution of pore pressure from the analysis indicates that injected $\mathrm{CO}_{2}$ was primarily confined within the target coal seam. Modeling results show ground heaving in response to $\mathrm{CO}_{2}$ injection. Effects of elastic modulus, reservoir permeability and injection pressure on $\mathrm{CO}_{2}$ sequestration in coal seams were investigated. Results show that elastic modulus has a significant influence on the amounts of injected $\mathrm{CO}_{2}$ and the propagation of $\mathrm{CO}_{2}$ plume. Injection pressure is proportional to the injection amount of $\mathrm{CO}_{2}$.

Deformation of the strata overlying the injection points can be one of the concerns related to high-pressure injection. Small vertical displacements at the ground surface were observed during the numerical analysis of all the selected sites. In fact, the overburden deformations at ground surface $\mathrm{CO}_{2}$ can be expected to be very small due to the depth of injection points. However, constant measurements of surface deformation can be used to monitor the movement of $\mathrm{CO}_{2}$ plume to detect large amount of $\mathrm{CO}_{2}$ leakage.

The screening criteria for selection of sites should include reservoir properties such as elastic properties, permeability, porosity, reservoir thickness and depth. Also, these properties for overburden strata can influence the overburden response during and after geologic sequestration of $\mathrm{CO}_{2}$ in coal seam. 


\section{ACKNOWLEDGEMENTS}

The author would like to express his sincere appreciation to his research advisor and committee chairman, Dr. Hema J. Siriwardane, for his continuous guidance, advice, and encouragement to the author throughout this thesis work. I also wish to thank Dr. Roger C. Viadero and Dr. Thomas H. Wilson for their participation in the examining committee and review of this thesis.

The financial support provided by U.S. Department of Energy for this project through the ZERT program at West Virginia University is greatly acknowledged. The author would like to thank his friends, G. Raj Kumar and Ronald Ingram for their help and encouragement during this research.

Special appreciations are expressed to the author's family for their valuable love and constant support. 


\section{TABLE OF CONTENTS}

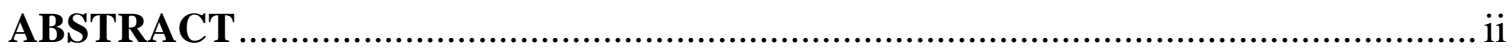

ACKNOWLEDGEMENTS ............................................................................... iii

TABLE OF CONTENTS ………………………………..................................... iv

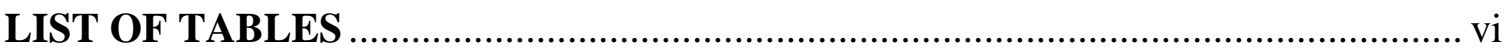

LIST OF FIGURES ............................................................................................... vii

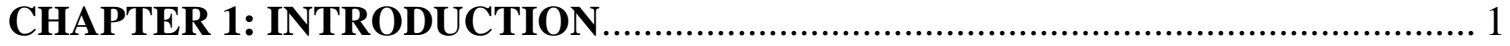

1.1 Background ..................................................................................................... 1

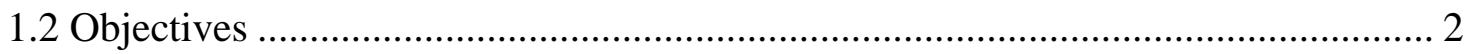

CHAPTER 2: LITERATURE REVIEW ........................................................... 5

2.1 Physical Properties of Coal ............................................................................. 5

2.1.1 Dual-Porosity System of Coal Seams ............................................................... 5

2.1.2 Stress and Shrinkage/Swelling Influences on Permeability................................ 6

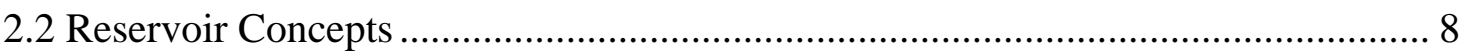

2.2.1 Gas Storage in Coal Seams .......................................................................... 8

2.2.2 Gas Flow in Coal Seams ......................................................................... 9

2.2.2.1 Diffusion in Coal Matrix....................................................................... 9

2.2.2.2 Darcy Flow in Cleats ................................................................................. 11

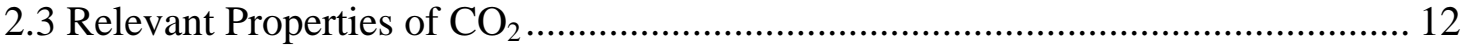

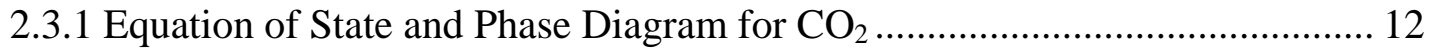

2.3.2 Viscosity of Carbon Dioxide ..................................................................... 13

2.4 Coalbed Methane Enhancements with $\mathrm{CO}_{2}$ Sequestration ...................................... 15

2.5 Environment and Safety Aspects of $\mathrm{CO}_{2}$-ECBM and Underground Injection....... 17

Control (UIC) Program ............................................................................................ 17

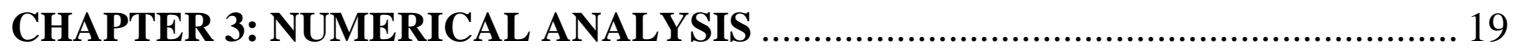

3.1 Effective Stress Principle for Porous Media............................................................. 19

3.1.1 Effective Vertical Stress Concepts for Fully Saturated Porous Media ............ 19

3.1.2 Effective Stress Concept for Partially Saturated Porous Media ....................... 20

3.2 Equilibrium Equations for Porous Media ................................................................... 21

3.3 Constitutive Behavior of Porous Media................................................................. 23

3.3.1 The Response of the Solid Grain ................................................................... 23 
3.3.2 The Response of the Liquid ....................................................................... 24

3.4 Continuity Equation for the Conservation of the Fluid Mass .................................. 25

3.5 Procedure for the Numerical Analysis ................................................................ 26

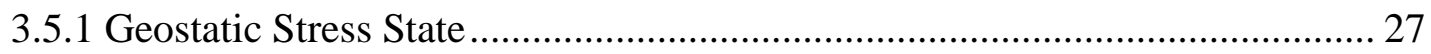

3.5.2 Initial Conditions and Boundary Conditions .................................................... 27

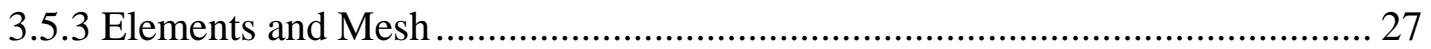

CHAPTER 4: ANALYSIS OF $\mathrm{CO}_{2}$ INJECTION IN GRANNY CREEK FIELD ... 29

4.1 Overview of the Appalachian Basin ............................................................................ 29

4.2 The Granny Creek field in Northern Appalachian basin ......................................... 31

4.3 Finite Element Model .......................................................................................... 36

4.4 Distribution of the Pore Pressure .......................................................................... 36

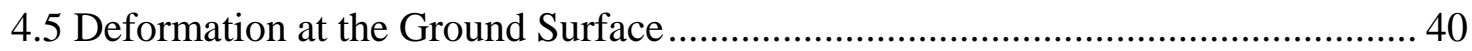

4.6 Discussion on the Numerical Analysis of $\mathrm{CO}_{2}$ Injection in Granny Creek Field... 43

4.7 Effects of Permeability of Coal Seams on $\mathrm{CO}_{2}$ Sequestration ................................ 43

4.8 Effects of Elastic Modulus on $\mathrm{CO}_{2}$ Sequestration in Coal Seams ........................... 45

\section{CHAPTER 5: ANALYSIS OF $\mathrm{CO}_{2}$ INJECTION AT A SITE IN MARSHALL}

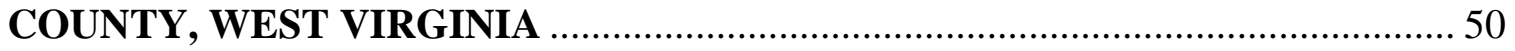

5.1 Description of the Pilot Project for $\mathrm{CO}_{2}$ Sequestration ............................................ 50

5.2 Numerical Study on the Effects of Injection Pressure ............................................. 53

\section{CHAPTER 6: ANALYSIS OF $\mathrm{CO}_{2}$ INJECTION IN PRATT COAL ZONE OF}

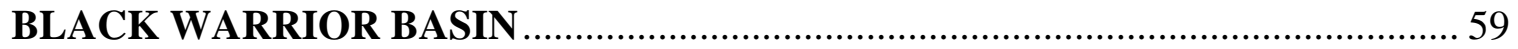

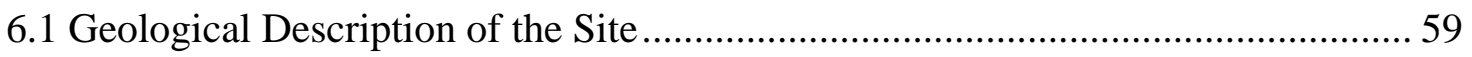

6.2 Geothermal and Pressure Conditions of the Reservoir .............................................. 61

6.3 Geomechanical Properties of the Overlying Strata.................................................... 62

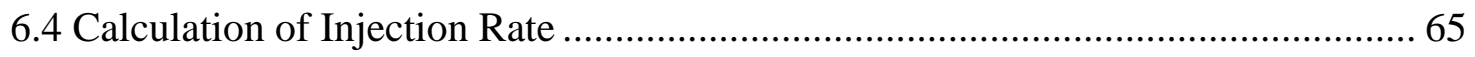

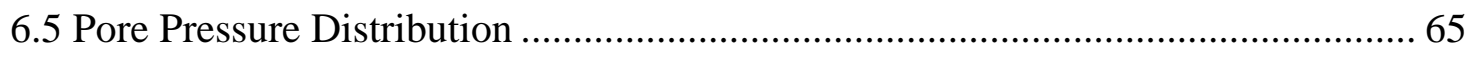

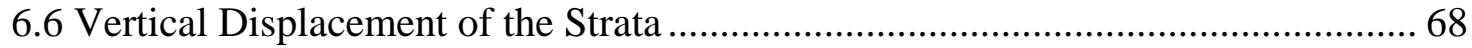

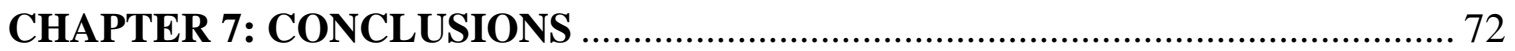

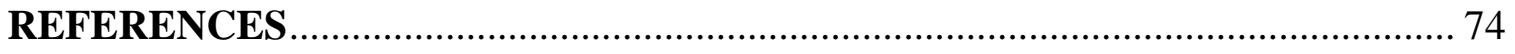

APPENDIX A - RESULTS FOR THE SITE IN MARSHALL COUNTY, WEST

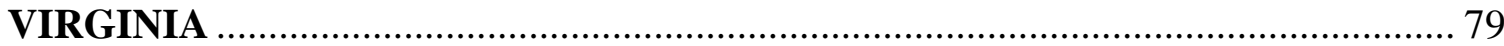




\section{LIST OF TABLES}

Table 2.1 The properties of carbon dioxide at triple point and critical point .................. 13

Table 4.1 Material properties used in the analysis for Granny Creek field ..................... 35

Table 5.1 Hypothetical properties of strata for the FEM model .................................... 53

Table 6.1 Material properties used in the analysis for Pratt coal zone ........................... 63 


\section{LIST OF FIGURES}

Figure 1.1: A schematic diagram for the sequestration of $\mathrm{CO}_{2}$ in coal seams.................. 4

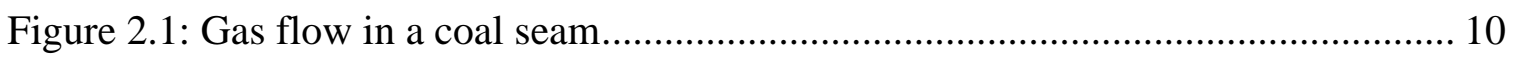

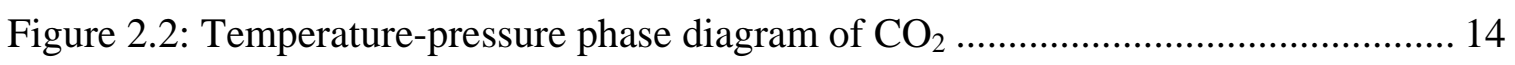

Figure 2.3: Viscosity of $\mathrm{CO}_{2}$ versus temperature with the variation of pressure ............. 16

Figure 3.1: Node ordering and face numbering for the 4-node element.......................... 28

Figure 4.1: Extent of the Appalachian basin coal region (Ruppert and Rice, 2001) ........ 30

Figure 4.2: Assumed lithologic column for Granny Creek field .................................... 32

Figure 4.3: Reservoir conditions at the Granny Creek field shown on the phase diagram

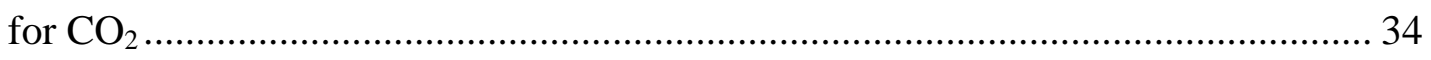

Figure 4.4: Non-uniform finite element mesh for the axisymmetric model for Granny Creek case 37

Figure 4.5: 3-D view of the non-uniform finite element mesh of the axisymmetric model

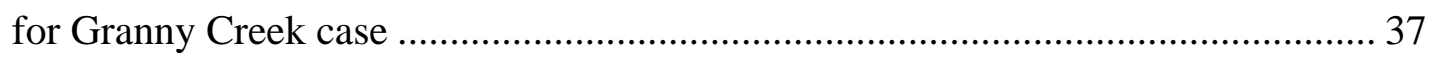

Figure 4.6: Distribution of the excess pore pressure at the end of injection period ......... 38

Figure 4.7: Distribution of the excess pore pressure at the end of dissipation period...... 38

Figure 4.8: Pore pressure dissipation with time after $\mathrm{CO}_{2}$ injection.............................. 39

Figure 4.9: Vertical displacement of the strata at the end of injection period ................. 41

Figure 4.10: Vertical displacement of the strata at the end of the dissipation period....... 41

Figure 4.11: 3-D view of the strata deformation at the end of 365-day injection............ 41

Figure 4.12: Variation of vertical displacement at the ground surface with time............ 42

Figure 4.13: Effects of permeability on $\mathrm{CO}_{2}$ injection amount ................................... 44

Figure 4.14: Effects of elastic modulus on $\mathrm{CO}_{2}$ injection amount ................................. 46

Figure 4.15: Variation of vertical displacement at ground surface with elastic modulus. 47

Figure 4.16: Influence of elastic modulus on the pore pressure distribution at the end of ..

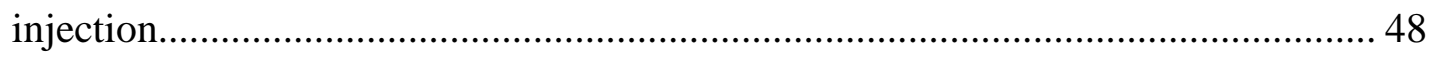

Figure 5.1: Location of the pilot sequestration site (after Cairns, 2002) ........................ 51

Figure 5.2: Schematic of the pilot site for $\mathrm{CO}_{2}$ sequestration in Marshall County, West

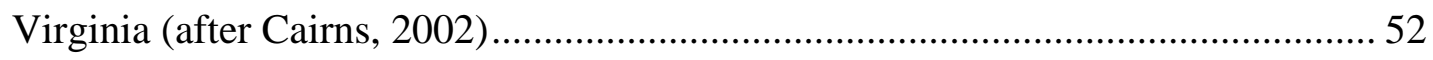

Figure 5.3: Assumed lithologic column for a site at Marshall County, West Virginia .... 54 
Figure 5.4: FEM model for the Marshall County site in Appalachian basin .................... 55

Figure 5.5: Cut view of the model for Marshall County site in Appalachian basin ......... 55

Figure 5.6: Injection amount versus injection pressure ........................................... 57

Figure 5.7: Flow vectors in the reservoir on the $45^{\text {th }}$ day after $\mathrm{CO} 2$ injection ................. 58

Figure 6.1: Assumed lithologic column for Pratt coal zone ........................................ 60

Figure 6.2: Reservoir conditions for Black Warrior basin on the phase diagram of $\mathrm{CO}_{2}$

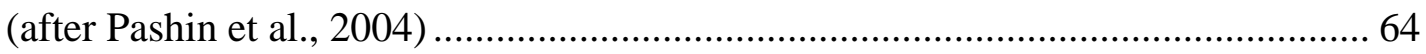

Figure 6.3: Distribution of pore pressure at the end of $\mathrm{CO}_{2}$ injection period.................. 66

Figure 6.4: Distribution of pore pressure at the end of $\mathrm{CO}_{2}$ dispersion period ................ 66

Figure 6.5: The dissipation of pore pressure with time after injection ........................... 67

Figure 6.6: Displacement of ground surface at the end of injection period..................... 69

Figure 6.7: Displacement of ground surface at the end of dispersion period .................. 69

Figure 6.8: 3-D view of the vertical displacement at $\mathrm{t}=365$ days .............................. 70

Figure 6.9: Variation of vertical displacements at the ground surface with time ............ 71

Figure A.1: Distribution of the excess pore pressure at the end of injection and dissipation

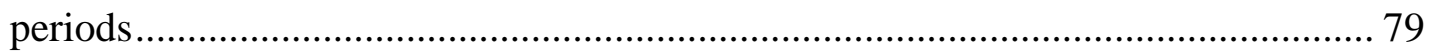

Figure A.2: Pore pressure dissipation after $\mathrm{CO}_{2}$ injection at the site in Marshall County,

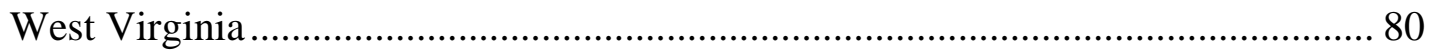

Figure A.3: Vertical displacement of the strata at the end of $\mathrm{CO}_{2}$ injection ................... 81

Figure A.4: Vertical displacement of the strata at the end of dissipation period.............. 81

Figure A.5: 3-D view of the strata deformation at the end of $\mathrm{CO}_{2}$ injection ................... 82

Figure A.6: Vertical displacement at the ground surface at the Marshall county case..... 83 


\section{CHAPTER 1: INTRODUCTION}

\subsection{Background}

Anthropogenic greenhouse gases (GHGs) mainly include carbon dioxide $\left(\mathrm{CO}_{2}\right)$, methane $\left(\mathrm{CH}_{4}\right)$, nitrous oxide $\left(\mathrm{N}_{2} \mathrm{O}\right)$, chlorofluorocarbons (CFCs), hydrofluorocarbons $\left(\mathrm{HFC}_{\mathrm{s}}\right)$, perfluorocarbons $\left(\mathrm{PFC}_{\mathrm{s}}\right)$, and sulphur hexafluorides $\left(\mathrm{SF}_{6}\right)$ (IPCC, 2001). These gases in the atmosphere absorb the heat radiation from the surface of the earth causing the earth temperature to rise. This increase in temperature is known as the greenhouse effect. It has been pointed out that the atmospheric concentrations of greenhouse gases have been dramatically changed by human activities (IPCC, 2001). Among these anthropogenic greenhouse gases, $\mathrm{CO}_{2}$ has been considered the most prevalent, accounting for $83.9 \%$ of total U.S. greenhouse gas emissions in 2004 (DOE, 2005 a). Furthermore, studies have shown that $\mathrm{CO}_{2}$ has increased by 31\% from 280 parts per million (ppm) in pre-industrial era to $367 \mathrm{ppm}$ in 1999 (DOE, 2002). The current $\mathrm{CO}_{2}$ concentration level in the atmosphere is the highest level reached during the past 420,000 years (IPCC, 2001). Also, the present emission rate of $\mathrm{CO}_{2}$ is the highest in nearly the past 20,000 years (IPCC, 2001). Fuel combustion accounts for three quarters of the anthropogenic emissions of $\mathrm{CO}_{2}$ to the atmosphere during the past 20 years (DOE, 2005 a).

Along with the increased concentration of atmospheric $\mathrm{CO}_{2}$, global average surface

temperature of the earth has increased by approximate $0.6 \pm 0.2{ }^{0} \mathrm{C}$ over the last century (IPCC, 2001). Intergovernmental Panel on Climate Change (IPCC) has predicted an average global rise in temperature of $1.4{ }^{\circ} \mathrm{C}$ to $5.8{ }^{\circ} \mathrm{C}$ between 1990 and 2100. Although the cause and effect relation between the atmospheric concentration of $\mathrm{CO}_{2}$ and global warming is still uncertain, the increase in emissions of $\mathrm{CO}_{2}$ and other GHGs has caused public concerns worldwide (EPA, 2005). In 1992, 154 nations signed and ratified the United Nations Framework Convention on Climate Change (UNFCCC) (EPA, 2005). The ultimate objective of UNFCCC is the "stabilization of greenhouse gas concentrations in the atmosphere at a level that would prevent dangerous anthropogenic interference with the 
climate system” (EPA, 2005). As an amendment to UNFCCC, Kyoto Protocol initiated in 1997 has been ratified by 162 countries. According to the Kyoto Protocol, the industrialized countries are expected to reduce their collective emissions of GHGs by 5.2\% of 1990 levels by the year 2010 (EPA, 2005). Sequestration of carbon has been considered as one approach to reduce anthropogenic $\mathrm{CO}_{2}$ emission and its atmospheric concentration (DOE, 2005 b).

Carbon sequestration is the capture and safe storage of carbon that would otherwise emit to the atmosphere (DOE, 1999). Geologic sequestration has been identified as one of the sequestration technologies. Geologic sequestration of $\mathrm{CO}_{2}$ is the disposal of it into underground formations such as oil and gas reservoirs, saline aquifers, and coal seams for geologically significant periods of time (Bachu, 2002). Significant importance has been given to the geologic sequestration of $\mathrm{CO}_{2}$ considering its enormous capacity for $\mathrm{CO}_{2}$

sequestration. Moreover, geologic sequestration of $\mathrm{CO}_{2}$ can provide other economic benefits such as enhanced oil recovery (EOR) and enhanced coalbed methane (ECBM) production. Sequestration of $\mathrm{CO}_{2}$ in coal seams is an excellent option since coal seams are often located close to power generation plants that produce large $\mathrm{CO}_{2}$ emissions (Reeves, 2001). Because of the proximity, the infrastructure cost would be lower. Figure 1.1 shows a schematic diagram of the sequestration of $\mathrm{CO}_{2}$ along with ECBM production in coal seams. In this scenario, $\mathrm{CO}_{2}$ usually is captured from a point-source, such as a power generation plant and pumped into the coalbed methane reservoirs. In reservoirs, the displacement of $\mathrm{CH}_{4}$ by $\mathrm{CO}_{2}$ can occur because the sorption capacity of coal for $\mathrm{CO}_{2}$ over methane can be approximately 2:1 or even greater (Mavor et al., 2002). The production of coalbed methane can be enhanced by injection of $\mathrm{CO}_{2}$, which can compensate for the cost of sequestration of $\mathrm{CO}_{2}$ in coal seams. This may even be profitable.

\subsection{Objectives}

The objective of the investigation presented in this report is to better understand the geomechanical response of the overburden strata to $\mathrm{CO}_{2}$ sequestration in coal seams. In 
order to fulfill this goal, this research work concentrates on the following specific objectives:

1. Gain basic knowledge of $\mathrm{CO}_{2}$ properties for geologic sequestration in coal seams. This mainly includes relevant properties of coal and $\mathrm{CO}_{2}$, and reservoir concepts for enhanced coalbed methane production.

2. Collect preliminary information for potential sequestration sites in the Appalachian basin. This includes geophysical data and geomechanical properties of different rock types at these sites.

3. Perform coupled flow-deformation analysis by using the Finite Element Method (FEM) to investigate the geomechanical response of the overburden strata during and after injection of $\mathrm{CO}_{2}$ in a hypothetical geologic sequestration operation in a coal seam. 


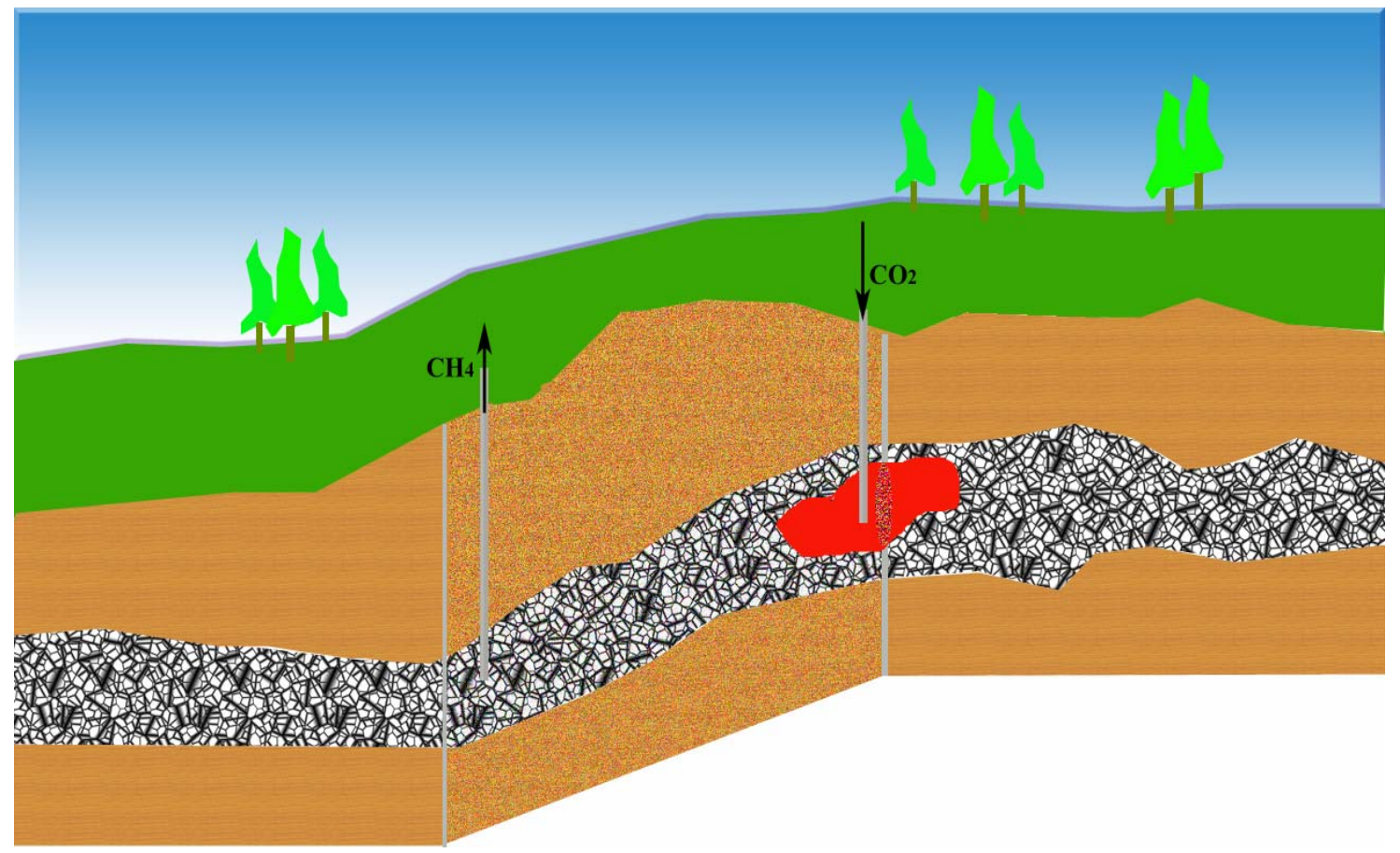

Figure 1.1: A schematic diagram for the sequestration of $\mathrm{CO}_{2}$ in coal seams 


\section{CHAPTER 2: LITERATURE REVIEW}

Investigations of several issues with respect to geophysics, geomechanics, geology, and reservoir engineering are necessary for large-scale geological sequestration of $\mathrm{CO}_{2}$ in coal seams. Geologic sequestration in coal seams can reduce $\mathrm{CO}_{2}$ emissions while enhancing coalbed methane production. This chapter provides a review of relevant properties of coal such as structure, stress-dependent permeability, and swelling and shrinkage. The pressure and temperature at reservoir conditions are expected to be significantly higher than atmospheric values. These conditions could potentially change the properties of injected $\mathrm{CO}_{2}$, and certain properties of $\mathrm{CO}_{2}$ are also reviewed in this section.

\subsection{Physical Properties of Coal}

As the geological storage host for $\mathrm{CH}_{4}$ and $\mathrm{CO}_{2}$, properties of coal are of critical importance for enhanced methane recovery using carbon dioxide. The transport of $\mathrm{CH}_{4}$ and $\mathrm{CO}_{2}$ through the coal seam is dependent on not only the flowability of the seam but also diffusion through the coal matrix. In this section, porosity of coal and permeabilityrelated properties are investigated. Other properties such as rank, mineral content and moisture content can also influence the capacity of $\mathrm{CO}_{2}$ adsorption and $\mathrm{CH}_{4}$ desorption.

\subsubsection{Dual-Porosity System of Coal Seams}

Early studies indicate that coal has a unique pore structure (Gan et al., 1972) consisting of macropores and micropores, which constitute the dual-porosity system of coal. Macropores and micropores are distinguished by their sizes. Macropores consist of natural fractures such as cleat system, joints and fault-related fractures. In particular, cleat system plays a major role in the transport of gases with a relatively high permeability, typically ranging from 3 to 30 millidarcy (md) (Rogers, 1994). Cleat systems consist of two sets of perpendicular fractures called the face cleat and butt cleat. Face cleats in general are continuous while butt cleats often terminate against the face 
cleat. Cleat systems usually contain less than $10 \%$ of the gas trapped within the coal seam. Cleat porosity is generally $1 \%$ to $5 \%$ (Rogers, 1994). As a result of the different structures between the face cleat and butt cleat, permeability anisotropy is expected.

The coal matrix represents micropores of the dual-porosity system because of its very fine micropore structure. In contrast to the cleat system, the coal matrix has an extremely low flow capacity but a very high gas storage capacity. An equivalent permeability of $10^{-9}$ to $10^{-12} \mathrm{md}$ for the coal matrix has been reported (Rogers, 1994). Coal matrix has methane storage capacity ranging from 300 to $400 \mathrm{scf} /$ ton in Black Warrior basin (Rogers, 1994). Most of the exchanges between $\mathrm{CO}_{2}$ and $\mathrm{CH}_{4}$ occur in the coal matrix through the processes of adsorption and desorption.

\subsubsection{Stress and Shrinkage/Swelling Influences on Permeability}

Permeability is one of the most important parameters governing the flow of $\mathrm{CO}_{2}$ in coal seams. Parameters such as the frequency of the natural fractures, their interconnections, size of aperture opening, direction of butt and face cleats, water saturations, burial depths, matrix shrinkage upon desorption and swelling during adsorption, and in situ stresses have an influence on the permeability of the reservoir (Rogers, 1994). The relationship between the permeability and hydraulic conductivity can be expressed as:

$$
K=\frac{k \rho g}{\mu}
$$

$K$ - hydraulic conductivity, $\mathrm{ft} / \mathrm{h}$

$k$ - intrinsic permeability, $\mathrm{ft}^{2}$

$\rho$ - density of the fluid, pcf

$\mu$ - dynamic viscosity of the fluid, $\mathrm{lb} / \mathrm{ft} \cdot \mathrm{h}$

Equation 2.1 shows that hydraulic conductivity depends on both solid and fluid properties. Intrinsic permeability depends on the geometric properties of the coal reservoir. Density and dynamic viscosity have an influence on the hydraulic 
conductivity. In this study, hydraulic conductivity was used as an input in the finite element analysis of the coupled flow-deformation analysis.

Studies have demonstrated that there is a relationship between the reduction of permeability and the increase of effective stress. An equation of stress-dependent permeability was established for an Australian coal (Gray, 1987):

$$
k=1.013 \times 10^{-45 \sigma^{\prime}}
$$

where $k$ - permeability in md

$$
\sigma^{\prime} \text { - effective stress in psi }
$$

This equation indicates that permeability approximately decreases by one order of magnitude with every increase of 435 psi in effective stress.

Typically, permeability of coal seams declines exponentially with the increase of stress (White et al., 2005). Based on the assumption of incompressible grains, an equation for permeability has been reported in the literature (McKee et al., 1988):

$$
k=k_{0} e^{-3 c \Delta \sigma^{\prime}}
$$

where $k_{0}$ - initial permeability in the unit of md $c$ - constant average pore compressibility in the unit of $\mathrm{psi}^{-1}, 1.87 \times 10^{-3} \mathrm{psi}^{-1}$ for Black Warrior basin.

$\Delta \sigma^{\prime}$ - change of effective stress in the unit of psi

This relationship was found to closely fit the laboratory data and field data from Black Warrior basin (McKee et al., 1988). 
The phenomena of shrinkage and swelling of coal matrix occur in the process of gas exchange between $\mathrm{CO}_{2}$ and $\mathrm{CH}_{4}$. Coal matrix shrinks along with $\mathrm{CH}_{4}$ desorption, which can open up the cleats causing an increase in permeability. A rapid increase of permeability along with an increased effective stress was observed at a certain pressure where significant desorption of $\mathrm{CH}_{4}$ occurs (Harpalani and Schraufnagel, 1990). This suggests that the process of desorption impacts more on the change of permeability than the effective stress does. By using non-adsorbing helium, it was demonstrated that permeability decreased with increased effective stress. Therefore, the increase in permeability was caused by the desorption effects in coal. The increased permeability was due to the shrinkage of coal matrices associated with desorption. Cleats affecting the permeability were widened as a consequence of the shrinkage of coal matrices (Harpalani and Schraufnagel, 1990). On the contrary, the preferential adsorption of $\mathrm{CO}_{2}$ within coal matrices can result in significant swelling of coal from $0.36 \%$ to $1.31 \%$ (Reucroft and Patel, 1986). As a result, considerable reductions of macropore sizes are expected due to the swelling effects, which cause a decrease in the permeability.

\subsection{Reservoir Concepts}

In this section, basic aspects of coalbed methane reservoirs are reviewed. During a typical $\mathrm{CO}_{2}$ sequestration in a coal seam, $\mathrm{CH}_{4}$ held by adsorption in the coal matrix is replaced by injected $\mathrm{CO}_{2}$. Then the freed gas $\left(\mathrm{CH}_{4}\right)$ is transferred into the cleat system by the process of diffusion through the micropores. In the cleat network, gas flow is governed by Darcy's law. Gas flows towards production wells because of the existing pressure gradient (Gamson et al., 1993).

\subsubsection{Gas Storage in Coal Seams}

As previously mentioned, the coal matrix characterized by micropores provides the most storage capacity of $\mathrm{CH}_{4}$ as well as the sequestration capacity of $\mathrm{CO}_{2}$. There are 
two aspects that contribute to the large storage capacity of the coal matrix for gases. These are:

1. The extremely high ratio of surface area to volume resulting from the micropore structure of the coal matrix.

2. The Van der Waals's intermolecular forces between the gas molecules and the solid molecules on the micropore surfaces of the matrix.

These two features are responsible for physical adsorption which is the basic gas storage mechanism in a coal seam. Moreover, the preference of coal sorption capacity for $\mathrm{CO}_{2}$ over methane makes the exchange between these two gases feasible.

\subsubsection{Gas Flow in Coal Seams}

For viability of $\mathrm{CO}_{2}$ sequestration in coal seams, the transport of gases in coal seams should be favorable for efficient $\mathrm{CO}_{2}$ sequestration and enhanced coalbed methane production. As Figure 2.1 shows, during the production stage $\mathrm{CH}_{4}$ diffuses from the adsorbent into the cleat system and then flows through the natural fractures into the wellbore. During $\mathrm{CO}_{2}$ sequestration in coal seams, the reverse process takes place. Two mechanisms are involved for gas transport in the coal matrix and the cleat system.

\subsubsection{Diffusion in Coal Matrix}

Desorbed gases have to go through micropores of coal matrix before they flow into the cleats. The transfer of gases in coal matrix is governed by diffusion. During diffusion, gases flow from the region of greater concentration to that of less concentration

until they reach a relative balance in concentration. Diffusion of gases in the coal matrix typically is extremely slow (Rogers, 1994). 


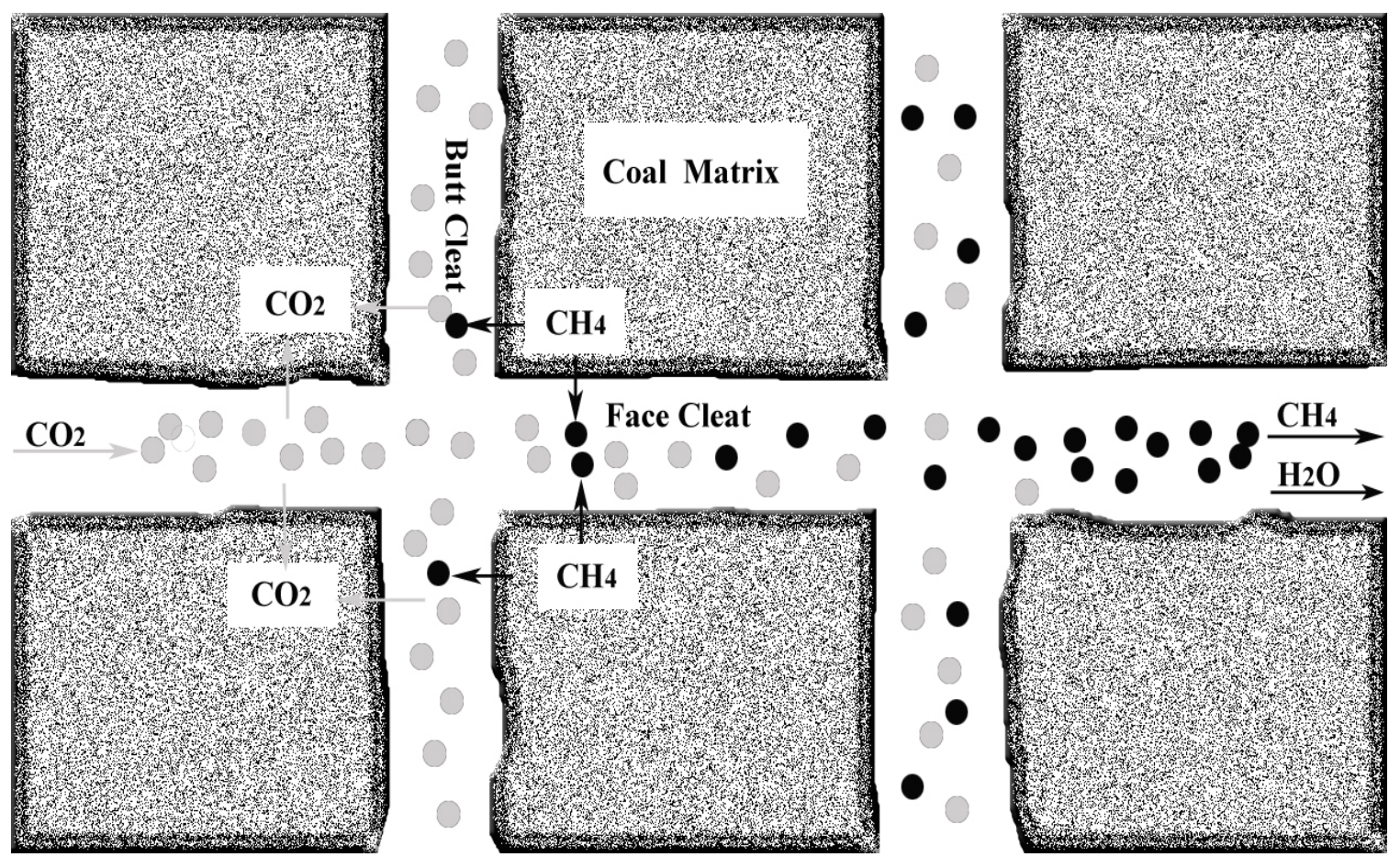

Figure 2.1: Gas flow in a coal seam 
Diffusion driven by concentration gradient can be expressed by Fick’s law which can be written as (Rogers, 1994):

$$
\frac{D}{r^{2}} \frac{\delta}{\delta r}\left(\frac{r^{2} C}{r}\right)=\frac{\delta C}{\delta t}
$$

where $D$ - effective diffusion coefficient, $\mathrm{ft} /$ day

$t$ - time, day

$C$ - concentration of gas, $\mathrm{mol} / \mathrm{ft}^{3}$

$r$ - radial distance from center of particle, $\mathrm{ft}$

The diffusion coefficient is usually a function of temperature, pressure, pore size, and water content. Effective diffusion coefficient ranging from $2.72 \times 10^{-5} \mathrm{ft} /$ day to $3.44 \times 10^{-3} \mathrm{ft} /$ day for methane in coal has been reported in the literature (Olague and Smith, 1989).

\subsubsection{Darcy Flow in Cleats}

Gases reach cleats by diffusion through micropores in the coal matrix. The gas flow in the network of natural fractures and cleats is governed by the Darcy's law, which can be expressed as:

$$
v=K i
$$

where $v$ - discharge velocity ( $\mathrm{ft} / \mathrm{h})$

$i$ - hydraulic gradient

$K$ - hydraulic conductivity (ft/h)

For conventional coalbed methane production, three flow regimes exist in the cleat system. A saturated flow of water is first expected though the fracture network causing a reduction of pressure. As the pressure continues to decrease, unsaturated flow occurs with small amount of desorbed gas carried in the water. Eventually, two-phase flow is 
reached near the wellbore as enough gases are desorbed from the coal matrix (McElhiney et al., 1989).

\subsection{Relevant Properties of $\mathrm{CO}_{2}$}

In general, the temperature and pressure in coal seams can be expected to be much higher than atmospheric values due to buried depth. This could considerably change certain properties such as density and viscosity of the injected $\mathrm{CO}_{2}$. Phase properties of $\mathrm{CO}_{2}$ as a function of temperature and pressure were reviewed. Properties such as the viscosity and density were investigated because of their importance in the flow and development of $\mathrm{CO}_{2}$ plume in the geologic reservoir.

\subsubsection{Equation of State and Phase Diagram for $\mathrm{CO}_{2}$}

For injected $\mathrm{CO}_{2}$ in the underground coal seams, it is critical to identify the state or the phase of $\mathrm{CO}_{2}$ before the study of its corresponding properties. Numerous equations of state (EOS) for either gases or liquids were developed from ideal gas law. As a significant amendment to ideal gas law, Van der Waals equation of state included the intermolecular effects by adding some terms dealing with intermolecular attractive forces (Rosenbaum, 1970). In 1949, the Redlich-Kwong equation of state, which is a considerable improvement over other equations, was introduced (Soave, 1993). However, it performs poorly with respect to the liquid phase (Soave, 1993). A new twoconstant EOS was proposed (Peng and Robinson, 1976). The Peng-Robinson EOS is widely accepted and used. In the present study, published data on $\mathrm{CO}_{2}$ properties were used (Span and Wagner, 1996). Based on this data, density of carbon dioxide can be calculated at a given temperature and pressure.

Information on the triple point and the critical point in the $\mathrm{CO}_{2}$ phase diagram can be found in the literature (Angus et al., 1976; Span and Wagner, 1996). In this study, data from a published handbook was used (Vargaftik et al., 1996). At the critical point 
the liquid state of the matter ceases to exist. The conditions at the critical point are shown in Table 2.1. The triple point and critical point of pure carbon dioxide are exhibited in Figure 2.2. The lines in Figure 2.2 are the boundaries of single phase regions and show the temperature-pressure conditions where two phases coexist.

Table 2.1 The properties of carbon dioxide at triple point and critical point

\begin{tabular}{|l|l|l|l|l|}
\hline Conditions & Pressure(psi) & Temperature( $\left.{ }^{\mathbf{0}} \mathbf{F}\right)$ & $\begin{array}{l}\text { Vapor } \\
\text { Density(pcf) }\end{array}$ & $\begin{array}{l}\text { Liquid } \\
\text { Density(pcf) }\end{array}$ \\
\hline Triple Point & 75.13 & -69.88 & 0.86 & 73.62 \\
\hline $\begin{array}{l}\text { Critical } \\
\text { Point }\end{array}$ & 1070.67 & 87.88 & 29.23 & 29.23 \\
\hline
\end{tabular}

\subsubsection{Viscosity of Carbon Dioxide}

Viscosity is a critical parameter for $\mathrm{CO}_{2}$ fluid with respect to its transport in a geologic formation. As one of the intrinsic properties of a fluid, viscosity can directly affect the hydraulic conductivity. Viscosity basically is a measure of the resistance of fluids to deform under shear stress (Bear, 1972). Dynamic viscosity, $\mu$ and kinetic viscosity, $v$ are two commonly used parameters for fluids in terms of viscosity, and they have the following relationship:

$$
v=\frac{\mu}{\rho}
$$

The viscosity of fluids, to a certain degree, varies with pressure and temperature. The viscosity of most fluids is more sensitive to temperature than pressure unless the pressure reaches a rather high value (Soo, 1967). Viscosity of liquids typically increases with pressure at a fixed temperature. The effects of temperature on viscosity are opposite for gases and liquids. For gases at low density, viscosity decreases with the reduction of temperature, while a temperature decrease causes a rise in viscosity of liquids (Soo, 1967). 


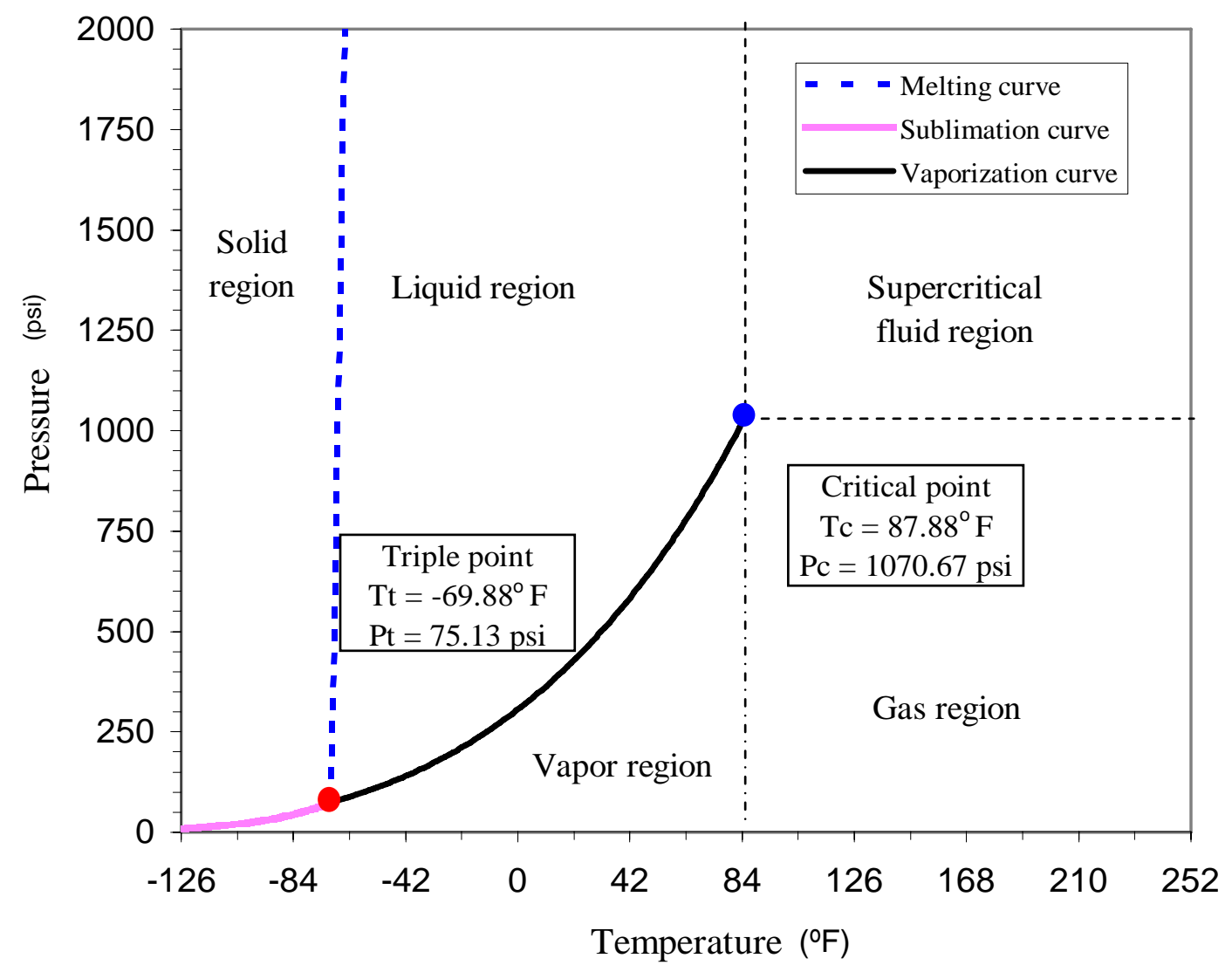

Figure 2.2: Temperature-pressure phase diagram of $\mathrm{CO}_{2}$ 
The viscosity can be expressed as a function of density and temperature as given below (Vesovic et al., 1990; Fenghour et al., 1998):

$$
\mu(\rho, T)=\mu_{0}(T)+\Delta \mu(\rho, T)+\Delta \mu_{c}(\rho, T)
$$

With calculated density, viscosity of $\mathrm{CO}_{2}$ can be numerically computed based on Equation 2.7 for a given condition of temperature and pressure. Figure 2.3 shows the dynamic viscosity values of $\mathrm{CO}_{2}$ with temperature under different pressures.

\subsection{Coalbed Methane Enhancements with $\mathrm{CO}_{2}$ Sequestration}

It has been reported that a significant amount of methane is contained in undisturbed coal seams (Gale and Freund, 2001). According to published literature, there is about 127 Tcf economically recoverable CBM of which 55 Tcf can be ECBM produced through $\mathrm{CO}_{2}$ sequestration (Stevens, 2002). Moreover, it has been reported that about 165 Tcf of $\mathrm{CO}_{2}$ which is equivalent to 13 years of current USA emissions from power generation can be sequestered in potential coal seams (Stevens, 2002). In conventional coalbed methane production, methane is desorbed from the coal matrix and then transported through the cleat system in the coal seam by the depressurization of water. Enhanced coalbed methane production by using $\mathrm{CO}_{2}$ sequestration displaces the methane gas by making use of the preference of the adsorption of $\mathrm{CO}_{2}$ over methane.

Allison unit in San Juan basin of north-central New Mexico is the first experimental $\mathrm{CO}_{2}-\mathrm{ECBM}$ recovery field demonstration site (Reeves, 2001). This site consists of four $\mathrm{CO}_{2}$ injection wells and nine methane production wells which have been used for conventional pressure-depletion production for more than five years before $\mathrm{CO}_{2}$ ECBM recovery (White et al., 2005). Starting from 1995, the initial $\mathrm{CO}_{2}$ injection rate was 5 million cubic feet of gas per day (MMCFD) followed by the rate of 3 MMCFD because of injectivity loss. 


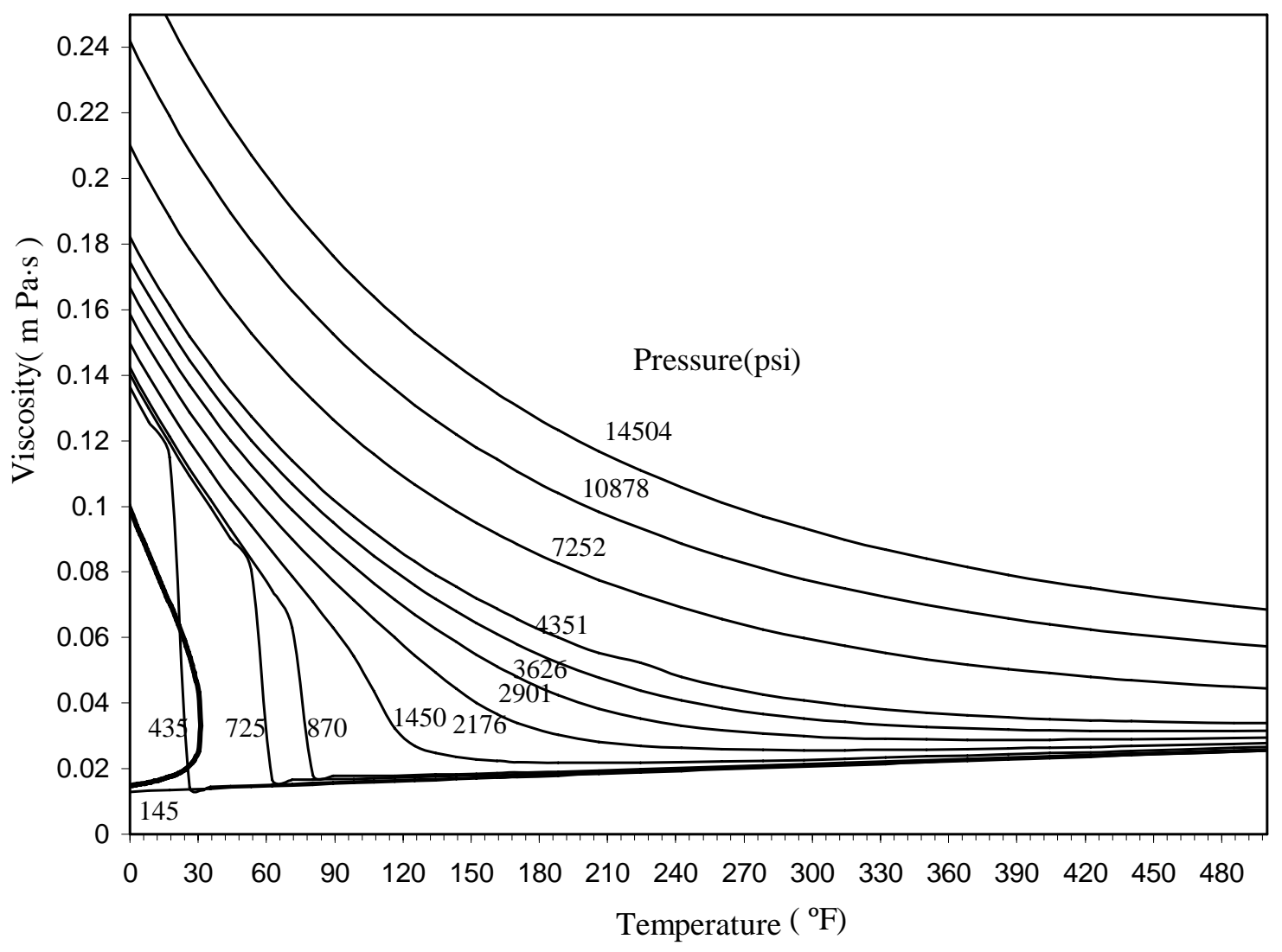

Figure 2.3: Viscosity of $\mathrm{CO}_{2}$ versus temperature with the variation of pressure 
It has been found that the concentration of $\mathrm{CO}_{2}$ in the production wells increased from $4 \%$ to $6 \%$ after 5 -year injection, which indicates the occurrence of $\mathrm{CO}_{2}$ sequestration and methane release. Furthermore, the data shows that the Allison unit has an enhanced $\mathrm{CH}_{4}$ production by $\mathrm{CO}_{2}$ injection (Reeves, 2001).

\subsection{Environment and Safety Aspects of $\mathrm{CO}_{2}$-ECBM and Underground Injection Control (UIC) Program}

Environmental issues concerning $\mathrm{CO}_{2}$ injection in coal seams can be expected although the assessment has not been systematically conducted. Concerns over the environmental impact of $\mathrm{CO}_{2}$ injection include leakage of injected fluids, seismic activity, overburden movements and the storage integrity.

Vertical migration of large amount of $\mathrm{CO}_{2}$ into surface is potential during or immediately after injection. The accumulation of $\mathrm{CO}_{2}$ denser than air usually near ground level can form an atmosphere with the deficiency of oxygen. Such a situation can

cause a threat to humans and ecosystems. It has been reported that forests were killed by catastrophic release of natural $\mathrm{CO}_{2}$ (White et al., 2005). The risks from the eruption of injected $\mathrm{CO}_{2}$ should be considered although it is less likely for deep underground sequestration. Remote sensing technologies and water quality analyses can be developed to monitor the near-surface region of injection sites and to detect leakage of $\mathrm{CO}_{2}$ (Bruant et al., 2002).

Another environmental concern associated with migration of injected $\mathrm{CO}_{2}$ is the potential that dissolved $\mathrm{CO}_{2}$ will transfer into a water aquifer. Dissolved $\mathrm{CO}_{2}$ can form carbonic acid, which can change pH value and the water quality (Bruant et al., 2002). Undesirable migration of injected fluids can also occur by diffusion across caprock formation, leakage through natural fractures and faults, and leakage through man-made wells (Celia et al., 2004). Measurement of pressure at the ground surface or down hole can be used to monitor the propagation of $\mathrm{CO}_{2}$ plume underground. Geophysical methods in particular seismic techniques can also be used as monitoring tools. The $\mathrm{CO}_{2}$ 
front can be observed by performing high-resolution 3-D seismic surveys before and after $\mathrm{CO}_{2}$ injection (White et al., 2005).

Comprehensive regulations are necessary for $\mathrm{CO}_{2}$ injection operations and monitoring although no particular laws govern $\mathrm{CO}_{2}$ sequestration activities currently. In 1974, the Safe Drinking Water Act (SDWA) was signed into law. The Underground Injection Control program was established as a part of this act to protect the underground sources of drinking water (USDW) from contamination by improper underground injection. The UIC program currently oversees more than 800,000 injection wells (EPA, 2002). The injections wells are classified into five categories according to the EPA injection well classification system (EPA, 2002). $\mathrm{CO}_{2}$ injection into coal seams for enhanced coalbed methane recovery belongs to Class II which is associated with the production of oil and gas.

In order to prevent the potential leakage of the injected fluids into overlying aquifers for USDW, injection pressure must be monitored carefully. The maximum pressure at the well head is determined so that the injection pressures do not generate new fractures or extend existing fractures into drinking aquifers.

Generation of fractures could be the key factor in terms of the underground injection control. At the so-called breakdown pressure, the fracturing of intact rock can take place along a plane perpendicular to the minimum principal stress in the rock. The extension of an existing fracture is caused by fracture propagation pressure which is considered equivalent to fracture parting pressure (Whittaker et al., 1992). Closure pressure is the pressure at which an existing fracture can be maintained open. Closure pressure is typically less than the fracture propagation pressure (Whittaker et al., 1992). Measured closure pressure can be used as the maximum injection pressure (EPA, 2004). 


\section{CHAPTER 3: NUMERICAL ANALYSIS}

A coal reservoir can be considered as porous media in regard to its structural constitution. In this study, finite element method (FEM) was used for the analysis of coupled pore fluid flow and deformation of the porous media resulting from $\mathrm{CO}_{2}$ sequestration in coal seams. Mathematical details of the finite element method can be found elsewhere (Cook et al., 2004). Relevant details of the finite element analysis are presented in this chapter.

\subsection{Effective Stress Principle for Porous Media}

The effective stresses in a fluid-filled porous media depend on the total stresses caused by the external loads and the pore pressure (Terzaghi et al., 1996). The stability or deformation of a porous medium depends on the effective stresses.

\subsubsection{Effective Vertical Stress Concepts for Fully Saturated Porous Media}

The effective vertical stress in a saturated medium equals the total vertical stress minus the pore pressure (Terzaghi, 1943):

$$
\sigma_{v}^{\prime}=\sigma_{v}-u_{w}
$$

where:

$$
\begin{aligned}
& \sigma_{v}{ }^{\prime} \text { - Effective vertical stress } \\
& \sigma_{v} \text { - Total vertical stress } \\
& u_{w} \text { - Pore pressure }
\end{aligned}
$$


The total vertical stress is calculated based on the unit weight and the thickness of all the material above the point of interest. The total stress at a given depth (z) in a uniform single layer with total unit weight, $\gamma$ can be calculated as:

$$
\sigma_{v}=z \gamma
$$

For several homogeneous layers of different unit weights, the total vertical stress can be calculated as:

$$
\sigma_{v}=\sum_{i=1}^{n} h_{i} \gamma_{i}
$$

where $h_{i}$ is the thickness of the layer of unit weight, $\gamma_{i}$.

The effective stress at a given depth can be calculated as:

$$
\sigma_{v}^{\prime}=\sum_{i=1}^{n} h_{i} \gamma_{i}^{\prime}
$$

where $\gamma_{i}^{\prime}$ is submerged unit weight which is equal to the total unit weight, $\gamma$ minus the unit weight of water, $\gamma_{w}$. In this study, Equation 3.3 was used for the calculation of stresses under geostatic equilibrium.

\subsubsection{Effective Stress Concept for Partially Saturated Porous Media}

The effective stress in a partially saturated porous media can be expressed as (Fredlund and Rahardjo, 1993):

$$
\sigma^{\prime}=\left(\sigma-u_{a}\right)+\chi\left(u_{a}-u_{w}\right)
$$


where:

$u_{a}$ - Pore-air pressure

$\chi$ - A parameter related to the degree of saturation of the soil

The relation between the parameter, $\chi$ and the degree of saturation, $s$, can be obtained experimentally. The value of $\chi$ parameter is equal to zero for dry media and one for fully saturated media. In this study, the parameter $\chi$ was assumed to be equal to the degree of saturation for simplicity (ABAQUS, 1998).

\subsection{Equilibrium Equations for Porous Media}

The equilibrium equations for a porous medium can be expressed as (ABAQUS, 1998):

$$
\int_{V} \sigma: \delta \varepsilon d V=\int_{V} \hat{f} \cdot \delta v d V+\int_{S} t \cdot \delta v d S
$$

where:

$$
\begin{aligned}
& \delta v \text { - Virtual velocity field } \\
& \delta \varepsilon \text { - Virtual rate of deformation, } \delta \varepsilon=\frac{\partial \delta v}{\partial x} \\
& \sigma \text { - True stress } \\
& t \text { - Surface tractions per unit area } \\
& \hat{f} \text { - Body forces per unit volume }
\end{aligned}
$$

In this study, the weight of the wetting liquid is one of the components of the body forces and can be expressed as (ABAQUS, 1998):

$$
f_{w}=\left(s n+n_{t}\right) \rho_{w} g
$$

where:

$$
n \text { - The porosity of the media }
$$


$n_{t}$ - The ratio of trapped wetting liquid to total volume

$\rho_{w}$ - The density of the wetting liquid

$g$ - The gravitational acceleration

Using Equation 3.7, the Equation 3.6 can be transformed as:

$$
\int_{v} \sigma: \delta \varepsilon d V=\int_{v} f \cdot \delta v d V+\int_{V}\left(s n+n_{t}\right) \rho_{w} g \cdot \delta v d V+\int_{s} t \cdot \delta v d S
$$

where $f$ are body forces excluding the weight of the wetting liquid.

The terms $\delta v$, virtual velocity field and $\delta \varepsilon$, virtual rate of deformation in Equation 3.6 can be interpolated according to conventions of finite element method (Cook et al., 2004):

$$
\delta v=N^{N} \delta v^{N}
$$

where $N^{N}$ represents interpretation functions. The virtual rate of deformation can be interpolated as:

$$
\delta \varepsilon=\beta^{N} \delta v^{N}
$$

where the interpolation function is $\beta^{N}=\frac{\partial \delta N^{N}}{\partial x}$

Equation 3.8 can be written as:

$$
\delta v^{N} \int_{V} \beta^{N}: \sigma d V=\delta v^{N}\left[\int_{V} N^{N} \cdot f d V+\int_{V}\left(s n+n_{t}\right) \rho_{w} N^{N} \cdot g d V+\int_{s} N^{N} \cdot t d S\right]
$$

The internal load vector can be expressed as:

$$
I^{N}=\int_{V} \beta^{N}: \sigma d V
$$


The external force array can be extracted from the right-hand side of Equation 3.9 as:

$$
P^{N}=\int_{V} N^{N} \cdot f d V+\int_{V}\left(s n+n_{t}\right) \rho_{w} N^{N} \cdot g d V+\int_{s} N^{N} \cdot t d S
$$

For equilibrium, the internal forces must be equal to the external forces. This can be written as:

$$
I^{N}-P^{N}=0
$$

\subsection{Constitutive Behavior of Porous Media}

A porous medium is regarded as a mixture of solid matter and voids containing liquid, gas, and entrapped liquid attached to the solid matter. The mechanical behavior includes the response of the solid and liquid to local pressure and the effective stress (ABAQUS, 1998).

\subsubsection{The Response of the Solid Grain}

The solid grain in porous media is assumed to have a mechanical response to local pressure as given below (ABAQUS, 1998):

$$
\frac{\rho_{g}}{\rho_{g}^{0}} \approx 1+\frac{1}{K_{g}}\left(s u_{w}+\frac{\bar{p}}{1-n-n_{t}}\right)-\varepsilon_{g}^{t h}
$$

where:

$$
\begin{aligned}
& \rho_{g} \text { - The density of the grain } \\
& \rho_{g}^{0} \text { - The density of the grain in the reference configuration } \\
& K_{g} \text { - The grain's bulk modulus } \\
& \bar{p} \text { - The average pressure stress in the porous media }
\end{aligned}
$$




$$
\varepsilon_{g}^{\text {th }} \text { - The volumetric expansion of the grain from temperature change }
$$

The volumetric thermal strain $\varepsilon_{g}^{\text {th }}$ can be expressed as:

$$
\varepsilon_{g}^{\text {th }}=3 \alpha_{g}\left(\theta-\theta_{g}^{0}\right)-\left.3 \alpha_{g}\right|_{\theta^{I}}\left(\theta^{I}-\theta_{g}^{0}\right)
$$

where:

$$
\begin{aligned}
& \alpha_{g} \text { - The thermal expansion coefficient for the solid grain } \\
& \theta \text { - The current temperature } \\
& \theta_{g}^{0} \text { - The reference temperature } \\
& \theta^{I} \text { - The initial temperature }
\end{aligned}
$$

For a solid grain, the volumetric change caused by pressure or thermal effects is assumed to be small.

\subsubsection{The Response of the Liquid}

The response of the liquid in the system can be expressed as (ABAQUS, 1998):

$$
\frac{\rho_{w}}{\rho_{w}^{0}} \approx 1+\frac{u_{w}}{K_{w}}-\varepsilon_{w}^{t h}
$$

where:

$\rho_{w}$ - The density of the liquid

$\rho_{w}^{0}$ - The reference density of the liquid

$K_{w}$ - The liquid's bulk modulus

$\varepsilon_{w}^{\text {th }}$ - Volumetric thermal strain of the liquid

The thermal strain can be expressed as: 


$$
\varepsilon_{w}^{t h}=3 \alpha_{w}\left(\theta-\theta_{w}^{0}\right)-\left.3 \alpha_{w}\right|_{\theta^{I}}\left(\theta^{I}-\theta_{w}^{0}\right)
$$

The values of $\frac{u_{w}}{K_{w}}$ and $\varepsilon_{w}^{\text {th }}$ are assumed to be small.

\subsection{Continuity Equation for the Conservation of the Fluid Mass}

A control volume containing a fixed amount of solid matter is considered. It is assumed to have a volume $V$ and a surface area $S$. Wetting liquid which can flow through this volume is written as $V_{w}$. The wetting liquid trapped in the volume is expressed as $V_{t}$. The total mass of wetting liquid in the control volume can be expressed as (ABAQUS, 1998):

$$
\int_{V} \rho_{w}\left[d V_{w}+d V_{t}\right]=\int_{V} \rho_{w}\left(n_{w}+n_{t}\right) d V
$$

where:

$$
\begin{aligned}
& \rho_{w} \text { - Density of the liquid } \\
& n_{w} \text { - Volume ratio of free wetting liquid at a point, } n_{w}=\frac{d V_{w}}{d V} \\
& n_{t} \text { - Volume ratio of the trapped wetting liquid, } n_{t}=\frac{d V_{t}}{d V}
\end{aligned}
$$

The time rate of change of this mass of wetting liquid in the control volume can be expressed as (ABAQUS, 1998):

$$
\frac{d}{d t}\left(\int_{V} \rho_{w}\left(n_{w}+n_{t}\right) d V\right)=\int_{V} \frac{1}{J} \frac{d}{d t}\left(J \rho_{w}\left(n_{w}+n_{t}\right)\right) d V
$$


where $J=\left|\frac{d V}{d V^{0}}\right|$ is the ratio of volume in the current configuration, $V$ to volume in the reference configuration, $V^{0}$.

The mass of the free wetting liquid crossing the surface of the control volume every unit time can be expressed as $-\int_{S} \rho_{w} n_{w} n \cdot v_{w} d S$ in which $v_{w}$ is the velocity of the liquid and $n$ is the outward normal to $S$. According to the conservation of mass during flow through the control volume, the time rate change of the liquid mass within the volume should be equal to the mass crossing the surface. This leads to the continuity equation which can be expressed as (ABAQUS, 1998):

$$
\int_{V} \frac{1}{J} \frac{d}{d t}\left(J \rho_{w}\left(n_{w}+n_{t}\right)\right) d V=-\int_{S} \rho_{w} n_{w} n \cdot v_{w} d S
$$

\subsection{Procedure for the Numerical Analysis}

The coupled flow-deformation analysis was carried out by using an axi-symmetric idealization for the $\mathrm{CO}_{2}$ injection. Finite element models consisted of multiple layers with different geotechnical properties. Coupled flow-deformation analyses were conducted by using ABAQUS (ABAQUS, 2001) finite element software package. The simulation was divided into two phases - $\mathrm{CO}_{2}$ injection and post-injection dissipation. $\mathrm{CO}_{2}$ injection was simulated by prescribing the bottom-hole pore pressure at nodal points where the assumed injection took place. The injection was maintained for a certain time period of time by holding the previously applied pore pressure value. By deactivating the pore pressure after a certain time period, the injection of $\mathrm{CO}_{2}$ can be stopped. During the second phase of the simulation, the pore pressure field at the termination of the $\mathrm{CO}_{2}$ injection will continue to change as the pore pressure in the formation dissipates with time. The simulation was extended into the second phase for investigating the effects pore pressure dissipation on the reservoir deformations. Material properties such as permeability, elastic modulus and Poisson's ratio were assumed. These properties characterize the flow and deformation that tale place in the overburden. 


\subsubsection{Geostatic Stress State}

A geotechnical problem typically deals with a geostatic state of stress at the beginning of the analysis to simulate conditions under geostatic loading due to selfweight of the material in the overburden (ABAQUS, 2001). This usually involves horizontal and vertical equilibrium of stresses. Only vertical stress equilibrium was considered in this research work since there were no body forces in the horizontal direction. The pore fluid was assumed to be in hydrostatic equilibrium during the geostatic procedure. For these multi-layer cases, geostatic equilibrium was established based on the effective stress principle and the given densities of the strata.

\subsubsection{Initial Conditions and Boundary Conditions}

The values of void ratio were specified as initial conditions for the saturated porous media. The saturation values were assumed to be 1 . Mechanical boundary conditions were assigned to the sides and bottom of the model to simulate field conditions. At the beginning of the analysis, pore pressure was applied at instantaneously at selected nodes to simulate the injection of $\mathrm{CO}_{2}$ in the coal seam. After completing the injection, pore pressure was deactivated to simulate the dispersion process of $\mathrm{CO}_{2}$ fluids.

\subsubsection{Elements and Mesh}

Axisymmetric elements for coupled pore fluid-deformation analysis were used in the finite element model. The 4-node elements have attributes of bilinear displacement variation and linear pore pressure variation. The corner nodes on elements possess properties of vertical and horizontal displacements, and pore pressure. Figure 3.1 shows details of node and face numbering for the 4-node elements used in this study.

Non-uniform mesh was generated for the axisymmetric model in order to have a refined mesh near the injection point. A finer mesh was used in the coal seam and the layers immediately above and below the coal seam. 


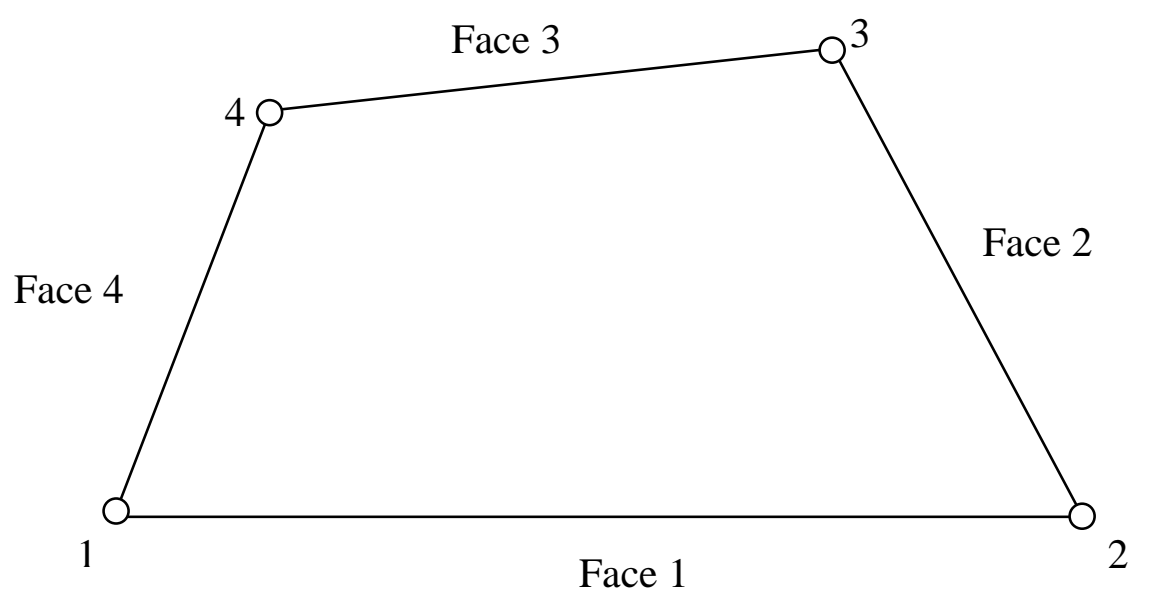

Figure 3.1: Node ordering and face numbering for the 4-node element 


\section{CHAPTER 4: ANALYSIS OF $\mathrm{CO}_{2}$ INJECTION IN GRANNY CREEK FIELD}

\subsection{Overview of the Appalachian Basin}

The Appalachian basin extends from the state of New York to Alabama and covers an area of more than 50,000 mile $^{2}$ as shown in Figure 4.1 (Ruppert and Rice, 2001). It can be divided into there coal regions according to local geologic structure and stratigraphy. The northern region consists of eastern Pennsylvania, eastern Ohio, western Maryland, and northern West Virginia. The central part includes west-central and southwestern West Virginia, eastern Kentucky, northern Tennessee, and southwestern Virginia. Southern Tennessee, northern Alabama, and northwestern Georgia constitute the south region of the basin (Ruppert and Rice, 2001).

The geological history of the formation of the Appalachian basin can be found elsewhere (Ruppert and Rice, 2001; Slatick and Hong, 1995). As one of the most abundant coal region in the world, the Appalachian basin has a cumulative production of approximate 31.3 billion tons since 300 years ago (Ruppert et al., 2002). According to the literature (Bhatt, 1995), the northern and central regions of the basin account for about $95 \%$ of the total Appalachian coal production or $40 \%$ of the total US coal production. Most of the Appalachian coal is used for electric power generation in the Eastern United States (Ruppert et al., 2002). In view of the presence of significant amount of coal in the Appalachian basin, two sites were selected from the northern Appalachian basin to study the influence of $\mathrm{CO}_{2}$ sequestration in coal seams. 


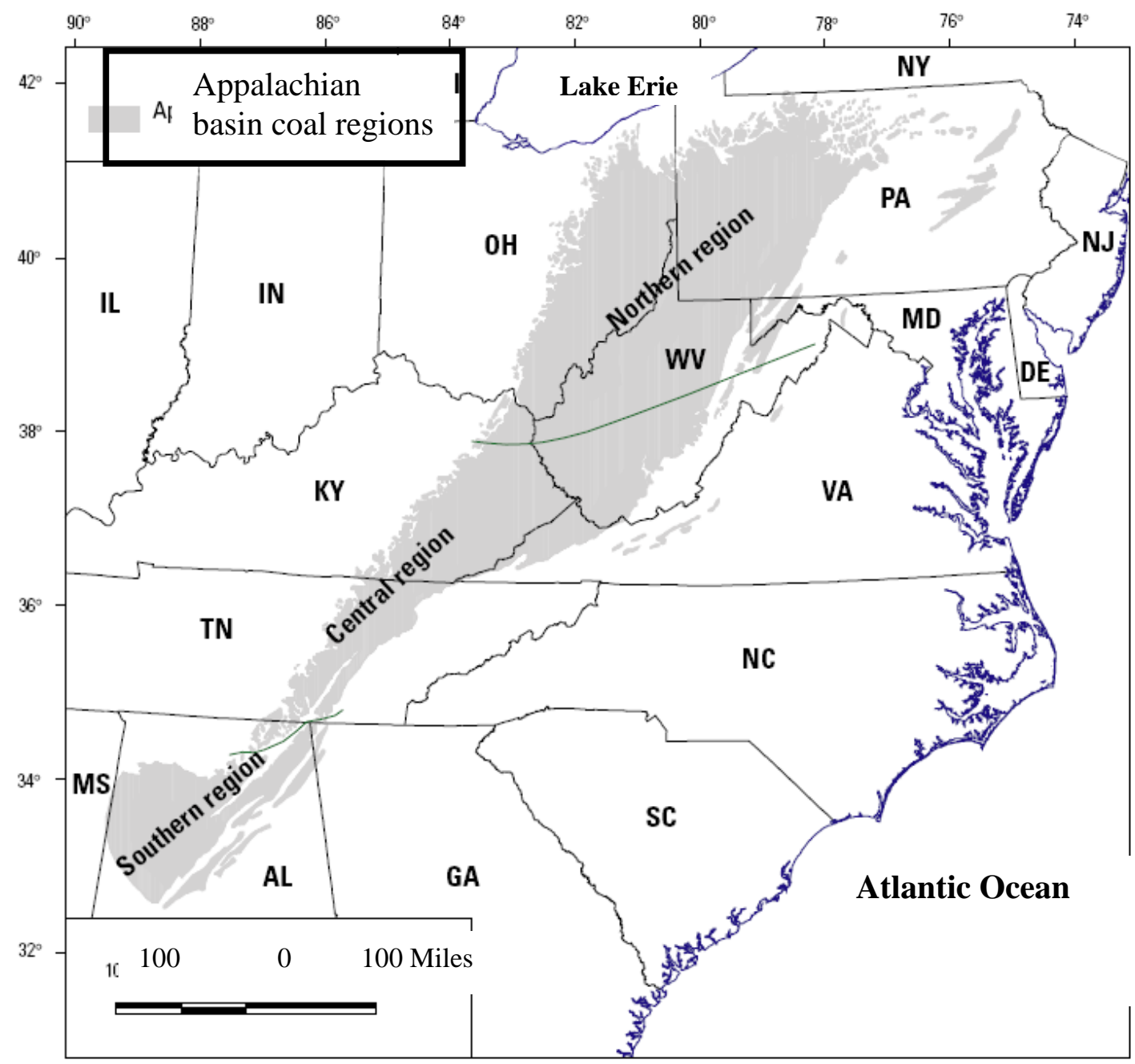

Figure 4.1: Extent of the Appalachian basin coal region (Ruppert and Rice, 2001) 


\subsection{The Granny Creek field in Northern Appalachian basin}

The Granny Creek field is located in western Clay and southeastern Roane counties in central West Virginia, and is about 25 miles northeast of the city of Charleston (Smosna and Bruner, 1997). The Big Injun sandstone of lower Mississippian age at an average elevation of -878 $\mathrm{ft}$ is an important oil reservoir in this field (Smith et al., 1983). The first $\mathrm{CO}_{2}$ injection project in this area was started in 1975 for enhanced oil recovery (EOR). After injection of 2,118 tons of $\mathrm{CO}_{2}$, it was stopped in 1980. It has been concluded that the $\mathrm{CO}_{2}$ injection for EOR in this field did not demonstrate economic feasibility at that point (Smith et al., 1983).

A coal zone was identified at a depth of approximate 844 to $869 \mathrm{ft}$ based on available geophysical measurements (Wilson, 2006). This coal zone is at the bottom of Greenbrier Limestone group of the middle Mississippian age according to the literature (Hohn et al., 1993). The Granny Creek field where this coal zone is located lies in the gently folded structure of the central Appalachian Plateau. There are two noticeable geological structures in the vicinity of Granny Creek field - the West Virginia dome and the Rome Trough (Smosna and Bruner, 1997). Granny Creek field lies on the eastern margin of the Rome Trough, which may result in subsidence-related reactivation of older basement faults (Hohn et al., 1993).

Based on the information provided by Dr. Thomas Wilson (Wilson, 2006), an assumed lithologic column with 24 subdivisions of the strata was generated as shown in Figure 4.2. The material properties that were used in the finite element analysis are shown in Table 4.1. Some of geomechanical properties of the strata can be calculated from geophysical exploration data. The value of Young's modulus, $E$ can be derived as (Sheriff, 1973):

$$
E=\rho V_{s}^{2}\left(\frac{3 V_{p}^{2}-2 V_{s}^{2}}{V_{p}^{2}-\frac{1}{3} V_{s}^{2}}\right)
$$




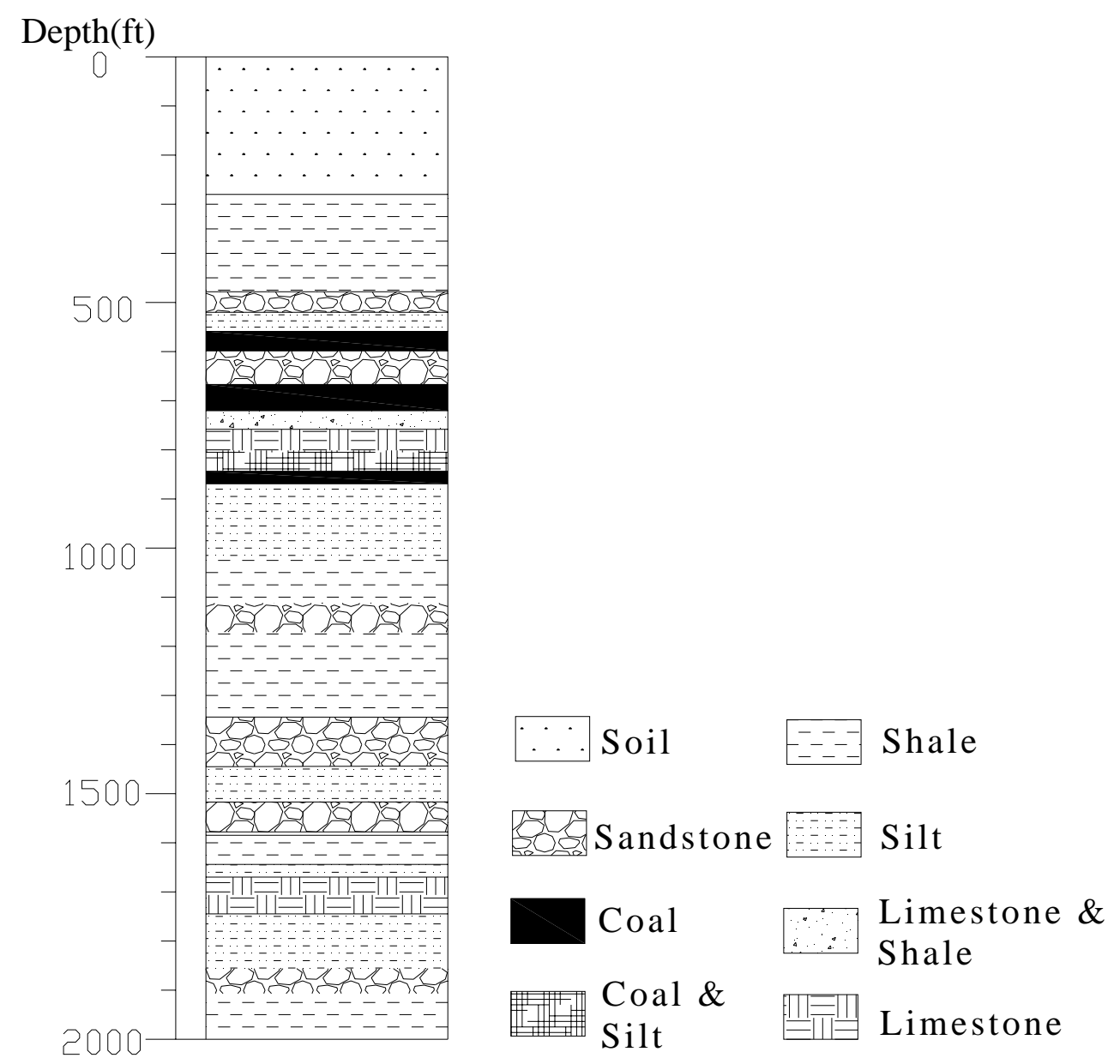

Figure 4.2: Assumed lithologic column for Granny Creek field 
where:

$$
\begin{aligned}
& V_{p} \text { - Compression wave velocity } \\
& V_{s} \text { - Shear wave velocity }
\end{aligned}
$$

Poisson's ratio $v$ can be computed by using the following equation (Sheriff, 1973):

$$
v=\frac{V_{p}^{2}-2 V_{s}^{2}}{2\left(V_{p}^{2}-V_{s}^{2}\right)}
$$

The geothermal temperature gradient is usually derived from the bottom-hole temperature and the ground temperature. A geothermal gradient value of $15^{\circ} \mathrm{F} / 1000 \mathrm{ft}$ was used in this study for Granny Creek field. Temperature of the reservoir was calculated to be in the range between $62.66{ }^{\circ} \mathrm{F}$ and $63.04{ }^{\circ} \mathrm{F}$ considering the ground average temperature of $50{ }^{\circ} \mathrm{F}$. The depth of the reservoir was assumed as $857 \mathrm{ft}$. The pressure gradient in geologic formations is usually assumed as 0.43 psi per foot (Pashin and McIntyre, 2003). The pressure in the reservoir was calculated as 377.62 psi to $388.37 \mathrm{psi}$ with a pressure gradient of $0.43 \mathrm{psi} / \mathrm{ft}$ and atmospheric pressure of $14.7 \mathrm{psi}$. The pressure-temperature phase conditions of the reservoir are exhibited in Figure 4.3. 


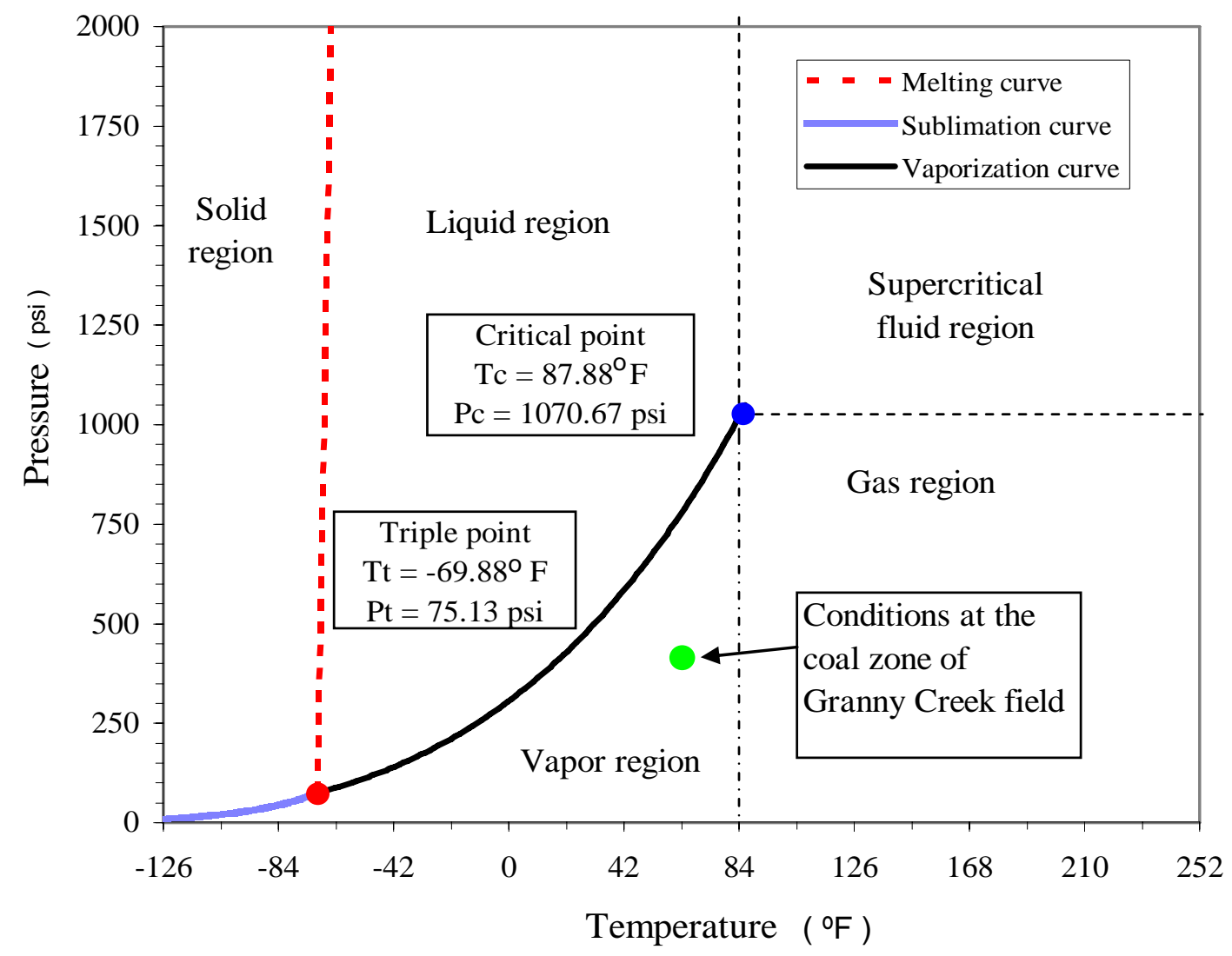

Figure 4.3: Reservoir conditions at the Granny Creek field shown on the phase diagram for $\mathrm{CO}_{2}$ 
Table 4.1 Material properties used in the analysis for Granny Creek field

\begin{tabular}{|l|l|l|l|l|l|l|l|l|}
\hline $\begin{array}{l}\text { Strata } \\
\text { Layer }\end{array}$ & $\begin{array}{l}\text { Depth } \\
\text { (ft) }\end{array}$ & Materials & $\begin{array}{l}\text { Density } \\
\text { (pcf) }\end{array}$ & E (psf) & $\begin{array}{l}\text { Poisson's } \\
\text { Ratio }\end{array}$ & $\begin{array}{l}\text { Hydraulic } \\
\text { Conductivity } \\
\text { (ft/day) }\end{array}$ & $\begin{array}{l}\text { Wetting } \\
\text { Liquid } \\
\text { Density } \\
\text { (pcf) }\end{array}$ & $\begin{array}{l}\text { Void } \\
\text { Ratio }\end{array}$ \\
\hline 1 & 280 & Soil & 100 & $1.60 \mathrm{E} 8$ & 0.45 & $1.77 \mathrm{E}-3$ & 62.5 & 0.10 \\
\hline 2 & 478 & Shale & 158 & $7.70 \mathrm{E} 8$ & 0.23 & $1.88 \mathrm{E}-4$ & 62.5 & 0.19 \\
\hline 3 & 520 & Sandstone & 162 & $8.10 \mathrm{E} 8$ & 0.26 & $3.11 \mathrm{E}-4$ & 62.5 & 0.15 \\
\hline 4 & 559 & Silt & 140 & $4.00 \mathrm{E} 8$ & 0.24 & $3.08 \mathrm{E}-4$ & 62.5 & 0.14 \\
\hline 5 & 598 & Coal & 120 & $3.50 \mathrm{E} 8$ & 0.20 & $2.37 \mathrm{E}-2$ & 62.5 & 0.20 \\
\hline 6 & 667 & Sandstone & 160 & $8.20 \mathrm{E} 8$ & 0.25 & $8.88 \mathrm{E}-4$ & 62.5 & 0.18 \\
\hline 7 & 720 & Coal & 130 & $5.00 \mathrm{E} 8$ & 0.29 & $9.06 \mathrm{E}-4$ & 62.5 & 0.21 \\
\hline & & Limestone & & & & & & \\
8 & 758 & \& shale & 159 & $5.10 \mathrm{E} 8$ & 0.30 & $1.25 \mathrm{E}-4$ & 62.5 & 0.18 \\
\hline 9 & 801 & Limestone & 165 & $9.00 \mathrm{E} 8$ & 0.27 & $1.31 \mathrm{E}-3$ & 62.5 & 0.20 \\
\hline 10 & 844 & Coal \& silt & 164 & $8.20 \mathrm{E} 8$ & 0.28 & $1.63 \mathrm{E}-4$ & 62.5 & 0.22 \\
\hline 11 & 869 & Coal & 142 & $7.40 \mathrm{E} 8$ & 0.28 & $2.81 \mathrm{E}-3$ & 62.5 & 0.30 \\
\hline 12 & 1019 & Silt & 167 & $9.50 \mathrm{E} 8$ & 0.27 & $2.50 \mathrm{E}-5$ & 62.5 & 0.20 \\
\hline 13 & 1112 & Shale & 166 & $9.60 \mathrm{E} 8$ & 0.28 & $6.88 \mathrm{E}-6$ & 62.5 & 0.21 \\
\hline 14 & 1171 & Sandstone & 164 & $7.60 \mathrm{E} 8$ & 0.27 & $1.44 \mathrm{E}-3$ & 62.5 & 0.29 \\
\hline 15 & 1344 & Shale & 157 & $1.09 \mathrm{E} 9$ & 0.15 & $1.25 \mathrm{E}-4$ & 62.5 & 0.22 \\
\hline 16 & 1445 & Sandstone & 156 & $1.05 \mathrm{E} 9$ & 0.17 & $6.25 \mathrm{E}-6$ & 62.5 & 0.13 \\
\hline 17 & 1517 & Silt & 162 & $1.03 \mathrm{E} 8$ & 0.21 & $3.19 \mathrm{E}-4$ & 62.5 & 0.19 \\
\hline 18 & 1578 & Sandstone & 158 & $1.07 \mathrm{E} 8$ & 0.18 & $1.88 \mathrm{E}-6$ & 62.5 & 0.16 \\
\hline 19 & 1644 & Shale & 164 & $8.70 \mathrm{E} 8$ & 0.28 & $2.38 \mathrm{E}-6$ & 62.5 & 0.20 \\
\hline 20 & 1670 & Silt & 140 & $4.40 \mathrm{E} 8$ & 0.31 & $2.50 \mathrm{E}-5$ & 62.5 & 0.15 \\
\hline 21 & 1745 & Limestone & 162 & $1.29 \mathrm{E} 8$ & 0.22 & $2.81 \mathrm{E}-5$ & 62.5 & 0.13 \\
\hline 22 & 1856 & Silt & 168 & $1.62 \mathrm{E} 8$ & 0.30 & $2.25 \mathrm{E}-4$ & 62.5 & 0.24 \\
\hline 23 & 1907 & Sandstone & 158 & $8.60 \mathrm{E} 8$ & 0.23 & $7.50 \mathrm{E}-5$ & 62.5 & 0.22 \\
\hline 24 & 2000 & Shale & 168 & $8.80 \mathrm{E} 8$ & 0.28 & $6.25 \mathrm{E}-7$ & 62.5 & 0.19 \\
\hline
\end{tabular}




\subsection{Finite Element Model}

An axisymmetric model with a size of $2,000 \times 10,000 \mathrm{ft}$ was created for this case as shown in Figure 4.4 and Figure 4.5. The coal seam is assumed to lie at a depth from 844 to $869 \mathrm{ft}$. The simulation consisted of 365-day $\mathrm{CO}_{2}$ injection followed by 400-day dissipation. The time-dependent deformations and pore-pressure distribution in the overburden were computed by using the finite element method (ABAQUS, 2001).

\subsection{Distribution of the Pore Pressure}

The distribution of excess pore pressure at the end of $\mathrm{CO}_{2}$ injection and dissipation is illustrated in Figure 4.6 and Figure 4.7, respectively. These figures also show that the injected fluids, as expected, were basically confined within the coalbed methane reservoir. The $\mathrm{CO}_{2}$ plume seems to be confined to the coal seam since it has higher permeability than the overlying and underlying strata. The values of pore pressure decrease with radial distance from the injection well. This is caused by the resistance to fluid flow through the porous medium. The resistance is caused by the force generated on the boundary as the fluid moves relative to the solid phase (Bear, 1972).

Figure 4.8 shows the process of dissipation of pore pressure with time after the closure of $\mathrm{CO}_{2}$ injection. The dramatic decrease of the pore pressure right after the deactivation of $\mathrm{CO}_{2}$ injection suggests that the continuity of high injection pressure is necessary for the development of $\mathrm{CO}_{2}$ plume and sequestration of $\mathrm{CO}_{2}$. 


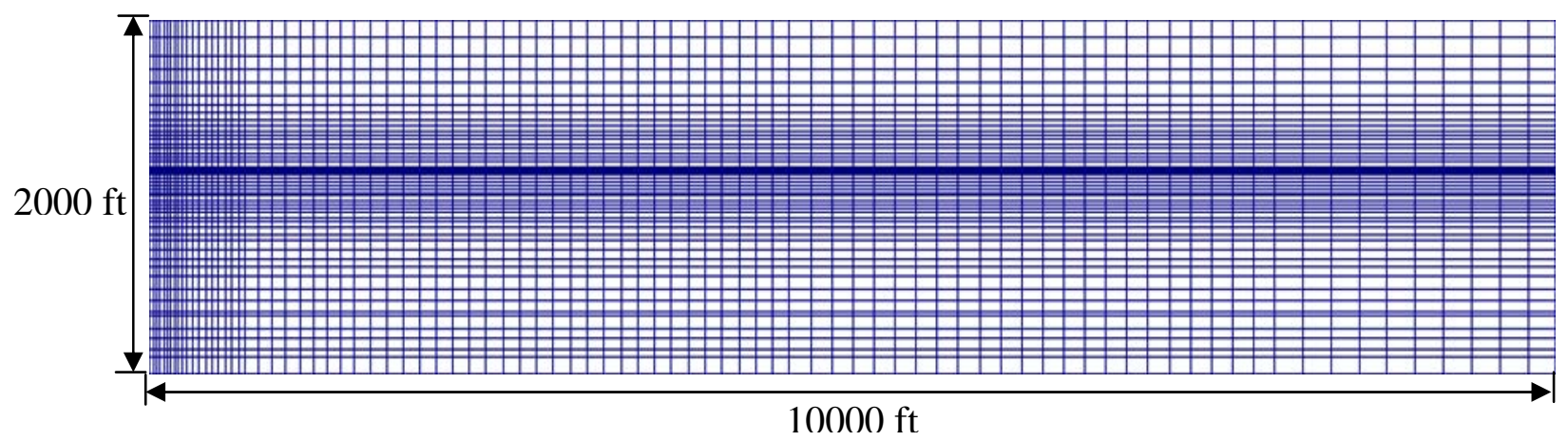

Figure 4.4: Non-uniform finite element mesh for the axisymmetric model for Granny Creek case

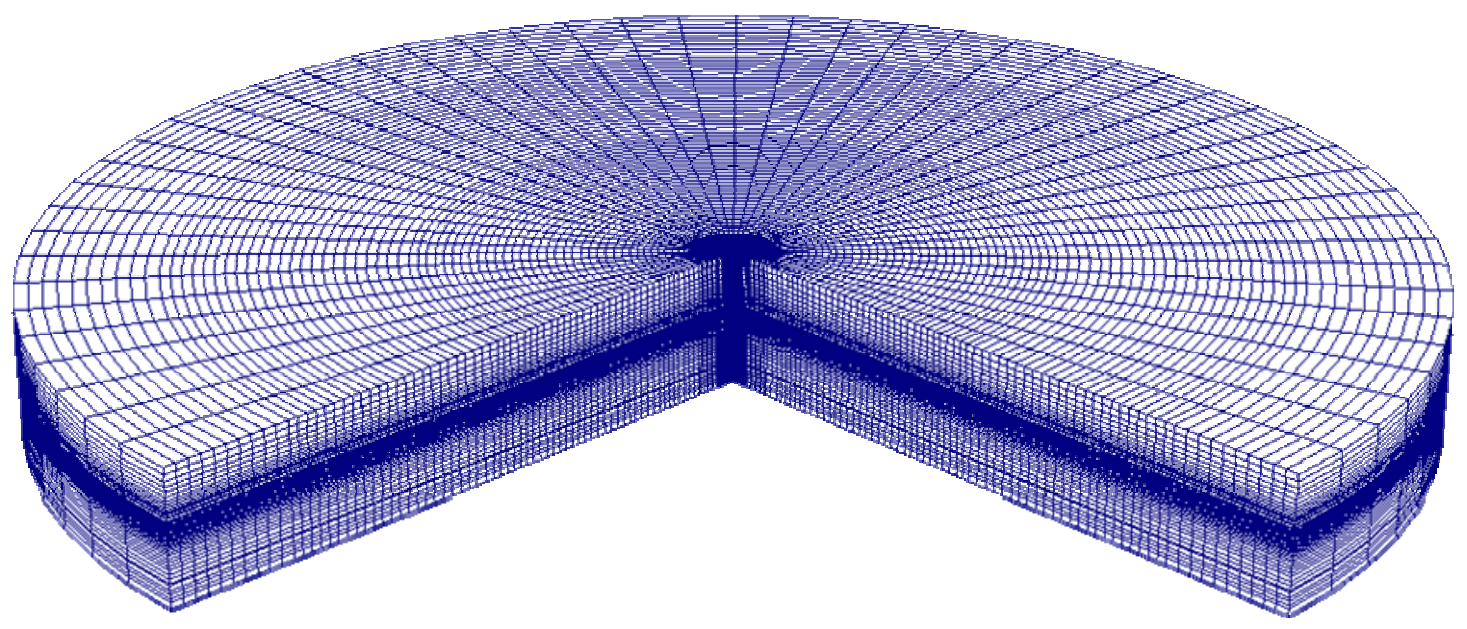

Figure 4.5: 3-D view of the non-uniform finite element mesh of the axisymmetric model for Granny Creek case 


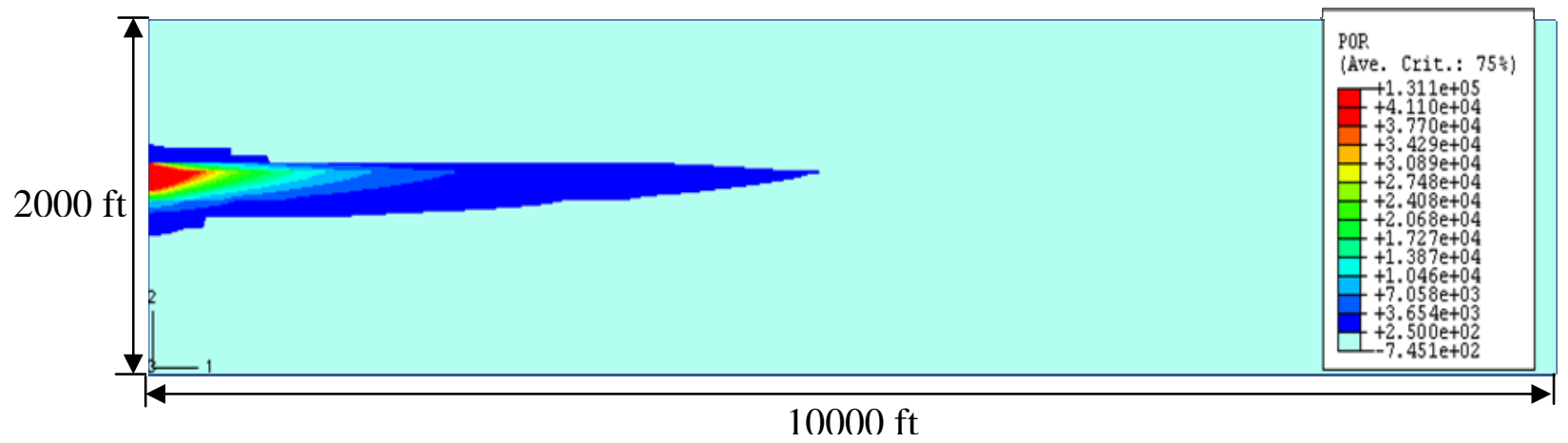

Figure 4.6: Distribution of the excess pore pressure at the end of injection period

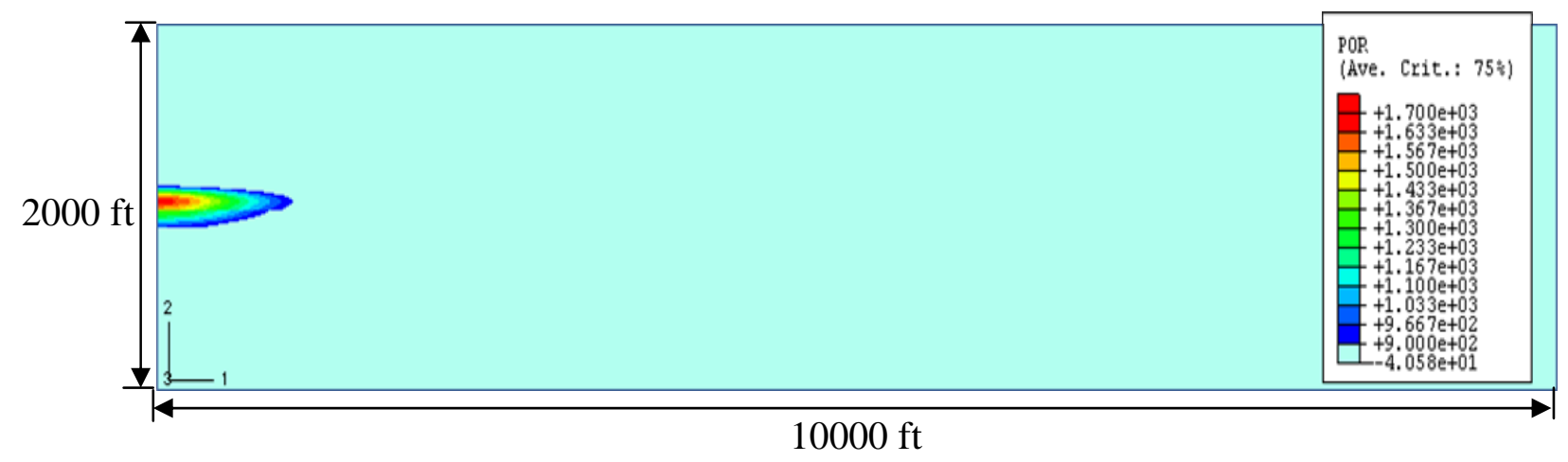

Figure 4.7: Distribution of the excess pore pressure at the end of dissipation period 


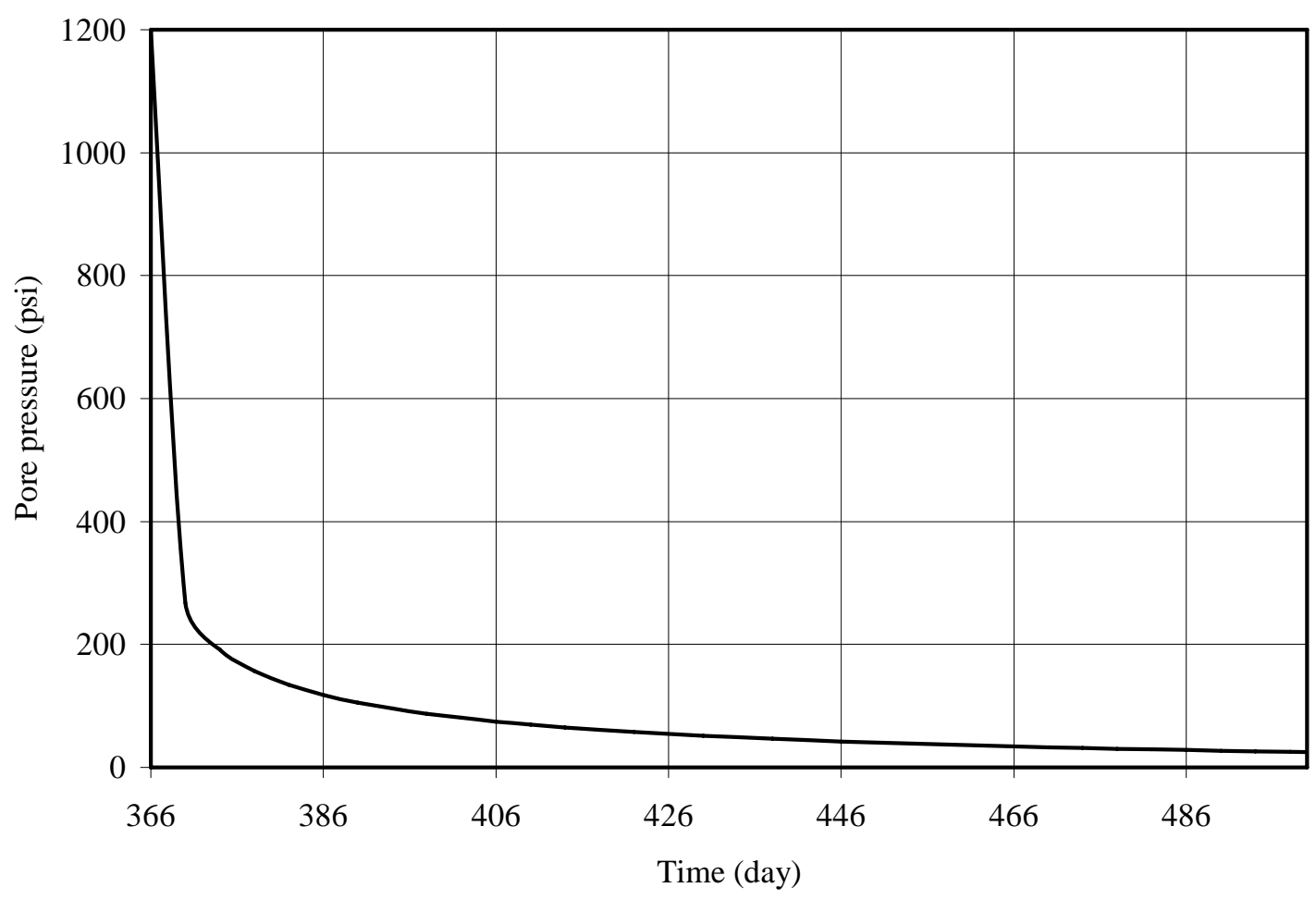

Figure 4.8: Pore pressure dissipation with time after $\mathrm{CO}_{2}$ injection 


\subsection{Deformation at the Ground Surface}

Figure 4.9 and Figure 4.10 show contours of vertical displacements in the overburden at the end of $\mathrm{CO}_{2}$ injection and dissipation, respectively. As expected, there was heaving of the overburden strata when $\mathrm{CO}_{2}$ was injected. Figure 4.11 displays a 3-D view of heaving of the overburden strata above the coal seam. As shown in Figure 4.11, the ground deformations occur near the $\mathrm{CO}_{2}$ injection point. This figure indicates the sensitive response of the overburden strata to $\mathrm{CO}_{2}$ injection.

The maximum vertical displacement of 0.092 in was observed at the ground surface at the end of the injection period (the $365^{\text {th }}$ day). The vertical displacement is very small because of the high Young's modulus assigned to the strata. Variation of ground surface displacement with time is shown in Figure 4.12. Surface displacements further illustrate the two processes of $\mathrm{CO}_{2}$ injection and dissipation. The ground surface displacements started to drop slightly when the injection was suspended. However, it did not return to the original state even after 400-day dissipation. This means the displacement caused by $\mathrm{CO}_{2}$ injection will not return to the original levels unless there is a serious leak.

Monitoring surface deformation can be useful in order to estimate the movement of $\mathrm{CO}_{2}$ plume and the status of $\mathrm{CO}_{2}$ sequestration. Tilt meters or inclinometers can be used to measure the ground surface deformation and the surface slope. The basic working mechanism for tilt meters and inclinometers is first generating an artificial horizon and measuring angular tilt with respect to the horizon. It can be expected that continuous measurement of surface deformations could provide information on the $\mathrm{CO}_{2}$ plume propagation, which is helpful for identifying potential $\mathrm{CO}_{2}$ leakages and preventing the possibilities of large-scale strata uplift. 


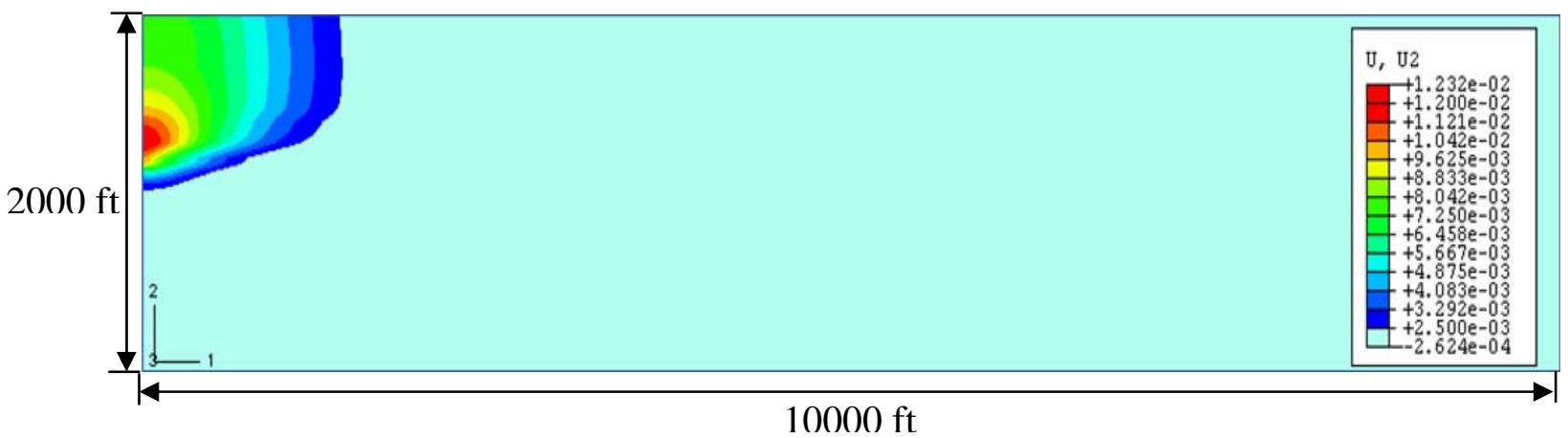

Figure 4.9: Vertical displacement of the strata at the end of injection period

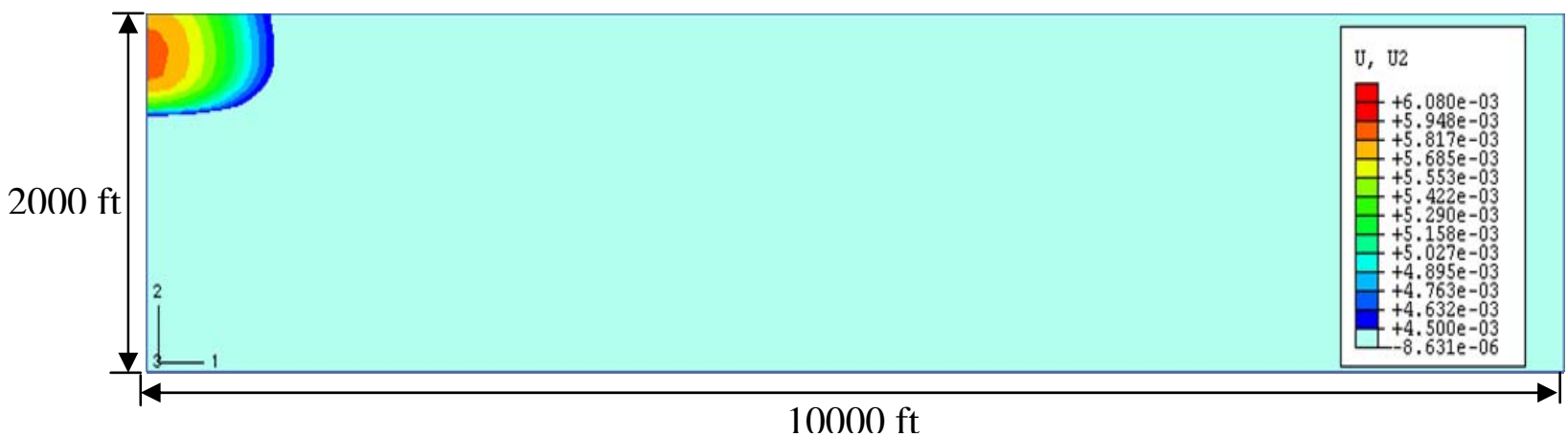

Figure 4.10: Vertical displacement of the strata at the end of the dissipation period

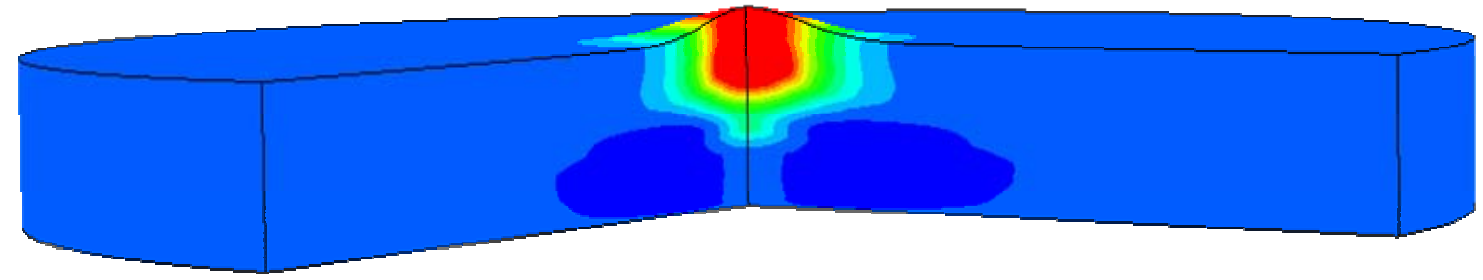

Figure 4.11: 3-D view of the strata deformation at the end of 365-day injection 


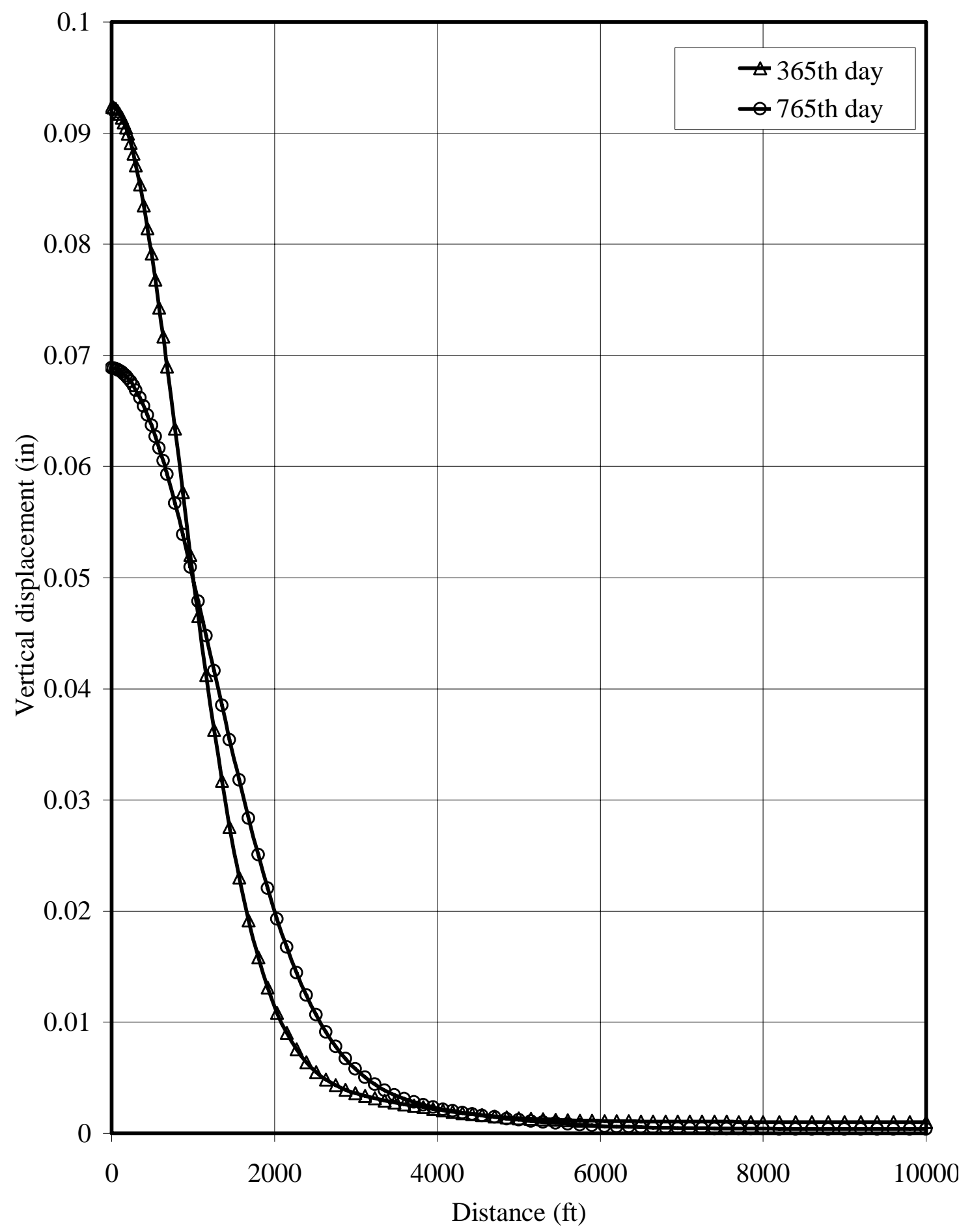

Figure 4.12: Variation of vertical displacement at the ground surface with time 


\subsection{Discussion on the Numerical Analysis of $\mathrm{CO}_{2}$ Injection in Granny Creek Field}

Results of the numerical analysis illustrate the processes of $\mathrm{CO}_{2}$ injection and dissipation based on the variation of pore pressure and deformation in the overburden strata. The results also provide enough information to determine the geomechanical response of strata to $\mathrm{CO}_{2}$ injection.

However, the coal zone at the Granny Creek field appears to be an unsuitable site for $\mathrm{CO}_{2}$ sequestration. Results show that under the injection pressure of $600 \mathrm{psi}$, a total amount of 147.3 tons of $\mathrm{CO}_{2}$ was injected into the coal seam during the one-year injection in this FEM simulation. Thus, the injection rate was calculated as 0.4 tons/day, which could be too small to be economical considering the costs of injection operations. To verify the possibility of higher injection rate, an unrealistically high injection pressure of 1,200 psi was applied in another numerical experiment at this site. The results show that the amount of injected $\mathrm{CO}_{2}$ was 1,281 tons for the one-year injection or 3.5 tons/day injection rate, which is still too low compared with observations made during field-scale pilot tests. The low injection rates indicate that the site is not suitable for $\mathrm{CO}_{2}$ sequestration.

\subsection{Effects of Permeability of Coal Seams on $\mathrm{CO}_{2}$ Sequestration}

Permeability of the target coal seam could be one of the critical factors that influence the movement of injected fluids during geologic sequestration of $\mathrm{CO}_{2}$. Higher permeability leads to better flowability of injected fluids in coal seams. This means $\mathrm{CO}_{2}$ plume could extend further along the coal seam. Therefore, larger amounts of $\mathrm{CO}_{2}$ can be injected into a coal seam with higher permeability.

Several numerical experiments were conducted to investigate the influence of permeability on geologic sequestration at the Granny Creek site. The influence of permeability on $\mathrm{CO}_{2}$ injection amount is shown in Figure 4.13. The injection amount is 


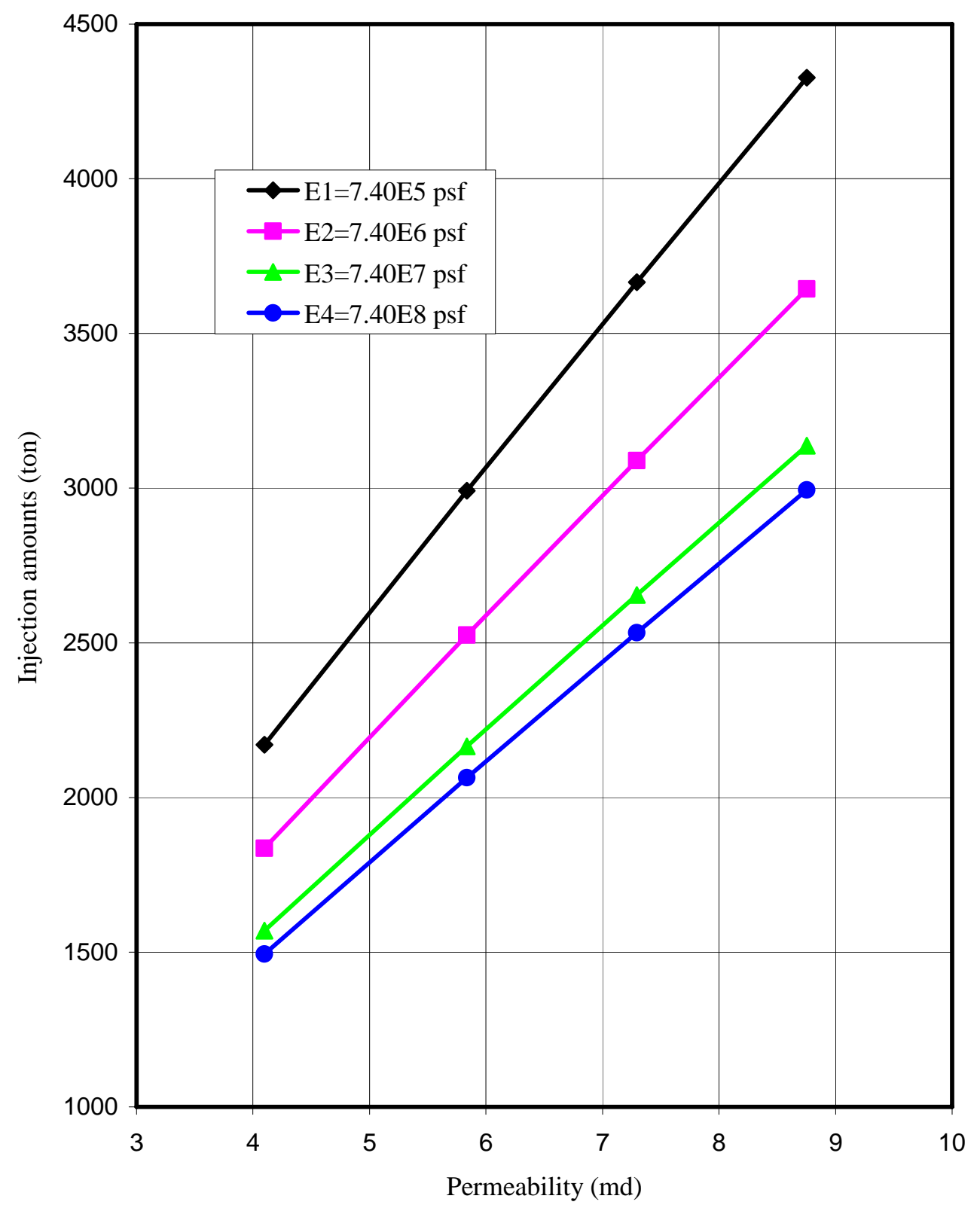

Figure 4.13: Effects of permeability on $\mathrm{CO}_{2}$ injection amount 
linearly proportional to the permeability. Therefore, the permeability of coal seam should be considered as one of the criteria for selecting $\mathrm{CO}_{2}$ sequestration sites.

\subsection{Effects of Elastic Modulus on $\mathrm{CO}_{2}$ Sequestration in Coal Seams}

Several finite element analyses were performed to study the effects of elastic modulus of the coal seam on $\mathrm{CO}_{2}$ injection and the subsequent ground deformations. Four sets of numerical experiments were carried out. Each set of experiments has the same initial conditions of permeability but with different elastic modulus. Furthermore, the injection pressure and injection time span were the same for all of the numerical experiments in this section. As one of the geomechanical parameters of the reservoir, elastic modulus plays an important role on the effectiveness of $\mathrm{CO}_{2}$ sequestration. Figure 4.14 indicates a significant decrease in the amount of injected $\mathrm{CO}_{2}$ with an increase of the elastic modulus of the coal seam. It should be noticed that even for the reservoirs with higher permeability the influence of modulus on the injection amount of $\mathrm{CO}_{2}$ is still considerable. Figure 4.15 shows the vertical displacements at the ground surface as a function of the elastic modulus. A decrease of elastic modulus leads to a comparatively significant rise in heaving at the ground surface, especially near the area overlying the injection points. Smaller deformations were observed for cases with larger elastic modulus.

Numerical results show that a reduction of elastic modulus to some extent prevents the movements of injected fluids along the coal seam and hence the propagation of $\mathrm{CO}_{2}$ plume. Figure 4.16 displays the pore pressure distribution (and hence the $\mathrm{CO}_{2}$ plume) at the end of injection for different values of elastic modulus. Results show that lower elastic modulus produces greater amount of injected $\mathrm{CO}_{2}$ under the same injection pressure and time span. 


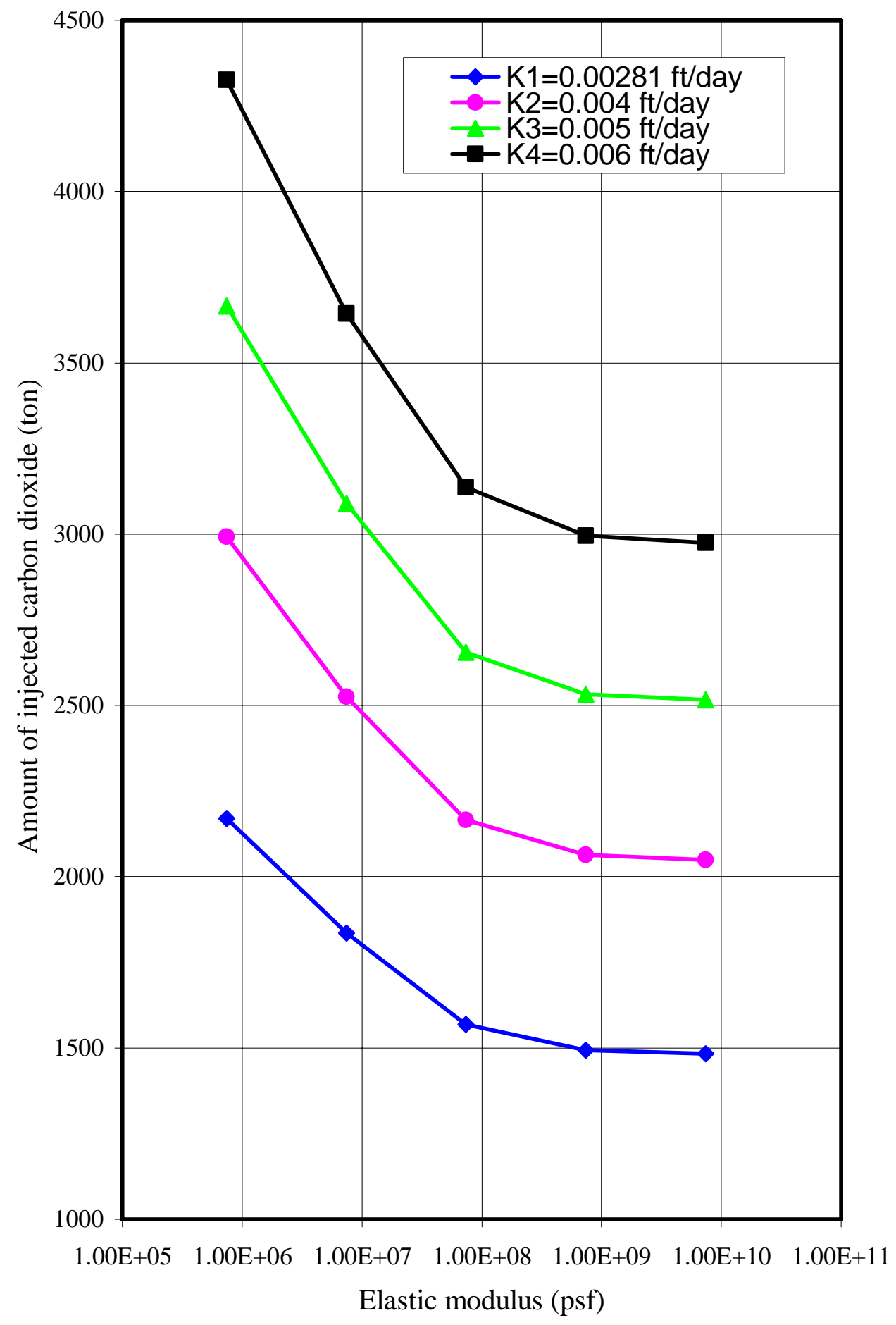

Figure 4.14: Effects of elastic modulus on $\mathrm{CO}_{2}$ injection amount 


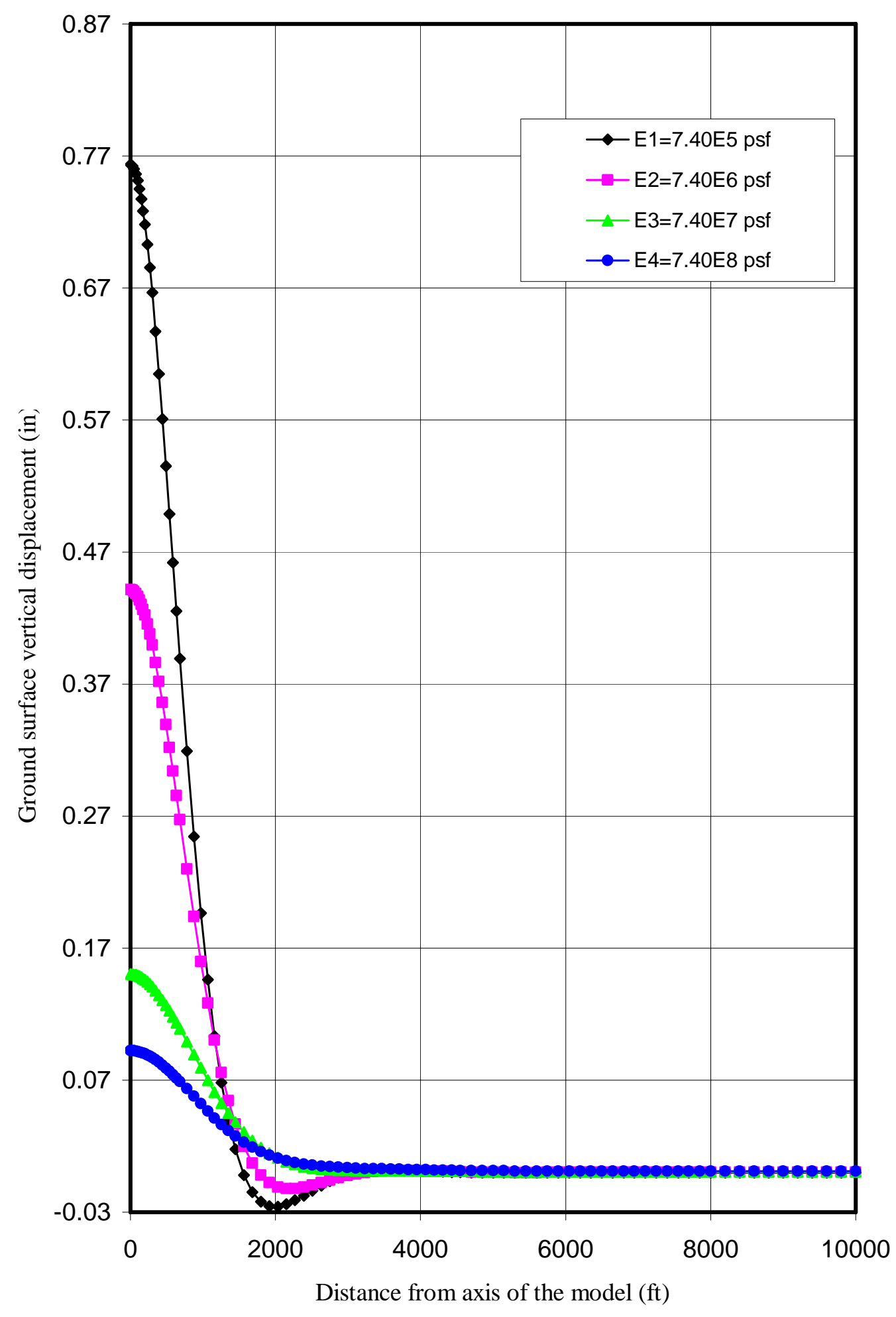

Figure 4.15: Variation of vertical displacement at ground surface with elastic modulus 
\$oep: 3rep-2 Frane: 100
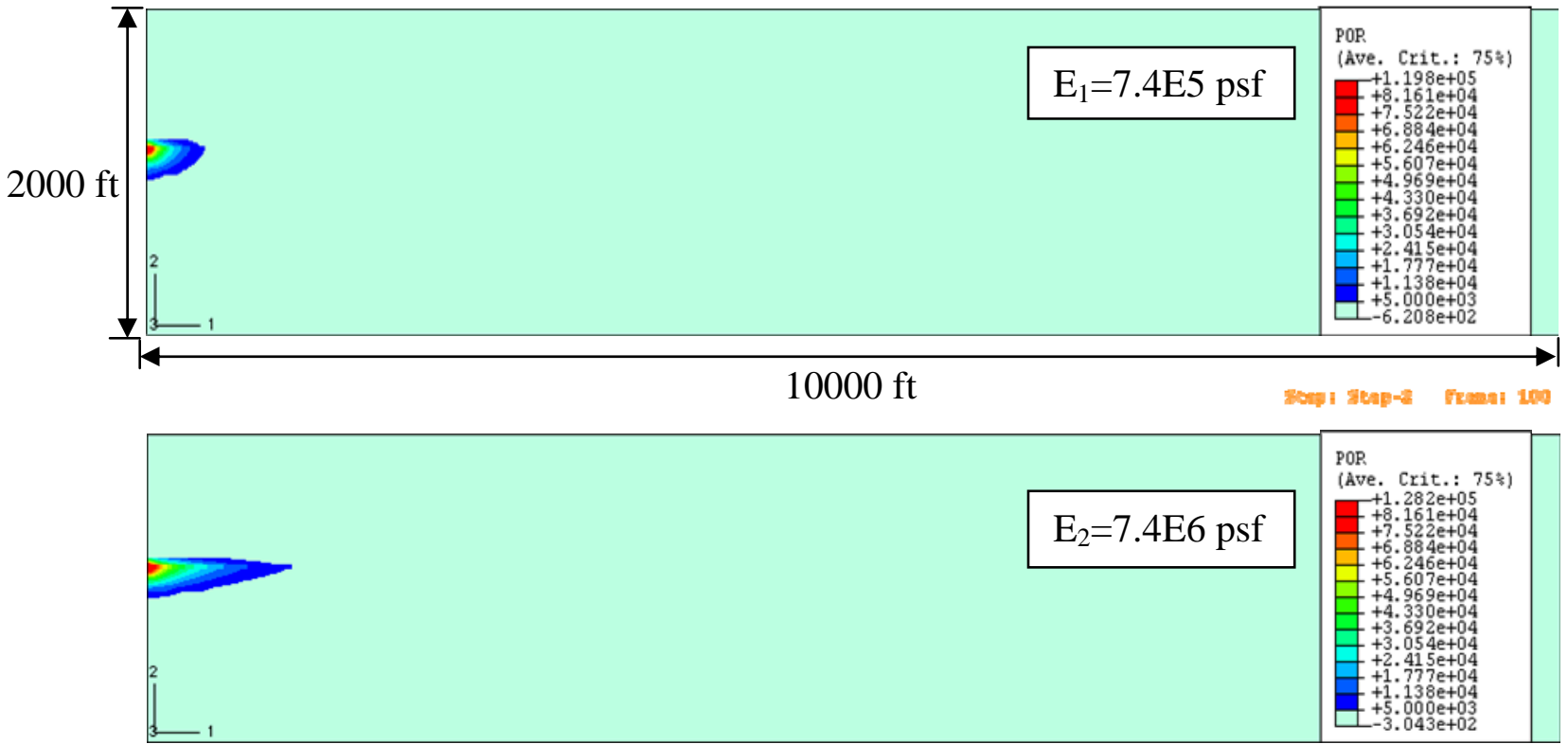

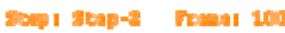

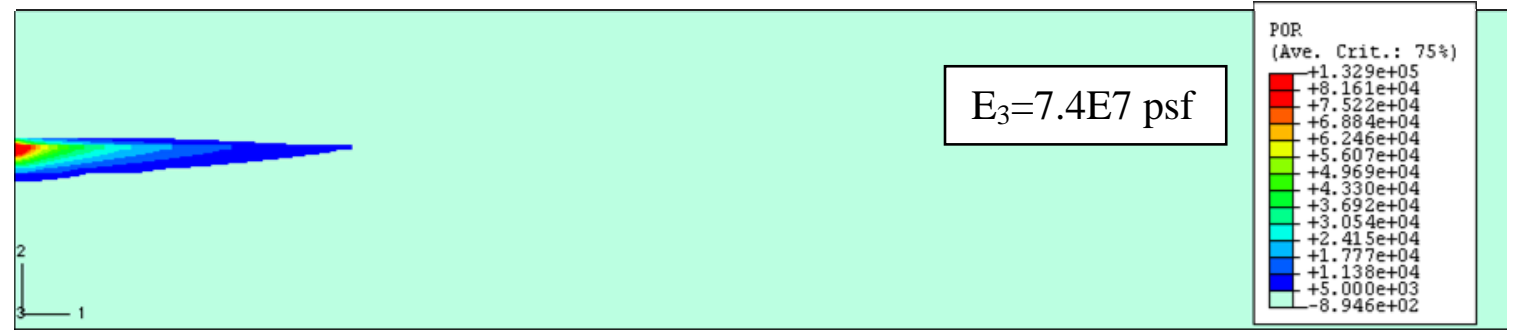

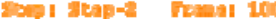

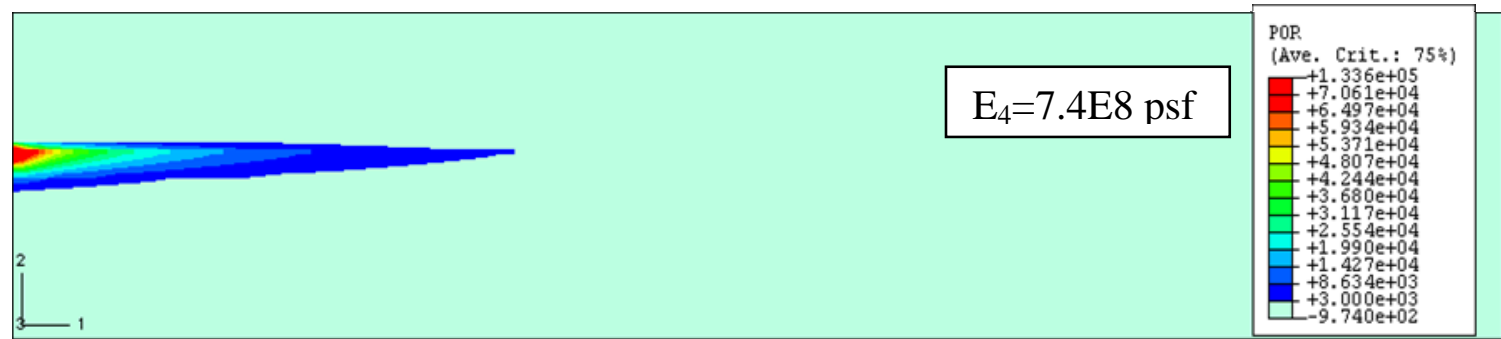

Figure 4.16: Influence of elastic modulus on the pore pressure distribution at the end of injection 
Elastic modulus of the coal seam can be one of the criteria for screening $\mathrm{CO}_{2}$ sequestration sites, considering its effects on $\mathrm{CO}_{2}$ injection and $\mathrm{CO}_{2}$ plume propagation. The favorable values of elastic modulus for $\mathrm{CO}_{2}$ sequestration need to be identified in order to assure that desired amounts of $\mathrm{CO} 2$ can be injected during the selected period for injection. 


\section{CHAPTER 5: ANALYSIS OF $\mathrm{CO}_{2}$ INJECTION AT A SITE IN MARSHALL COUNTY, WEST VIRGINIA}

\subsection{Description of the Pilot Project for $\mathrm{CO}_{2}$ Sequestration}

A seven-year project with support from the U.S. Department of Energy has been initiated in Marshall County in northern West Virginia (Figure 5.1) to study CBM recovery along with $\mathrm{CO}_{2}$ sequestration in coal seams (Cairns, 2002). Based on the thickness of the coal seam, accessibility, and topography, an unmineable coal reservoir lying at a depth of about 1,400 ft in Northern Appalachian basin was chosen as the $\mathrm{CO}_{2}$ sequestration site for this experimental project. The target coals of the Northern Appalachian basin mainly consist of Waynesburg, Pittsburgh, Bakerstown, Freeport, and Kittanning coal seams. The selected reservoir lies in the Upper Freeport coal seam which is right beneath the Pittsburgh coal seam (Cairns, 2002). The Upper Freeport coal seam near this pilot site is approximately $4.25 \mathrm{ft}$ thick. It has an average gas content of 182 scf/ton. The coal in the area of this project site is unmineable because of irregularities in the thickness distribution (Wilson et al., 2003).

The project consists of three vertical wells combined with horizontal wells extended in the target coal seam as shown in Figure 5.2. Two horizontal wells were drilled from the vertical wells located at the corners. These orthogonal horizontal wells have lengths up to 3,000 ft. Similarly, four orthogonal horizontal wells with lengths of $1,000 \mathrm{ft}$ were drilled from the central well. As shown in Figure 5.2, a rectangular network of horizontal wells located in the target coal seam was formed after the completion of these wells. All three vertical wells were initially used as production wells for CBM in the coal seam. The central well was converted into a $\mathrm{CO}_{2}$ injection well after the depletion of the reservoir for certain time period while the other two wells were used to pump gases out of the reservoir. Injection of $\mathrm{CO}_{2}$ has lasted for about two years at the site. During the injection, the propagation of $\mathrm{CO}_{2}$ has been monitored via additional wells (Cairns, 2002). 


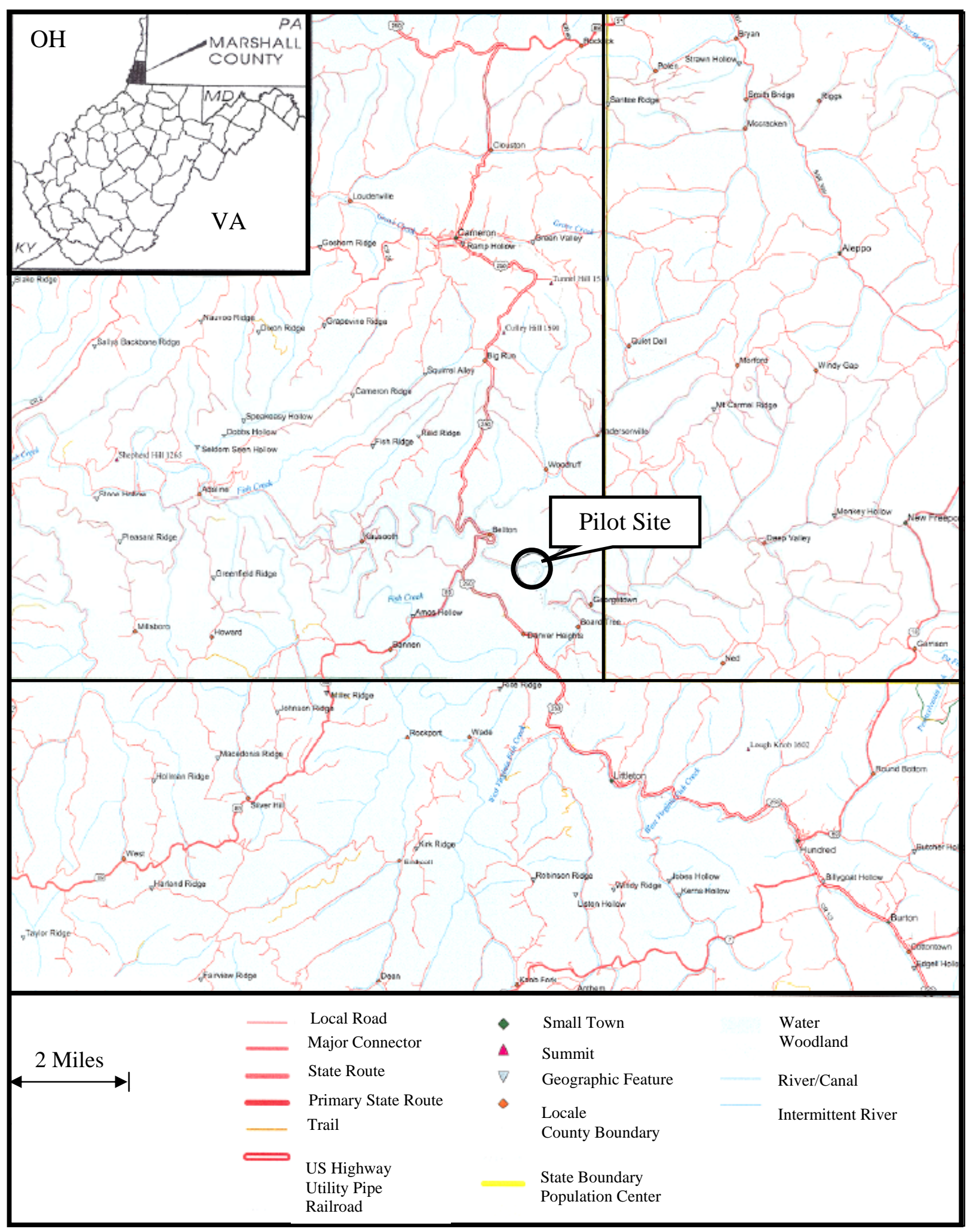

Figure 5.1: Location of the pilot sequestration site (after Cairns, 2002) 


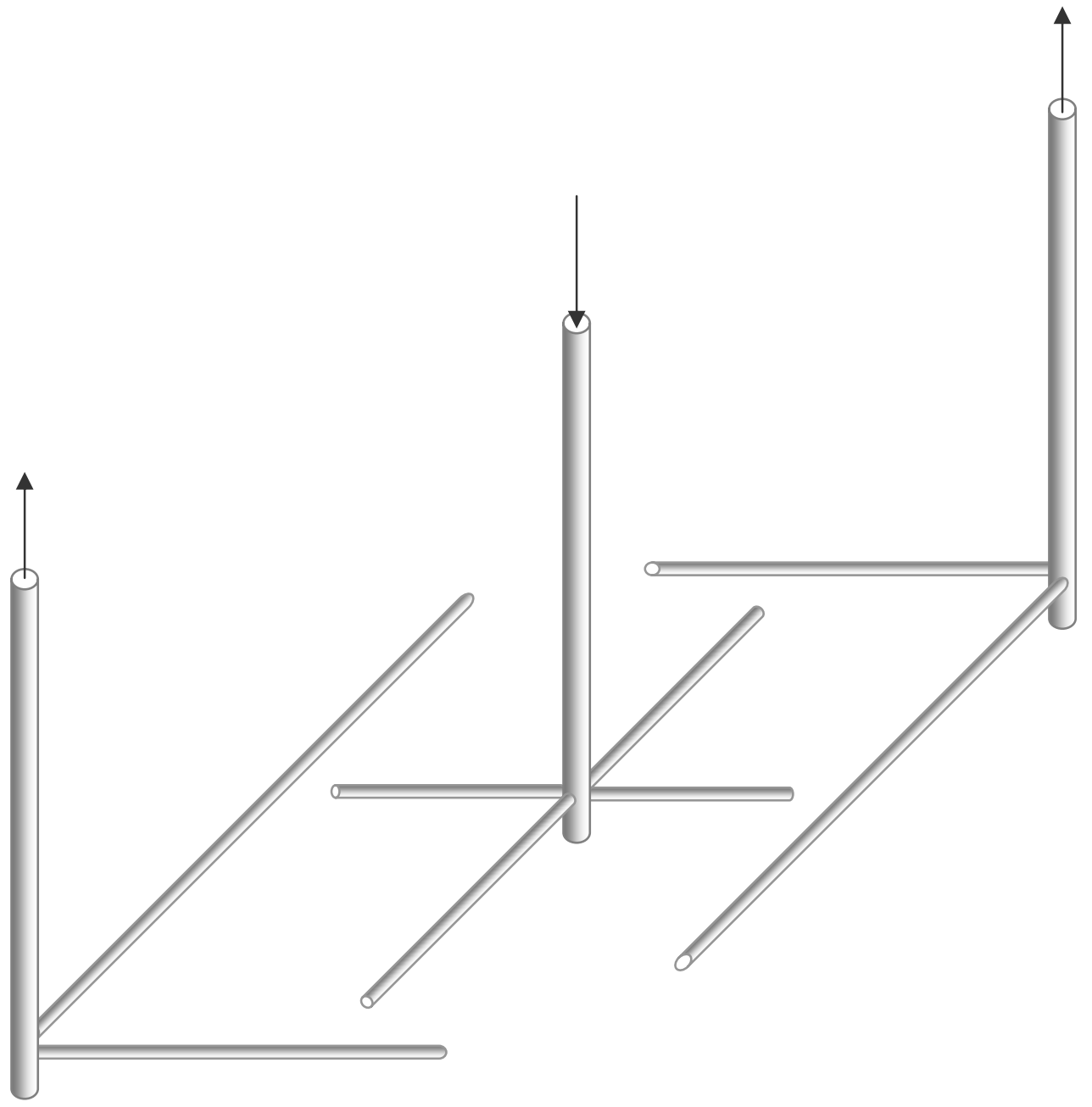

Figure 5.2: Schematic of the pilot site for $\mathrm{CO}_{2}$ sequestration in Marshall County, West Virginia (after Cairns, 2002) 


\subsection{Numerical Study on the Effects of Injection Pressure}

It is expected that horizontal wells can boost the flowability of the reservoir and increase the effectiveness of injection compared to the pattern of only vertical wells. A simulation of CBM recovery with $\mathrm{CO}_{2}$ sequestration for the well pattern in Figure 5.2 indicated that injector length (length for each of the four horizontal wells perpendicular to the central located well site) plays an important role in carbon sequestration (Sams et al., 2005). It has also been shown that an injector length between 295 and $590 \mathrm{ft}$ was the needed to maximize the amount of sequestered carbon dioxide for this wells pattern (Sams et al., 2005).

The geologic column used in this study is shown in Figure 5.3. For this pilotscale project, numerical experiments were conducted to study the effects of injection pressure on the carbon dioxide sequestration. An axisymmetric model with size of $3,000 \times 15,000 \mathrm{ft}$ (refer to Figure 5.4 and 5.5) was created. The numerical procedure was similar to that used in the simulation of Granny Creek case presented earlier in this report. Therefore, numerical details are not given in this section. The hypothetical injection was continued for two years in the modeling study as proposed for the project. Simulations were extended for another two-year period immediately following the injection to allow the dissipation of pore pressure of injected fluids. The properties of strata used in this model are listed in Table 5.1.

Table 5.1 Hypothetical properties of strata for the FEM model

\begin{tabular}{|l|l|l|l|l|l|l|l|}
\hline $\begin{array}{l}\text { Strata } \\
\text { Num. }\end{array}$ & $\begin{array}{l}\text { Depth } \\
\text { (ft) }\end{array}$ & Materials & $\begin{array}{l}\text { Unit } \\
\text { Weight } \\
\text { (pcf) }\end{array}$ & E (psf) & $\begin{array}{l}\text { Poisson's } \\
\text { Ratio }\end{array}$ & $\begin{array}{l}\text { Hydraulic } \\
\text { Conductivity } \\
\text { (ft/day) }\end{array}$ & $\begin{array}{l}\text { Void } \\
\text { Ratio }\end{array}$ \\
\hline 1 & 400 & Soil & 90 & $1.6 \mathrm{E} 8$ & 0.45 & $1.77 \mathrm{E}-3$ & 0.10 \\
\hline 2 & 900 & Silt & 162 & $1.3 \mathrm{E} 8$ & 0.21 & $3.19 \mathrm{E}-4$ & 0.19 \\
\hline 3 & 1150 & Mudstone & 125 & $1.7 \mathrm{E} 8$ & 0.30 & $1.81 \mathrm{E}-5$ & 0.16 \\
\hline 4 & 1400 & Shale & 167 & $5.2 \mathrm{E} 8$ & 0.25 & $3.08 \mathrm{E}-5$ & 0.14 \\
\hline 5 & 1450 & Coal & 84 & $1.4 \mathrm{E} 8$ & 0.30 & $2.37 \mathrm{E}-2$ & 0.20 \\
\hline 6 & 1700 & Shale & 167 & $5.2 \mathrm{E} 8$ & 0.25 & $3.08 \mathrm{E}-5$ & 0.14 \\
\hline 7 & 2000 & Mudstone & 125 & $1.7 \mathrm{E} 8$ & 0.30 & $1.81 \mathrm{E}-5$ & 0.16 \\
\hline 8 & 2300 & Silt & 162 & $1.3 \mathrm{E} 8$ & 0.21 & $3.19 \mathrm{E}-4$ & 0.19 \\
\hline 9 & 2600 & Mudstone & 125 & $1.7 \mathrm{E} 8$ & 0.30 & $1.81 \mathrm{E}-5$ & 0.16 \\
\hline 10 & 3000 & Sandstone & 145 & $6.4 \mathrm{E} 8$ & 0.20 & $1.88 \mathrm{E}-4$ & 0.19 \\
\hline
\end{tabular}




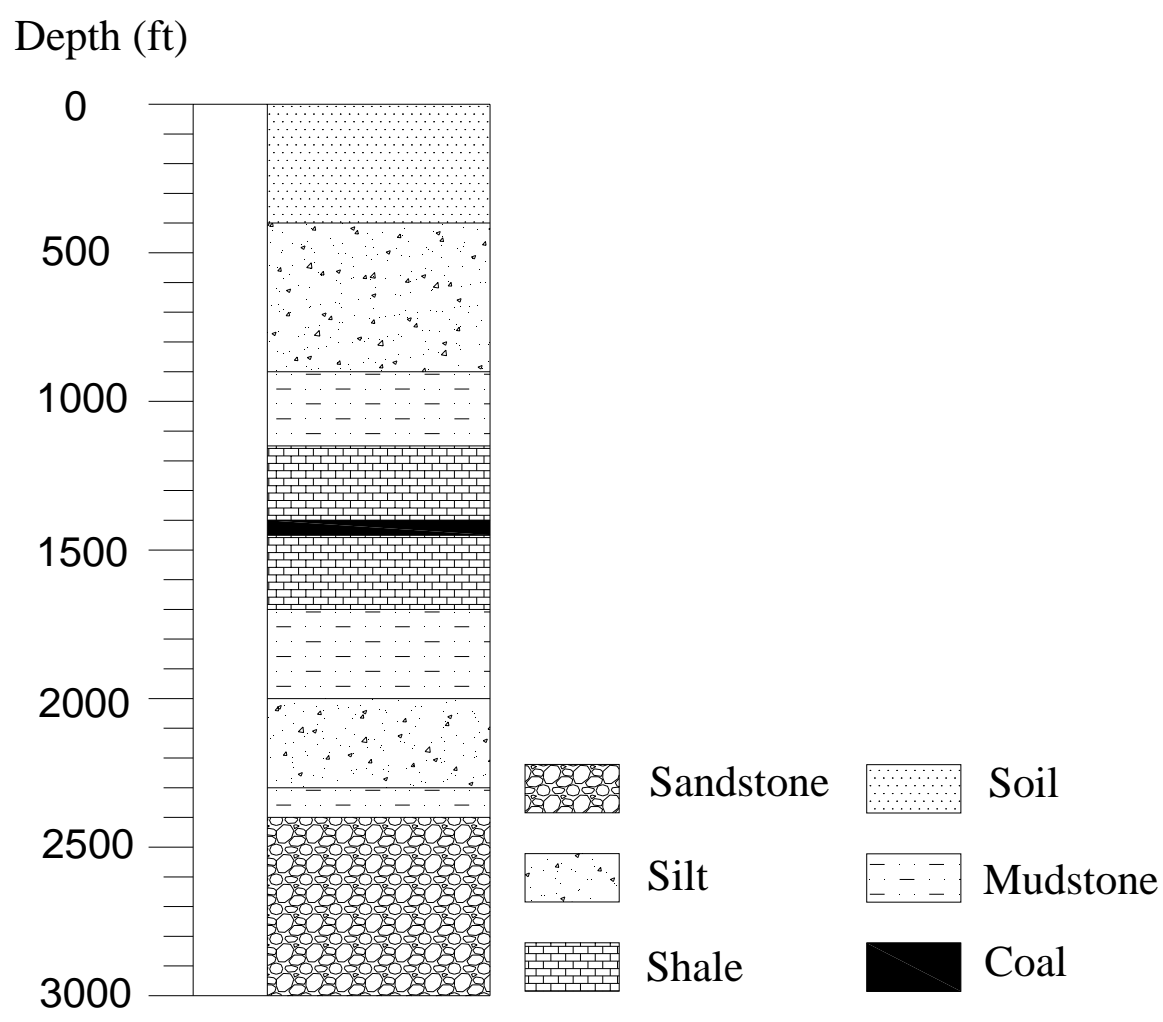

Figure 5.3: Assumed lithologic column for a site at Marshall County, West Virginia 


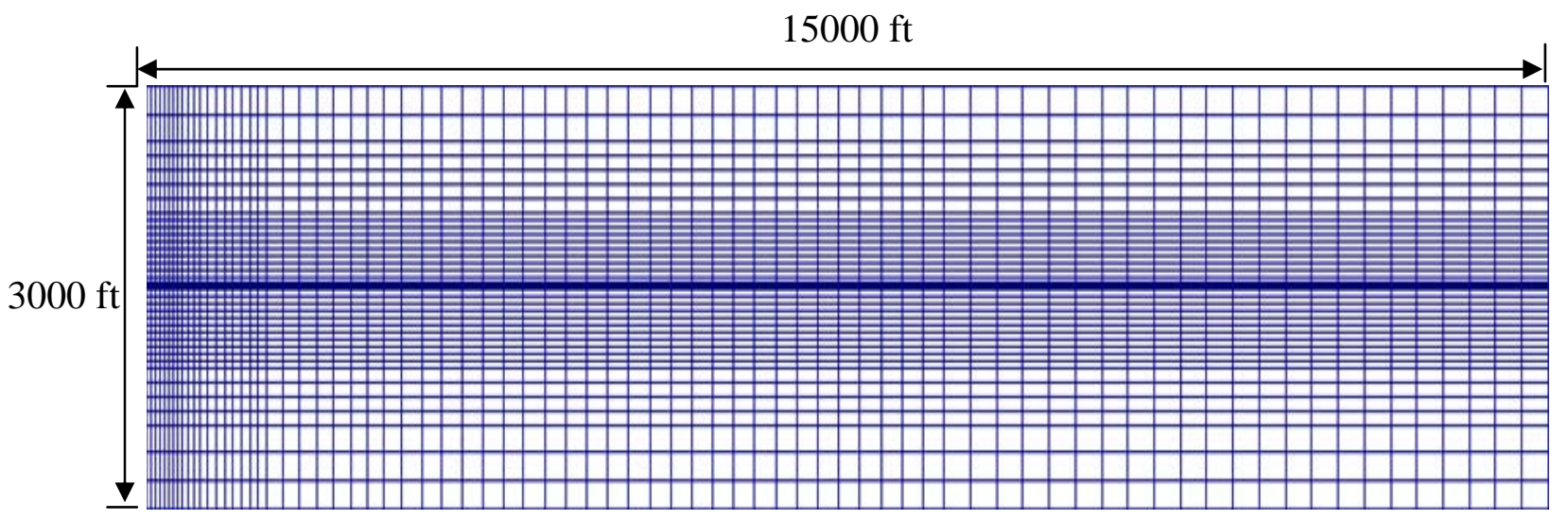

Figure 5.4: FEM model for the Marshall County site in Appalachian basin

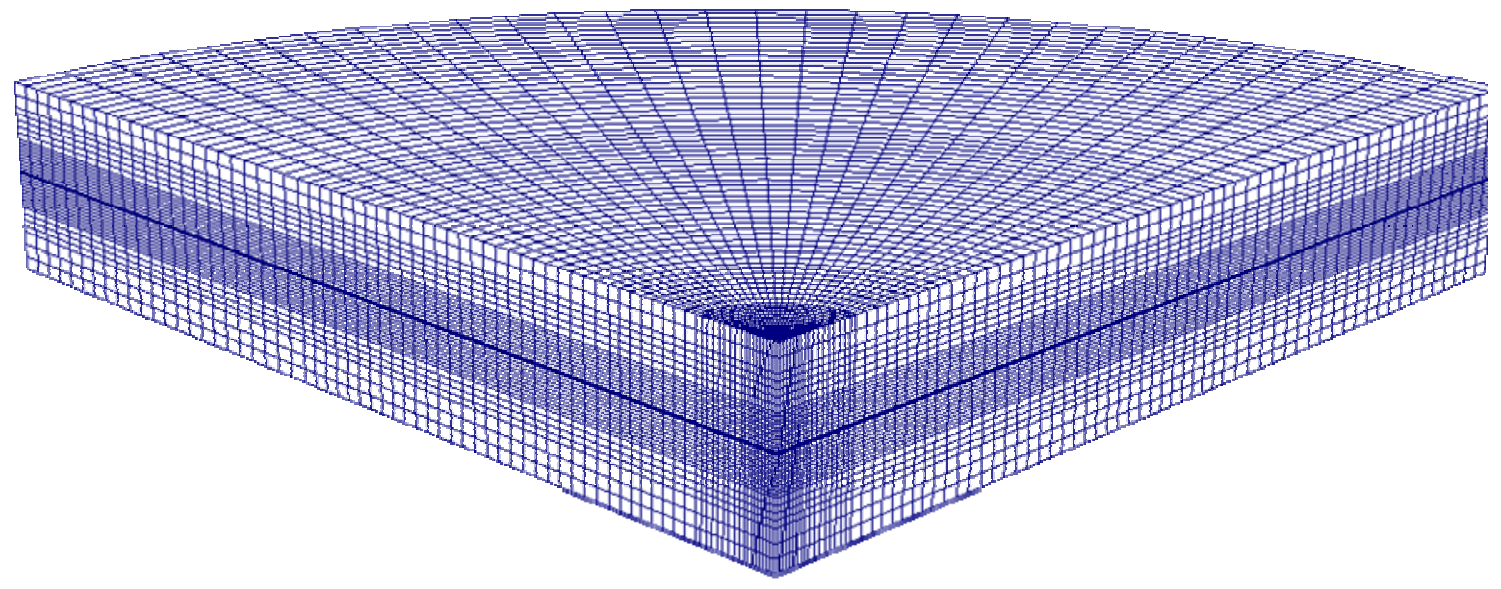

Figure 5.5: Cut view of the model for Marshall County site in Appalachian basin 
In general, increasing injection pressure causes increased quantity of carbon dioxide sequestered with fixed injection time period and given properties of the strata. Results from the analysis are shown in Figure 5.6 which the relationship between the injection pressure and injection amount at this site. As expected, Figure 5.6 indicates that injection pressure has a significant effect on injection amount.

Numerical experiments conducted in this study shows that the maximum extension of fluids in the reservoir appears on about the $45^{\text {th }}$ day after $\mathrm{CO}_{2}$ injection. For the case with high injection pressure of 1,200 psi and 1000 psi, flow vectors in Figure 5.7 reached the boundary of the model opposite to the injection locations on the $45^{\text {th }}$ day after the suspension of the injection. Furthermore, fluid flow was prevalent in the strata even far overlying the coal seam, which means large amount of vertical leakages occurred in this case. The injected fluid plume was mainly confined in the area of target coal seam and the flow vectors did not reach the lateral boundary for the cases with injection pressures of $600 \mathrm{psi}$ and $800 \mathrm{psi}$. In this project, injected $\mathrm{CO}_{2}$ is expected to be confined to the rectangle region with a side length of 3,000 ft as shown in Figure 5.2. Therefore, the magnitude of injection pressure should be maintained in a proper range to avoid $\mathrm{CO}_{2}$ leakage although higher pressure gives rise to larger amounts of $\mathrm{CO}_{2}$ injection. The desired injection pressure needs to be determined on the basis of properties of the strata and time span of $\mathrm{CO}_{2}$ injection. A value between 600 psi and 800 psi appears to be the suitable pressure for this FEM model with given properties. Because of uncertainties in material properties in field studies, regular and frequent monitoring of $\mathrm{CO}_{2}$ plume propagation is necessary in order to prevent leakages.

Figures in Appendix A show the deformations and pore pressure distributions from the numerical analysis of $\mathrm{CO}_{2}$ injection at the site in Marshall county, West Virginia. 


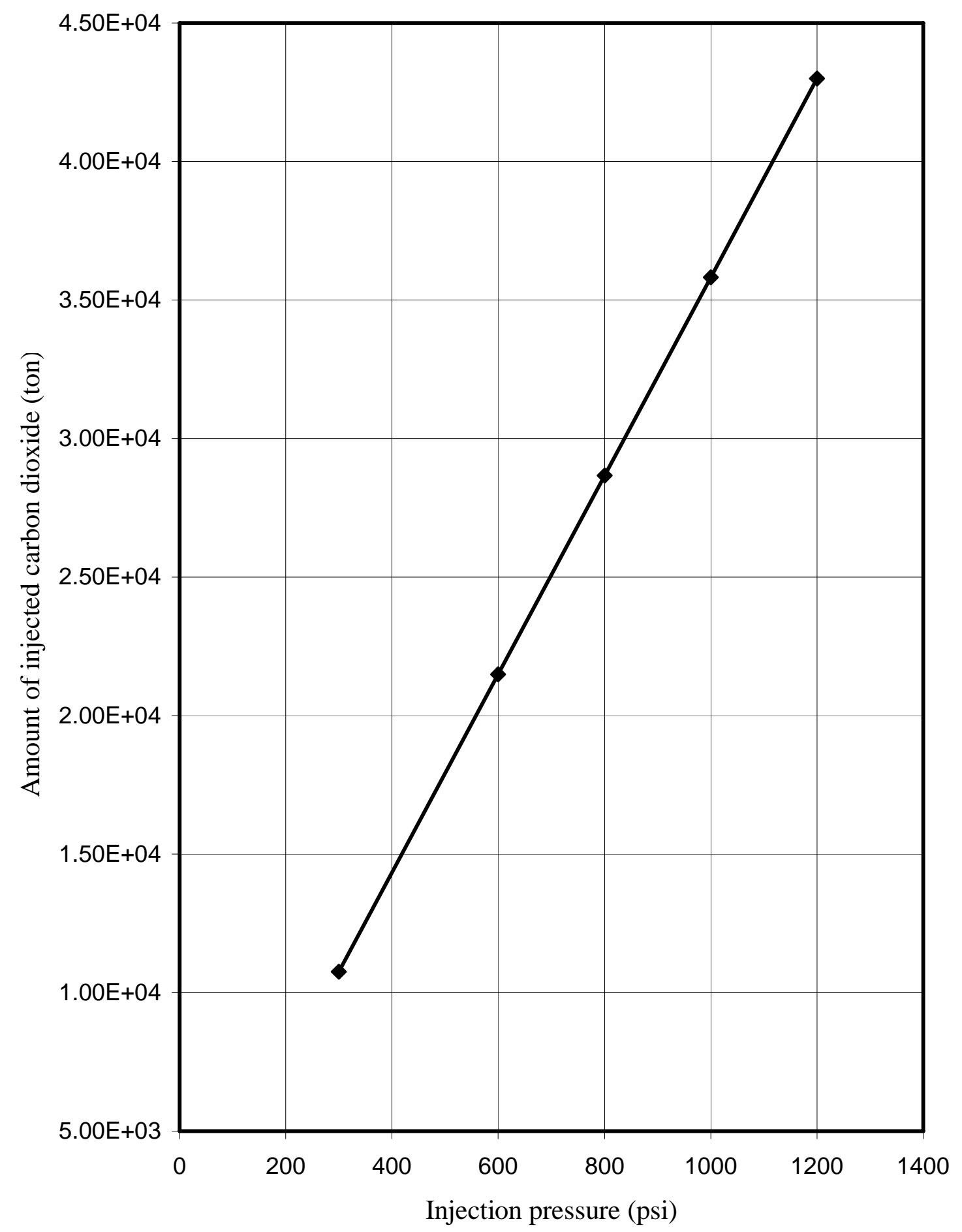

Figure 5.6: Injection amount versus injection pressure 

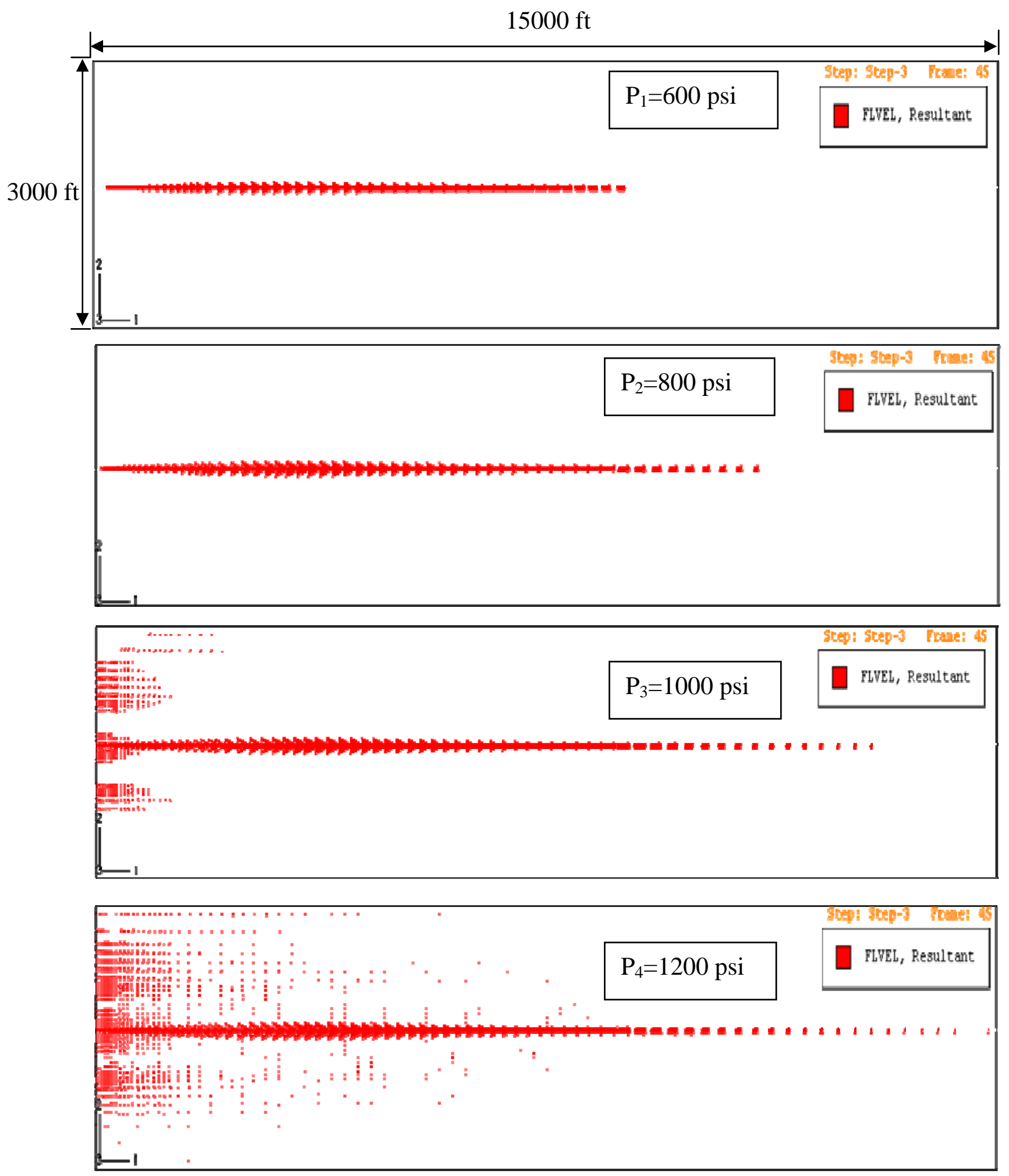

Figure 5.7: Flow vectors in the reservoir on the $45^{\text {th }}$ day after CO2 injection 


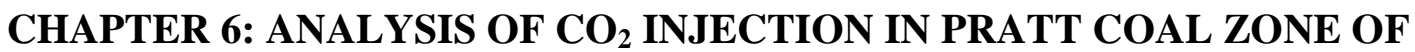 BLACK WARRIOR BASIN}

\subsection{Geological Description of the Site}

A numerical study for $\mathrm{CO}_{2}$ injection was carried out at a hypothetical site in Black Warrior basin which is a late Paleozoic foreland basin (Mclntyre et al., 2003). The coal seam considered in this study is the Pratt coal zone. The Black Warrior Basin extends nearly 230 miles from west to east and 188 miles from north to south which covers an area of approximate 23,000 square miles in Alabama and Mississippi (EPA, 2004). It is the Upper Pottsville formation of Pennsylvanian age which is approximately 300 million years old (Thomas, 1988). A significant amount of coalbed methane has been produced in the Black Warrior basin.

Figure 6.1 shows an approximate lithologic column based on the information given in the literature (Pashin et al., 2004). In the present study, this column was divided into 11 layers which were considered to be homogenous within each layer. The coal seam interval lies between 1,900 ft and 1,923 ft with an average effective thickness of 23 ft.

In the Pratt coal zone, sandstone layers consists of single-story and multistory bodies which makes the strata more complicated. Also lots of existing faults and folds contribute much to the complexity of the geologic structures (Pashin et al., 2004). These structures influence the transport of gas and water in the reservoir. Faults establish the basic discontinuities of the coalbed methane reservoir, and the system of the natural fractures is one of the important properties of this geological structure (Pashin et al., 2004). 


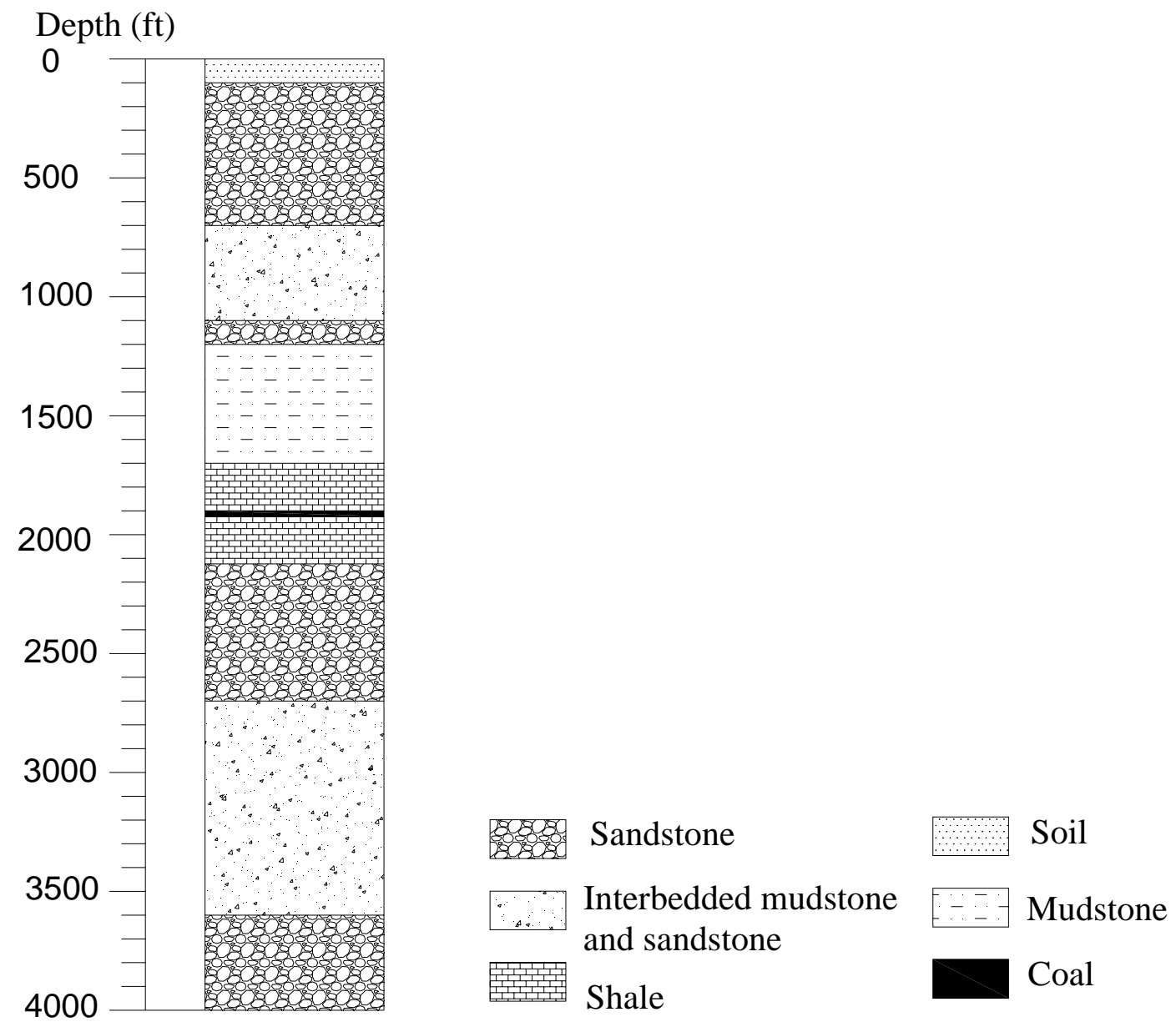

Figure 6.1: Assumed lithologic column for Pratt coal zone 
Literature indicates that the Pottsville Formation where Pratt coal zone is located is an unconfined aquifer (EPA, 2004). The matrix permeability of the Pottsville rocks, such as mudstone and cemented sandstone is very low. The faults, fractures, and joints dominantly form the flow pattern of the Pottsville Formation. This means the fracturerelated permeability is more important for coalbed methane production and $\mathrm{CO}_{2}$ sequestration in the Pottsville Formation (EPA, 2004).

\subsection{Geothermal and Pressure Conditions of the Reservoir}

The coal sorption capacity is sensitive to temperature and pressure (Yang and Saunders, 1985). Moreover, reservoir temperature and pressure determine the phase of injected $\mathrm{CO}_{2}$. The phase of injected $\mathrm{CO}_{2}$ under reservoir conditions is one of the most critical factors for efficient sequestration and stable storage. Previous studies have indicated that much more $\mathrm{CO}_{2}$ can be stored in coal seams under supercritical conditions than at other temperatures and pressures (Kroos et al., 2001).

According to the published data in Black Warrior basin, the geothermal temperature gradient was derived from the bottom-hole temperature and ground surface temperature of $74{ }^{\circ} \mathrm{F}$ (Pashin and McIntyre, 2003). It was found that the geothermal gradient ranges from $6{ }^{\circ} \mathrm{F} / 1000 \mathrm{ft}$ to approximately $20{ }^{\circ} \mathrm{F} / 1000 \mathrm{ft}$ depending on the location in the Black Warrior basin. An average geothermal gradient of $9{ }^{\circ} \mathrm{F} / 1000 \mathrm{ft}$ was reported in the literature (Pashin et al., 2004). For Pratt coal zone, the reservoir temperature increases southwestward from less than $80{ }^{\circ} \mathrm{F}$ in the north-eastern part of the coalbed methane fairway to more than $110{ }^{\circ} \mathrm{F}$ in the south-western part (Pashin et al., 2004). It has been reported that the temperature in the fields of Cedar Cove, Holt, and Robinson' Bend all located in the Pratt coal zone reach the critical temperature of $88{ }^{\circ} \mathrm{F}$ for $\mathrm{CO}_{2}$ (Pashin et al., 2004).

In the model used in this study, the coal seam was assumed to be located at a depth between $1900 \mathrm{ft}$ and $1923 \mathrm{ft}$ which has an average depth of $1911.5 \mathrm{ft}$. The corresponding temperature increase for the coal seam can be calculated as $17.2{ }^{\circ} \mathrm{F}$ in 
accordance with the geothermal gradient of $9{ }^{\circ} \mathrm{F} / 1000 \mathrm{ft}$. Assuming that the near ground surface temperature is $74{ }^{\circ} \mathrm{F}$, the reservoir temperature can be calculated as $91.2{ }^{\circ} \mathrm{F}$, which exceeds the critical temperature of $88{ }^{\circ} \mathrm{F}$ for $\mathrm{CO}_{2}$.

The hydrostatic pressure gradient in the Black Warrior coalbed methane fairway varies from a normal value of $0.43 \mathrm{psi} / \mathrm{ft}$ to an extremely low value of $0.05 \mathrm{psi} / \mathrm{ft}$ (Pashin et al., 2004). Wells in some areas, such as Cedar Cove, Deerlick Creek, Blue Creek, and Oak Grove fields have pressure gradients close to the normal value. In these areas, published data show that the hydrostatic pressure at the top of the Pratt coal zone is typically higher than 700 psi (Pashin et al., 2004). Large areas of extremely low pressure are found in Brookwood, Oak Grove, Blue Creek, and White Oak Creek fields. In these areas, hydrostatic pressure at the top of the Pratt coal zone is less than 100 psi (Pashin and McIntyre, 2003).

Reservoirs below the depth of 2,480 ft can reach the critical pressure for $\mathrm{CO}_{2}$ assuming that the normal pressure gradient is $0.43 \mathrm{psi} / \mathrm{ft}$ and the $\mathrm{CO}_{2}$ critical pressure is 1070 psi. Almost all the coalbed methane wells above this depth have the bottom-hole temperatures beyond the critical temperature for $\mathrm{CO}_{2}$. Therefore, supercritical fluid conditions are potentially widespread in the Pottsville Coal Interval where Pratt coal zone is located as shown in Figure 6.2.

\subsection{Geomechanical Properties of the Overlying Strata}

The assumed geomechanical properties used in the analysis of geologic sequestration in the Pratt coal zone are shown in Table 6.1. There were no measured data on elastic properties of coal and overburden materials. Therefore, the values reported in Table 6.1 were assumed for the purpose of the analysis of the hypothetical injection at the field site. 
Table 6.1 Material properties used in the analysis for Pratt coal zone

\begin{tabular}{|l|l|l|l|l|l|l|l|l|}
\hline $\begin{array}{l}\text { Strata } \\
\text { Layer }\end{array}$ & $\begin{array}{l}\text { Depth } \\
\mathbf{f f t}\end{array}$ & Materials & $\begin{array}{l}\text { Density } \\
\mathbf{( p c f )}\end{array}$ & $\mathbf{E}$ (psf) & $\begin{array}{l}\text { Poisson's } \\
\text { Ratio }\end{array}$ & $\begin{array}{l}\text { Hydraulic } \\
\text { Conductivity } \\
\text { (ft/day) }\end{array}$ & $\begin{array}{l}\text { Unit } \\
\text { Weight of } \\
\text { Wetting } \\
\text { Liquid } \\
\text { (pcf) }\end{array}$ & $\begin{array}{l}\text { Void } \\
\text { Ratio }\end{array}$ \\
\hline 1 & 100 & Soil & 90 & $1.6 \mathrm{E} 8$ & 0.45 & $1.77 \mathrm{E}-3$ & 62.5 & 0.10 \\
\hline 2 & 700 & Sandstone & 145 & $6.4 \mathrm{E} 8$ & 0.20 & $1.88 \mathrm{E}-4$ & 62.5 & 0.19 \\
\hline 3 & 1100 & $\begin{array}{l}\text { Interbedded } \\
\text { mudstone } \\
\text { and } \\
\text { sandstone }\end{array}$ & 131 & $4.2 \mathrm{E} 8$ & 0.25 & $8.88 \mathrm{E}-4$ & 62.5 & 0.18 \\
\hline 4 & 1200 & Sandstone & 145 & $6.4 \mathrm{E} 8$ & 0.20 & $1.88 \mathrm{E}-4$ & 62.5 & 0.19 \\
\hline 5 & 1700 & Mudstone & 125 & $1.7 \mathrm{E} 8$ & 0.30 & $1.81 \mathrm{E}-5$ & 62.5 & 0.16 \\
\hline 6 & 1900 & Shale & 167 & $5.2 \mathrm{E} 8$ & 0.25 & $3.11 \mathrm{E}-6$ & 62.5 & 0.15 \\
\hline 7 & 1923 & Coal & 84 & $1.4 \mathrm{E} 8$ & 0.30 & $2.37 \mathrm{E}-2$ & 62.5 & 0.20 \\
\hline 8 & 2123 & Shale & 167 & $5.2 \mathrm{E} 8$ & 0.25 & $3.08 \mathrm{E}-6$ & 62.5 & 0.14 \\
\hline 9 & 2700 & Sandstone & 145 & $6.4 \mathrm{E} 8$ & 0.20 & $1.88 \mathrm{E}-4$ & 62.5 & 0.19 \\
\hline 10 & 3600 & $\begin{array}{l}\text { Interbedded } \\
\text { mudstone } \\
\text { and }\end{array}$ & 131 & $4.2 \mathrm{E} 8$ & 0.25 & $8.88 \mathrm{E}-4$ & 62.5 & 0.18 \\
& & & & & & & & \\
\hline 11 & 4000 & Sandstone & & & & & & \\
\hline
\end{tabular}




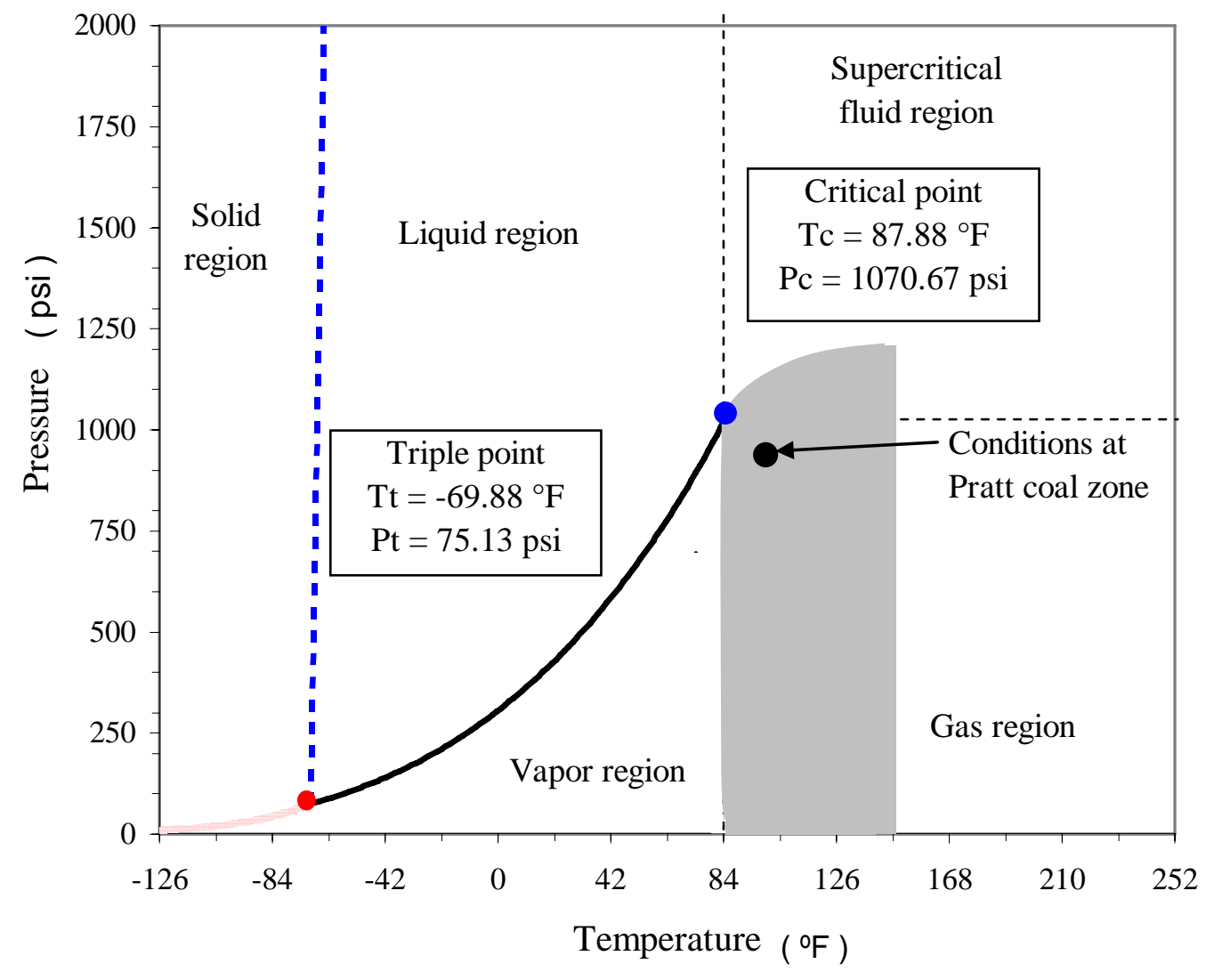

Figure 6.2: Reservoir conditions for Black Warrior basin on the phase diagram of $\mathrm{CO}_{2}$ (after Pashin et al., 2004) 


\subsection{Calculation of Injection Rate}

In this numerical analysis of geomechanical response of the overburden to $\mathrm{CO}_{2}$ sequestration in coal seams, a simulation of one-year injection followed by 400-day dissipation of $\mathrm{CO}_{2}$ in the coal seam was simulated by applying and changing the boundary condition of pore pressure. The results of the numerical analysis are discussed below.

Results from the finite element analysis show that the total volume of $\mathrm{CO}_{2}$ injection was 9,647 tons during the one-year injection. This translates to an average injection rate of 26.43 tons/day assuming the density of $\mathrm{CO}_{2}$ as $37.5 \mathrm{pcf}$. This density is consistent with the assumed reservoir conditions.

\subsection{Pore Pressure Distribution}

For a saturated porous medium, an increase in total vertical stress leads to an equal increase in pore pressure because the compressibility of the porous medium structure is much greater than that of water or grains. This increment of pore pressure is considered as excess pore pressure since it is in excess of a reference static or steady-state pore pressure. In this study, the output of pore pressure is the excess pore pressure which shows the change of initial pore pressure.

Figure 6.3 and Figure 6.4 show the distribution of excess pore pressure at the end of $\mathrm{CO}_{2}$ injection and dissipation, respectively. Figure 6.5 shows the process of dissipation of pore pressure with time after the closure of $\mathrm{CO}_{2}$ injection. 


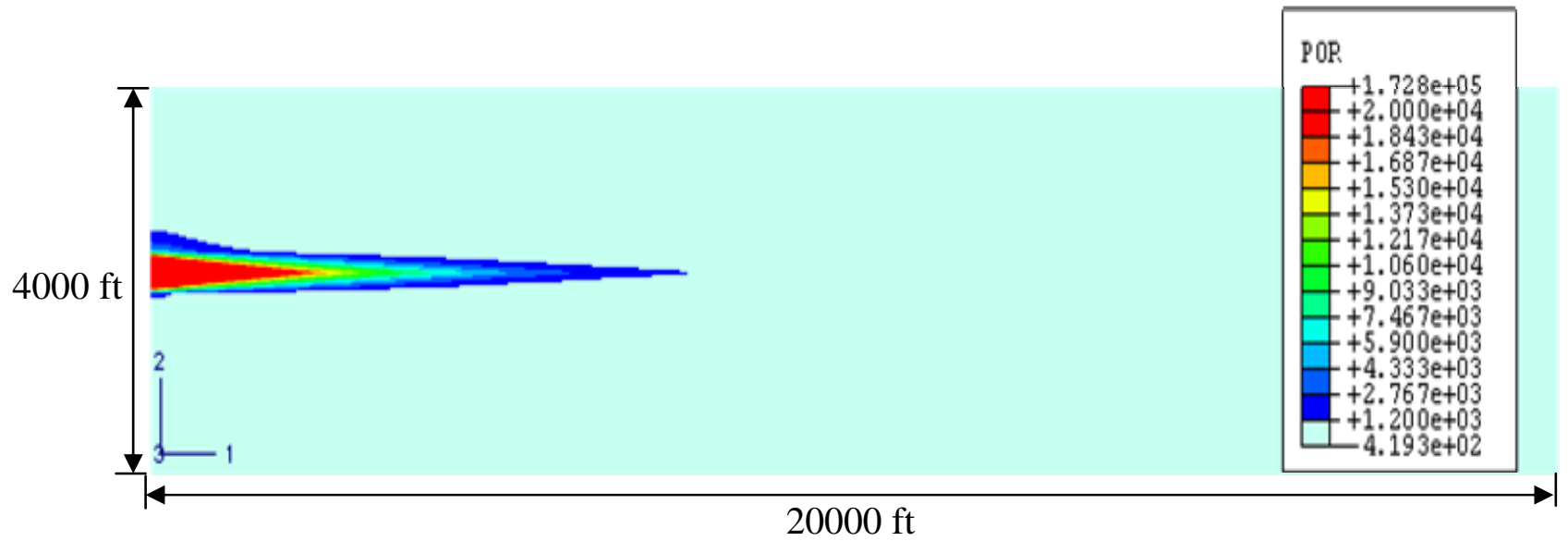

Figure 6.3: Distribution of pore pressure at the end of $\mathrm{CO}_{2}$ injection period

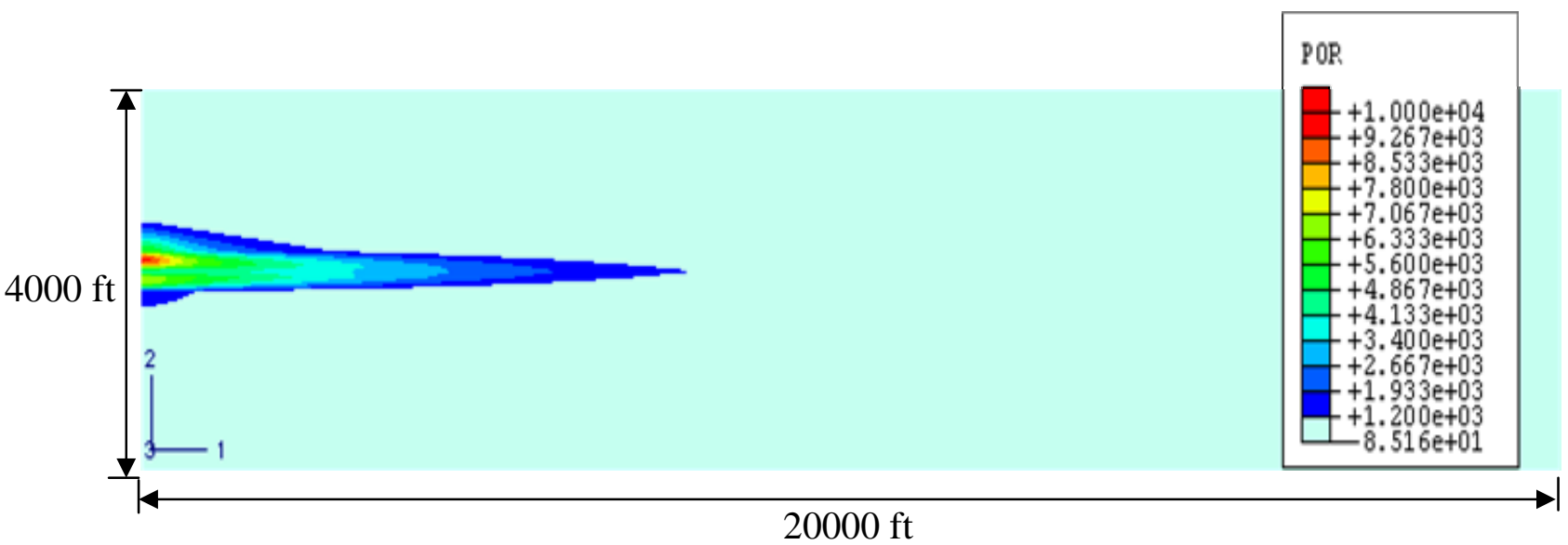

Figure 6.4: Distribution of pore pressure at the end of $\mathrm{CO}_{2}$ dispersion period 


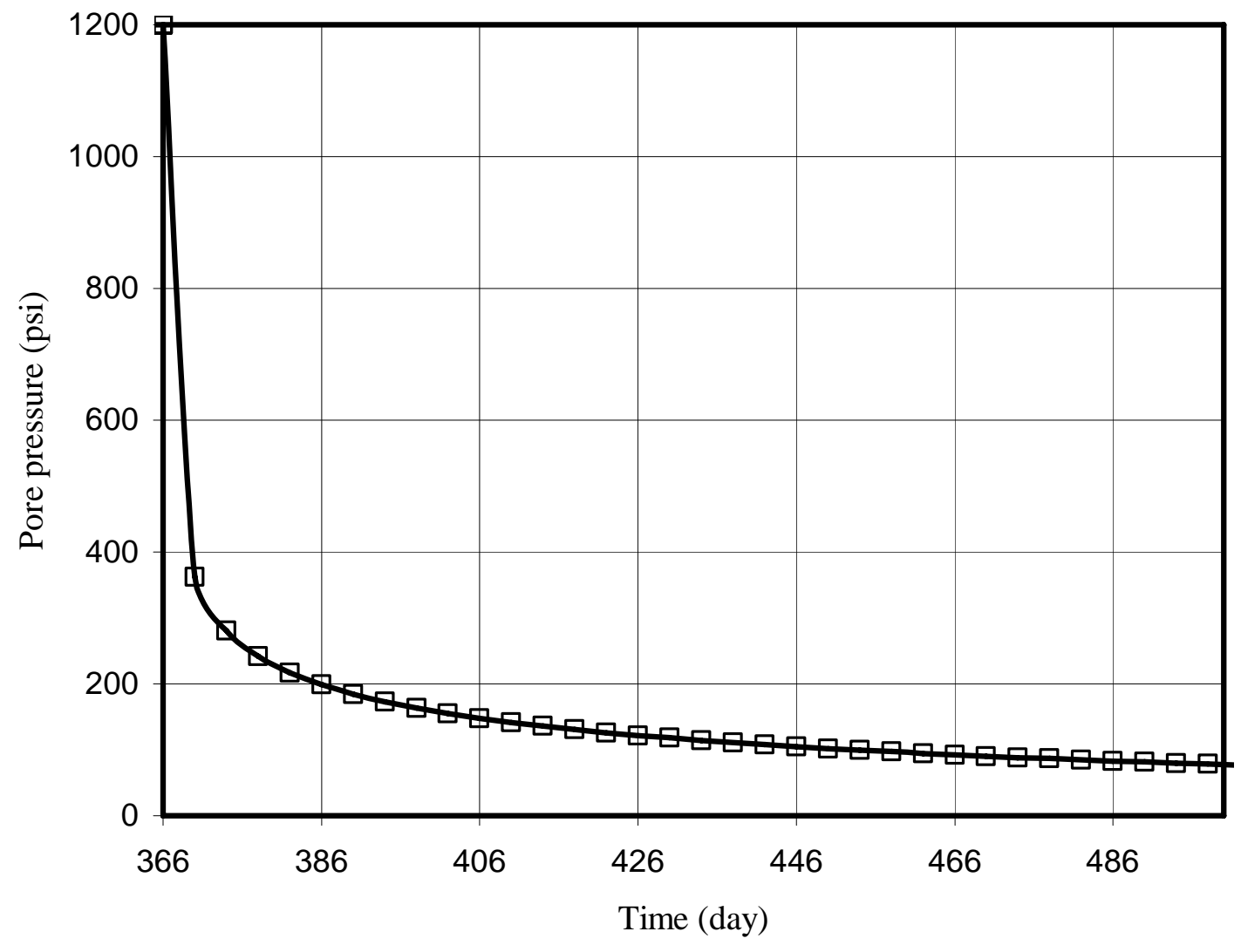

Figure 6.5: The dissipation of pore pressure with time after injection 


\subsection{Vertical Displacement of the Strata}

Vertical displacements of the strata on the $365^{\text {th }}$ and $765^{\text {th }}$ day are exhibited in Figure 6.6 and Figure 6.7, respectively. Figure 6.8 shows a 3-D view of the resultant heaving of the overburden strata at the end of the injection period.

The computed vertical displacement at ground surface is equal to 0.114 in at the end of the injection period (the $365^{\text {th }}$ days). The response of the strata to the hypothetical $\mathrm{CO}_{2}$ injection is insignificant considering the maximum vertical displacement. However, such displacements are measurable with tilt meters and can be used in surface monitoring methods. Figure 6.9 shows the vertical displacement along the ground surface the end of injection and dissipation, respectively. The difference in magnitudes of surface displacements between the two time points indicates that the ground movements drop slightly as the pore pressure dissipated in the coal seam. In fact, the displacements at the ground surface started to drop immediately after the injection. 


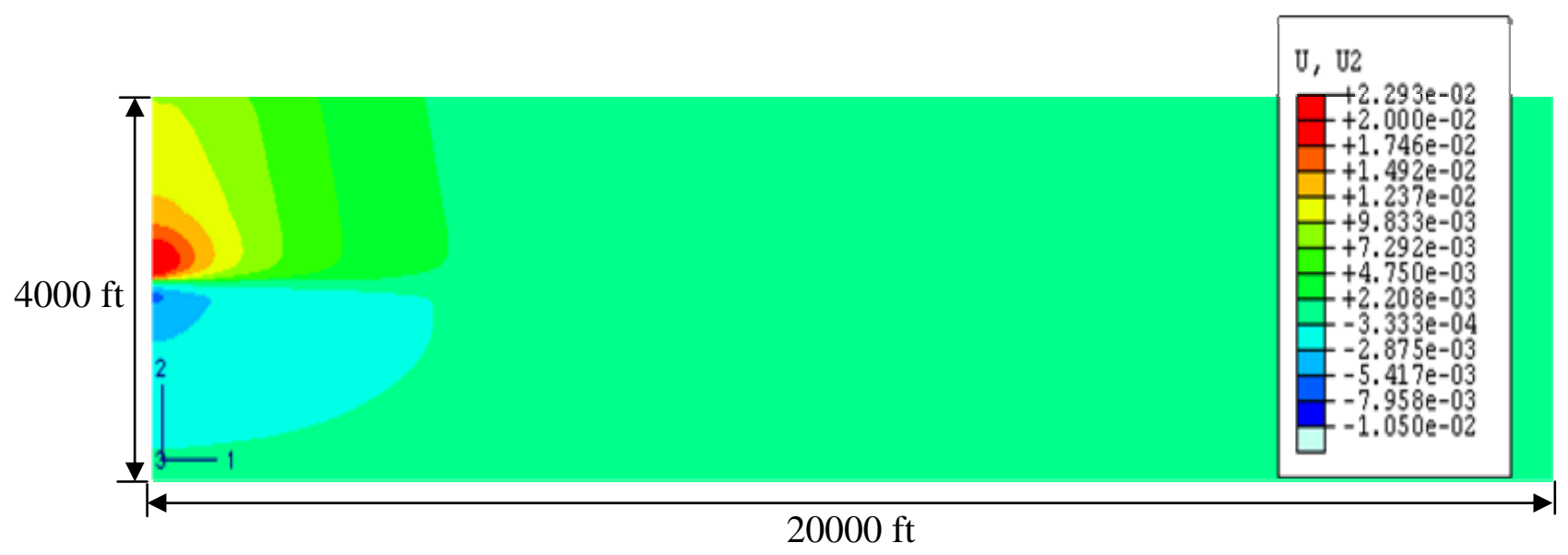

Figure 6.6: Displacement of ground surface at the end of injection period

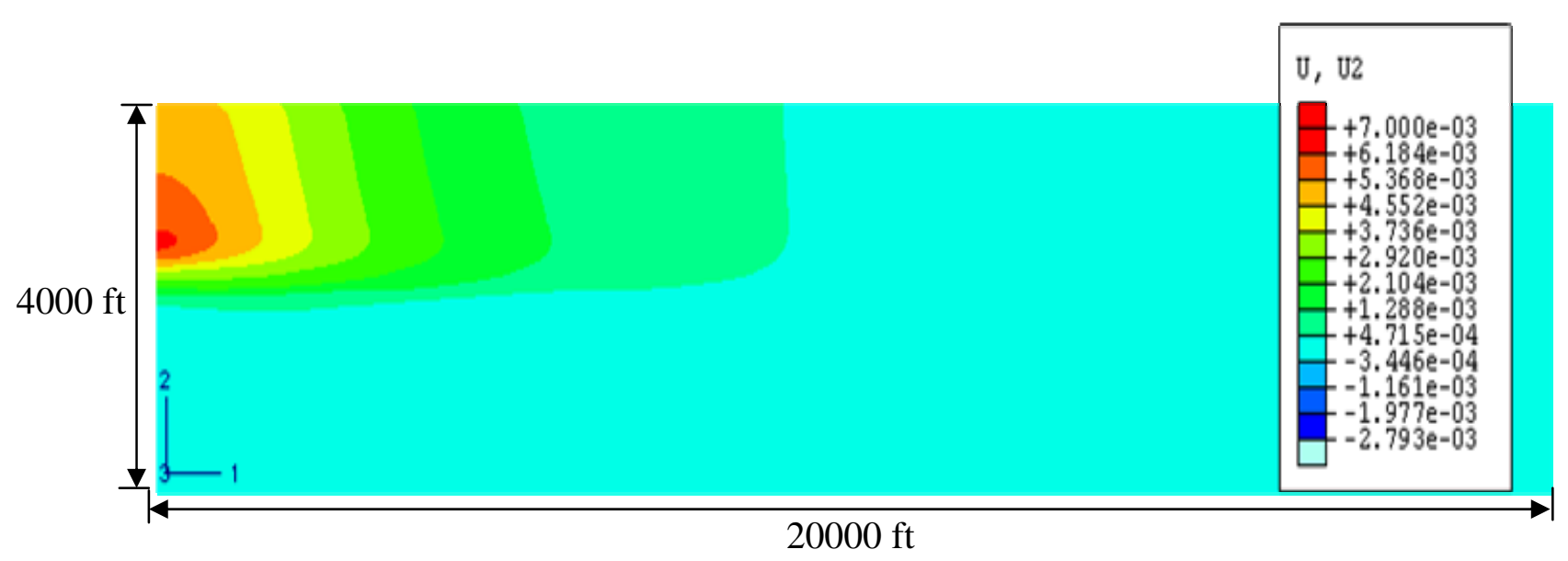

Figure 6.7: Displacement of ground surface at the end of dispersion period 


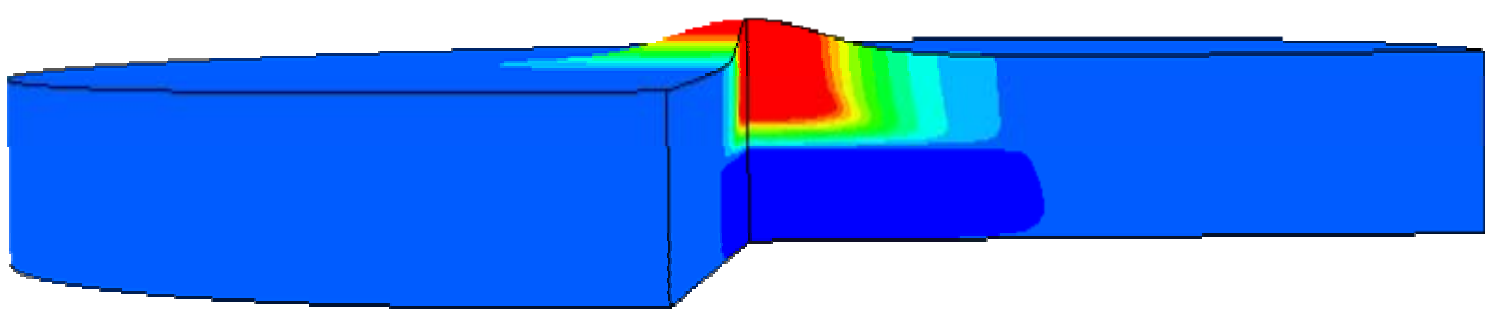

Figure 6.8: $3-\mathrm{D}$ view of the vertical displacement at $\mathrm{t}=365$ days 


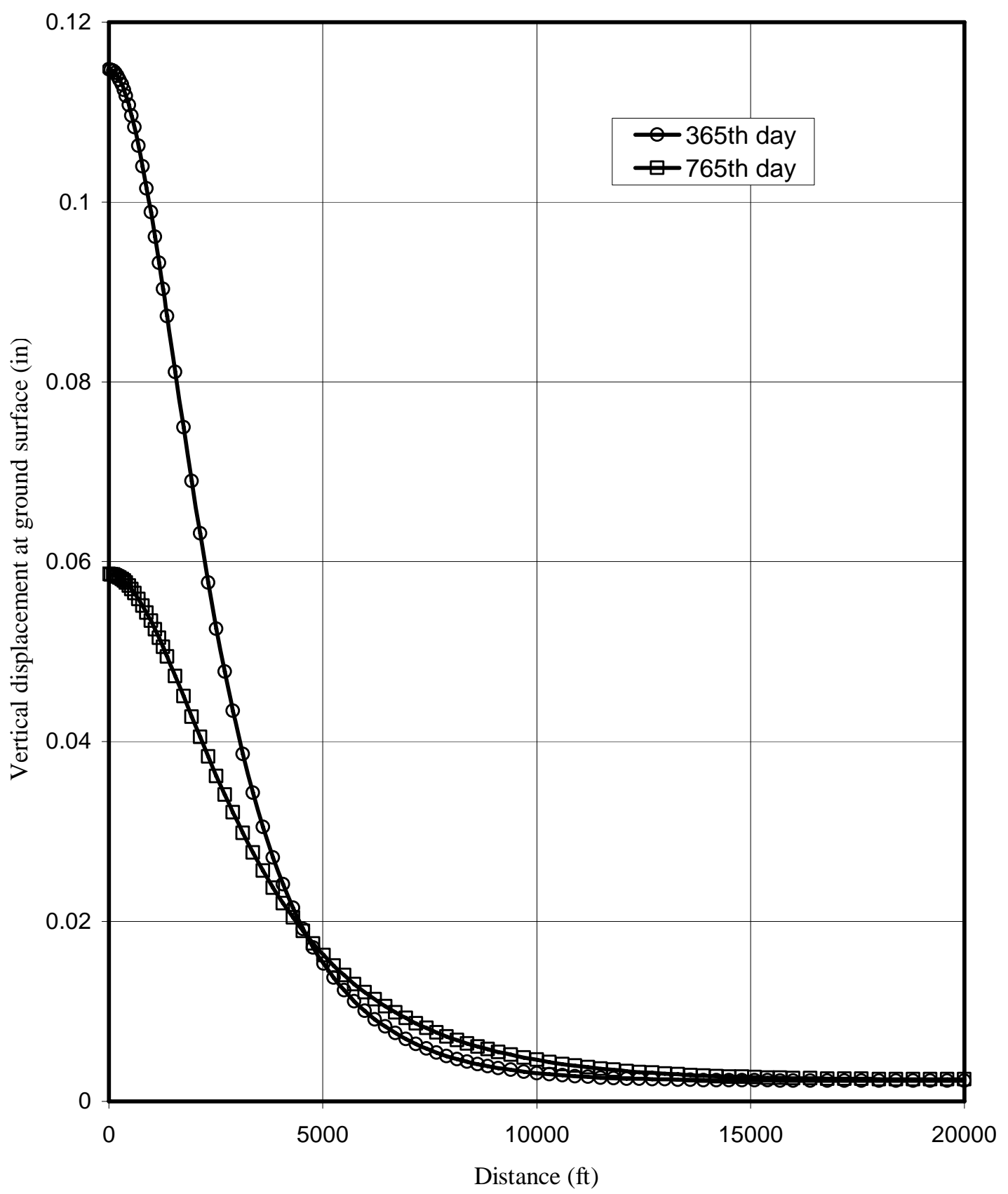

Figure 6.9: Variation of vertical displacements at the ground surface with time 


\section{CHAPTER 7: CONCLUSIONS}

Geologic sequestration of $\mathrm{CO}_{2}$ in coal seams has attracted attention because of its added value for enhanced coalbed methane which can potentially compensate for the relatively high costs of needed infrastructure for $\mathrm{CO}_{2}$ sequestration. However, better understanding of several issues with respect to geophysics, geomechanics, geology, and reservoir engineering is necessary for large-scale geological sequestration of $\mathrm{CO}_{2}$ in coal seams. This research work provides preliminary knowledge of overburden response when coal is used as the geologic storage host for $\mathrm{CO}_{2}$. The phase properties of $\mathrm{CO}_{2}$ were investigated since conditions of the coal reservoirs for $\mathrm{CO}_{2}$ sequestration are typically different from atmospheric conditions.

Finite element analysis of coupled deformation and flow was performed at three coal sites selected from Appalachian basin and Black Warrior basin. The analysis concentrated on geomechanical aspects of the strata movements during and after $\mathrm{CO}_{2}$ injection. Results of the analysis reflect the processes of the $\mathrm{CO}_{2}$ injection and subsequent pore-pressure dissipation. Results show abrupt changes in pore pressure and vertical displacement after the termination of $\mathrm{CO}_{2}$ injection. The distribution of pore pressure throughout the strata illustrates the mechanics of $\mathrm{CO}_{2}$ plume propagation. Comparative study shows that propagation of injected $\mathrm{CO}_{2}$ is influenced by the magnitudes of reservoir elastic modulus, reservoir permeability and injection pressure. It has been observed that a decrease of elastic modulus results in a smaller of $\mathrm{CO}_{2}$ plume for fixed injection pressure and time period. In general, higher injection pressure causes further extension of $\mathrm{CO}_{2}$ plume. A proper range of injection pressure, however, is necessary to prevent $\mathrm{CO}_{2}$ migration into overlying strata.

As one of the factors of interest, total injected amount of $\mathrm{CO}_{2}$ was investigated in the numerical analysis. It is associated with the injection pressure, reservoir permeability, reservoir thickness and reservoir elastic modulus. Total injection amount is approximately linearly proportional to injection pressure while elastic modulus has inverse effects on injection amounts of $\mathrm{CO}_{2}$. 
Deformation of the strata overlying the injection points can be one of the concerns related to high-pressure injection. Small vertical displacements at the ground surface were observed during the numerical analysis of all the selected sites. In fact, the overburden deformations at ground surface $\mathrm{CO}_{2}$ can be expected to be very small due to the depth of injection points. However, constant measurements of surface deformation can be used to monitor the movement of $\mathrm{CO}_{2}$ plume to detect large amount of $\mathrm{CO}_{2}$ leakage.

The screening criteria for selection of sites should include reservoir properties such as elastic properties, permeability, porosity, reservoir thickness and depth. Also, these properties for overburden strata can also influence the overburden response during and after geologic sequestration of $\mathrm{CO}_{2}$ in coal seam. Furthermore, proper injection pressure needs to be determined to prevent $\mathrm{CO}_{2}$ leakages while achieving the maximum injection amount. 


\section{REFERENCES}

ABAQUS version 6.2. (2001). ABAQUS Standard User's Manual, 6.7.2-1. Hibbitt, Karlsson \& Sorensen, Inc., Pawtucket, Rhode Island.

ABAQUS version 5.8. (1998). ABAQUS Theory Manual, 2.8.1-1. Hibbitt, Karlsson \& Sorensen, Inc., Pawtucket, Rhode Island.

Angus, S., Armstrong, B. and Reuck, K. M. de. (1976). International Thermodynamic Tables of the Fluid State, Carbon Dioxide. Pergamon Press, Oxford.

Bachu, S. (2002). Sequestration of $\mathrm{CO}_{2}$ in geological media in response to climate change: Road map for site selection using the transform of the geologic space into the $\mathrm{CO}_{2}$ phase space. Energy Conversion and Management, 43(1): 87-102.

Bear, J. (1972). Dynamics of Fluids in Porous Media. American Elsevier Publishing Company, inc., New York.

Bhatt, S.K. (1995). Appalachian coal: an overview. Mining Engineering, 47(12): 10891090.

Bruant, R.G., Jr., Guswa, A.J., Celia, M.A., and Peters, C.A. (2002). Safe storage of $\mathrm{CO}_{2}$ in deep saline aquifers. Environmental Science \& Technology, June 1, 241A-245A

Cairns, G.L. (2002). Enhanced coal bed methane production and sequestration of $\mathrm{CO}_{2}$ in unmineable coal seams. Semi-Annual Progress Report under Contractor No. DEFC26-01NT41148.

Celia, M.A., Bachu, S., Nordbotten, J.M., Gasda, S.E., and Dahle, H.K. (2004). Quantitative estimation of $\mathrm{CO}_{2}$ leakage from geological storage: analytical models, numerical models, and data needs. Proc. GHGT-7 Meeting, Vancouver, September 2004.

Cook, R.D., Malkus, D.S., Plesha, M.E., and Witt, R.J. (2004). Concepts and Applications of Finite Element. $4^{\text {th }}$ edition, John Wiley \& Sons, Inc., New York.

Department of Energy (DOE). (1999). Carbon Sequestration Research and Development. www.ornl.gov/carbon_sequestration/

Department of Energy (DOE). (2002). $\mathrm{CO}_{2}$ Capture and Storage in Geologic Formations. U.S. DOE, Office of Fossil Energy, Washington DC. January, 2002.

Department of Energy (DOE). (2005a). Emissions of Greenhouse Gases in the United States 2004. DOE/EIA-0573(2004). 
Department of Energy DOE. (2005b). Carbon Sequestration Technology Roadmap and Program Plan 2005.

Environmental Protection Agency (EPA). (1994). Determination of maximum injection pressure for Class I wells. EPA Region 5-UIC Section Regional Guidance \#7.

Environmental Protection Agency (EPA). (2002). Protecting Drinking Water through Underground Injection Control-Drinking Water Pocket Guide \# 2. EPA 816-K-02001

Environmental Protection Agency (EPA). (2004). Evaluation of Impacts to Underground Sources of Drinking Water by Hydraulic Fracturing of Coalbed Methane Reservoirs. EPA 816-R-04-003

Environmental Protection Agency (EPA). (2005). Inventory of U.S. Greenhouse Gases Emissions and Sinks: 1990-2003. EPA 430-R-05-003.

Fenghour, A., Wakeham, W.A and Vesovic, V. (1998). The viscosity of carbon dioxide. Journal of Physical and Chemical Reference Data, 271:31-44.

Fredlund, D. G. and Rahardjo, H., (1993). Soil Mechanics for Unsaturated Soils. John Wiley \& Sons, Inc., New York.

Gale J. and Paul Freund. (2001). Coal-bed methane enhancement with $\mathrm{CO}_{2}$ sequestration worldwide potential. Environmental Geosciences, 8(3): 210-217.

Gamson, P.D., B.Basil Beamish, and David P. Johnson. (1993). Coal microstructures and micropermeability and their effects on natural gas recovery. Fuel, 72(1): 87-99.

Gan, H., S.P.Nandi, and P.L.Walker, Jr. (1972). Nature of the porosity in American coals. Fuel, 51(4):272-277.

Gray, Ian. (1987). Reservoir Engineering in Coal Seams: Part 1 - The Physical Process of Gas Storage and Movement in Coal Seams. SPE Reservoir Engineering, 2(1): 2834.

Harpalani, S., and Richard A. Schraufnagel. (1990). Shrinkage of coal matrix with release of gas and its impact on permeability of coal. Fuel, 69(5): 551-556.

Hohn, M.E., McDowell R.R., Vargo, A.G., Matchen, D.L., Heald, M.T., and Britton, J.Q. (1993). Petroleum geology and reservoir characterization of the Big Injun Sandstone (Price Formation) in the Granny Creek field, Clay and Roane counties, West Virginia. West Virginia Geological and Economic Survey Publication B-44.

Intergovernmental Panel on Climate Change (IPCC). (2001). Climate Change 2001: A Scientific Basis. Cambridge University Press, Cambridge, U.K. 
Kroos, B.M., van Bergen, F., Gensterblum, Y., Siemons, N, Pagnier, H. J. Ml, and David, P., (2001). High Pressure Methane and Carbon Dioxide Sorption on Dry and Moisture-Equilibrated Pennsylvanian Coals. International Journal of Coal Geology, 51: 69-92.

Mavor, M.J., William D. Gunter, Jhon R. Robinson, and John Gale, (2002). Testing for $\mathrm{CO}_{2}$ sequestration and enhanced methane production from coal. SPE Gas Technology Symposium Liquid Fuels Use Chronometric Spectrum, April 30May 2, Calgary, Alberta, Canada.

McElhiney, J.E., R.A. Koenig, and R.A. Schraufnagel. (1989). Evaluation of coalbed methane reserves involves different techniques. Oil \& Gas Journal, 87(44): 63-72.

Mckee, C.R., Bumb, A.C., and Koenig, R.A. (1988). Stress-dependent permeability and porosity of coal and other geologic formations. SPE Formation Evaluation, 3(1):81-91.

Mclntyre, M.R., R.H. Groshong, J.C. Pashin and Hongwei Yin. (2003). Structure of Cedar Cove and Peterson Coalbed Methane Fields and Correlation to Gas and Water Production. Report for the contract DE-FC26-00NT40927 with DOE.

Olague, N.E. and Smith, D.M. (1989). Diffusion of gases in American coals. Fuel, 68(11):1381-1387.

Pashin, J. C., Carroll, R.E., Richard H. Groshong, Jr., Dorothy E. Raymond, Marcella McIntyre, and J. Wayne Payton. (2004). Geologic Screen Criteria for Sequestration of $\mathrm{CO}_{2}$ in Coal: Quantifying Potential of the Black Warrior Coalbed Methane Fairway, Alabama. Final Report submitted to NETL under contract DE-FC26-00NT40927.

Pashin, J. C., and McIntyre, M.R. (2003). Temperature-pressure conditions in coalbed methane reservoirs of the Black Warrior basin: implications for carbon sequestration and enhanced coalbed methane recovery. International Journal of Coal Geology, 54: 167-183.

Peng, D.Y. and Donald B. Robinson. (1976). A new tow-constant equation of state. Ind. Eng. Chem., Fundam., 15(1): 59-64.

Reeves, Scott R. (2001). Geological sequestration of $\mathrm{CO}_{2}$ in deep, unmineable coalbeds: in integrated research and commercial-scale field demonstration project. SPE Annual Technical Conference and Exhibition, New Orleans, Louisiana, Sep.30-Oct.3, 2001.

Reucroft, P.J. and H.Patel. (1986). Gas-induced swelling in coal. Fuel, 65(6):816-820. 
Rogers, R. E. (1994). Coalbed Methane: Principles and Practice. PTR Prentice Hall, New Jersey.

Rosenbaum, E. J. (1970). Physical Chemistry. Meredith Corporation, New York.

Ruppert, L.F., and Rice, C.L. (2001). Chapter B-Coal resource assessment methodology and geology of the northern and central Appalachian Basin coal regions, in Northern and Central Appalachian Basin Coal Regions Assessment Team, 2000 resource assessment of selected coal beds and zones in the northern and central Appalachian Basin coal regions. U.S. Geological Survey Professional Paper 1625-C, CD-ROM, version 1.0.

Ruppert, L.F., Suan Tewalt, and Linda Bragg. (2002). Coal resources of selected coal beds and zones in the northern and central Appalachian basin. U.S. Geological Survey Fact Sheet FS-004-02.

Sams, W.N., Bromhal, G., Jikich, S., Ertekin, T., and Smith, D.H. (2005). Field-project Designs for carbon dioxide sequestration and enhanced coalbed methane production. Energy \& Fuels, 19:2287-2297.

Sheriff, Robert E. (1973). Encyclopedic Dictionary of Exploration Geophysics. Society of Exploration Geophysicist, Okla.

Slatick, E.R., and B.D.Hong. (1995). Coal geology, reserves and production in northern and central Appalachia. Mining Engineering, 47(12): 1091-1093.

Smith, R.V., Burtch, F.W., and Watts, R.J. (1983). Project reveals $\mathrm{CO}_{2}$ confinement problems. Oil \& Gas Journal, 81(4):60-66.

Smosna, R., and Bruner, K.R. (1997). Braid-delta facies interpreted from cores, Granny Creek oil field of West Virginia. Southeastern Geology, 37(1): 39-54.

Soave, G. (1993). 20 years of Redlich-Kwong equation of state. Fluid Phase Equilibria. 82(1):345-359.

Soo, S.L. (1967). Fluid Dynamics of Multiphase Systems. Blaisdell Publishing Company, Massachusetts.

Span, R. and Wagner, W. (1996). Equation of state for carbon dioxide covering the fluid region triple-point temperature to $1100 \mathrm{~K}$ at pressure up to $800 \mathrm{MPa}$. J. Phys. Chem. Ref. Data, 256:1509-1596.

Stevens, S.H. (2002). Presentation. First International Forum on Geologic Sequestration of $\mathrm{CO}_{2}$ in Deep, Unmineable Coalseams, March 14-15, Houston, TX.

Terzaghi, K. (1943). Theoretical Soil Mechanics. John Wiley \& Sons, Inc., New York. 
Terzaghi, K., Peck, R. B., and Mesri, G. (1996). Soil Mechanics in Engineering Practice. Third Edition. John Wiley \& Sons, Inc., New York.

Thomas, W.A. (1988). The Black Warrior basin, in Sloss, L.L., ed., Sedimentary Cover North American Craton. The Geology of North America, Vol. D-2, Geology Society of America, Boulder CO.

Vargaftik, N. B., Vinogradov, Y. K., and Yargin, V. S. (1996). Handbook of Physical Properties of Liquids and Gases. Begell House, New York, third edition.

Vesovic, V., Wakeham, W. A., Olchowy, G. A., Sengers, J. V., Watson, J. T. R. and Millat, J. (1990). The transport properties of carbon dioxide. Journal of Physical and Chemical Reference Data, 193: 763-808.

White, Curt M., Smith, D.H., Jones, K.L., Goodman, A.L., Jikich, S.A., LaCount, R.B. , DuBose, S.B., Ozdemir, E., Morsi, B.I., and Schroeder, K.T. (2005). Sequestration of carbon dioxide in coal with enhanced coalbed methane recovery - a review. Energy \& Fuels, 19(3): 659-724.

Whittaker, B.N., Singh, R.N., and Sun, G. (1992). Rock Fracture Mechanics - Principles, Design and Applications. Elsevier, New York.

Wilson, T. H. (2006). Personal communication on geophysical data for Granny Creek field.

Wilson, T.H., Jamie Tallman, Henry Rauch, Arthur Wells, and Duane Smith. (2003). Reconnaissance studies of a pilot carbon sequestration site in the central Appalachians of West Virginia. Northeastern Geology and Environmental Sciences, 25(4):330-345

Yang, R. T., and Saunders, J. T. (1985). Adsorption of Gases on Coals and Heat-treated Coals at Elevated Temperature and Pressure. Fuel, 64: 616-620 


\section{APPENDIX A - RESULTS FOR THE SITE IN MARSHALL COUNTY, WEST VIRGINIA}
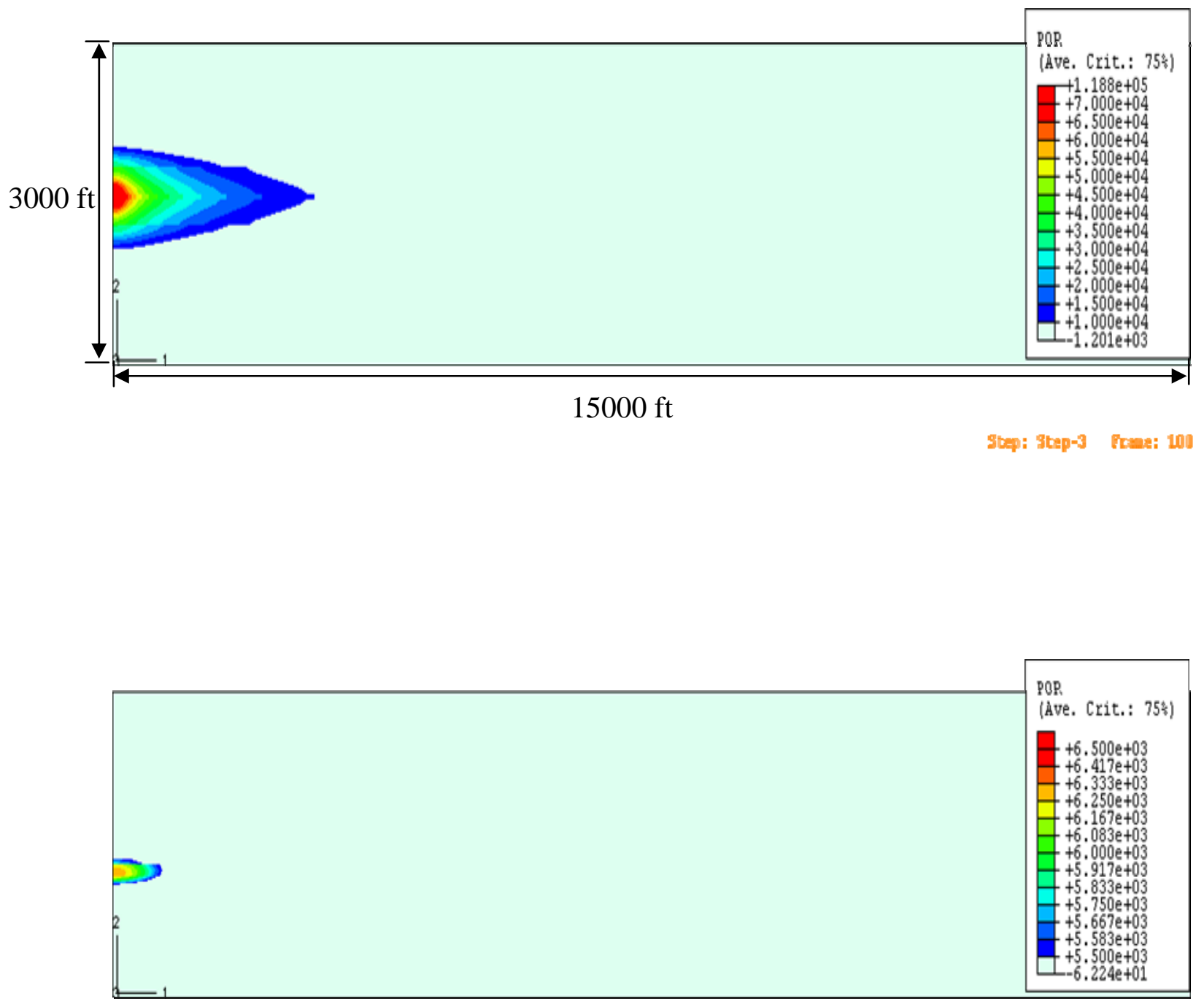

Figure A.1: Distribution of the excess pore pressure at the end of injection and dissipation periods 


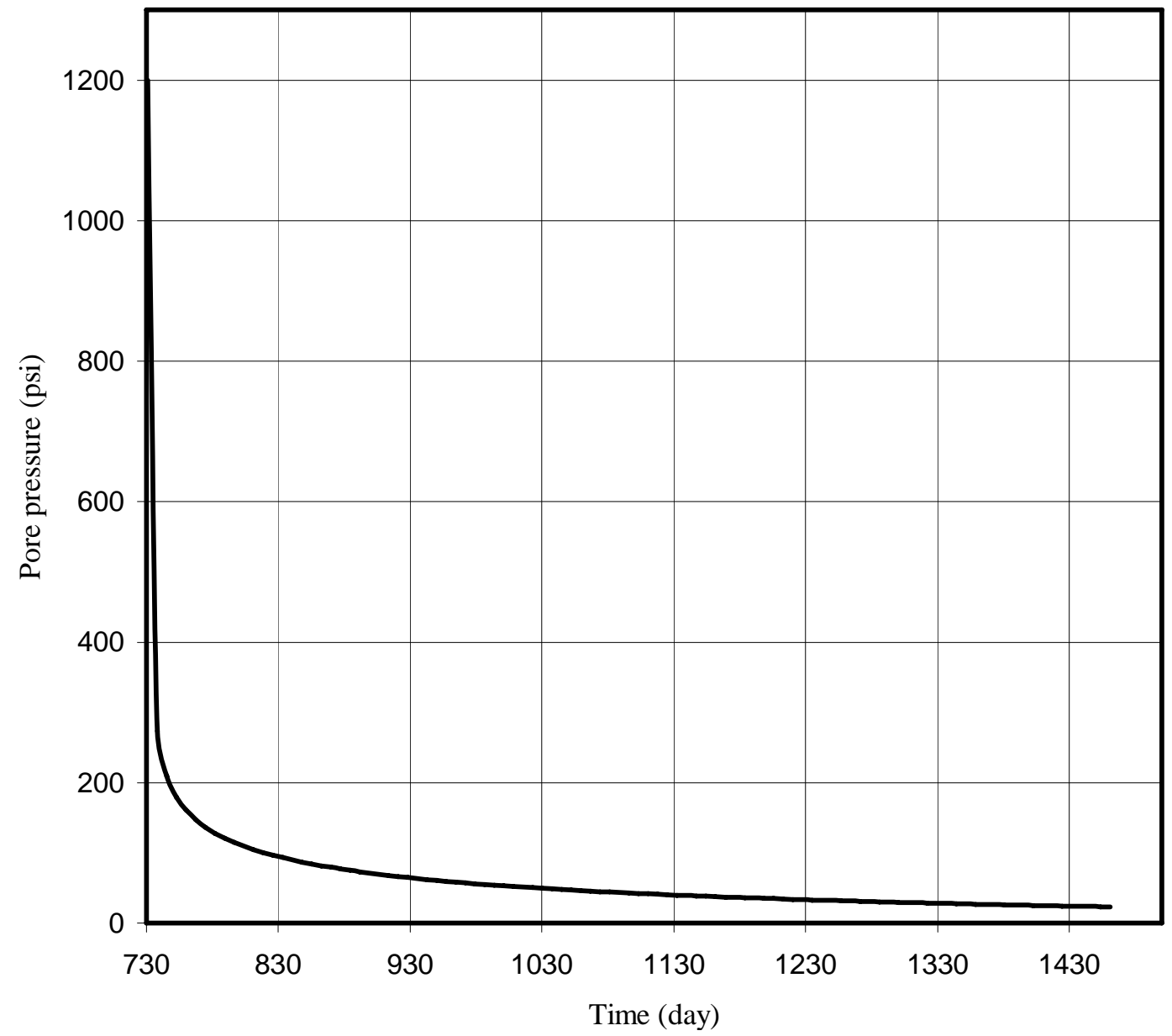

Figure A.2: Pore pressure dissipation after $\mathrm{CO}_{2}$ injection at the site in Marshall County, West Virginia 


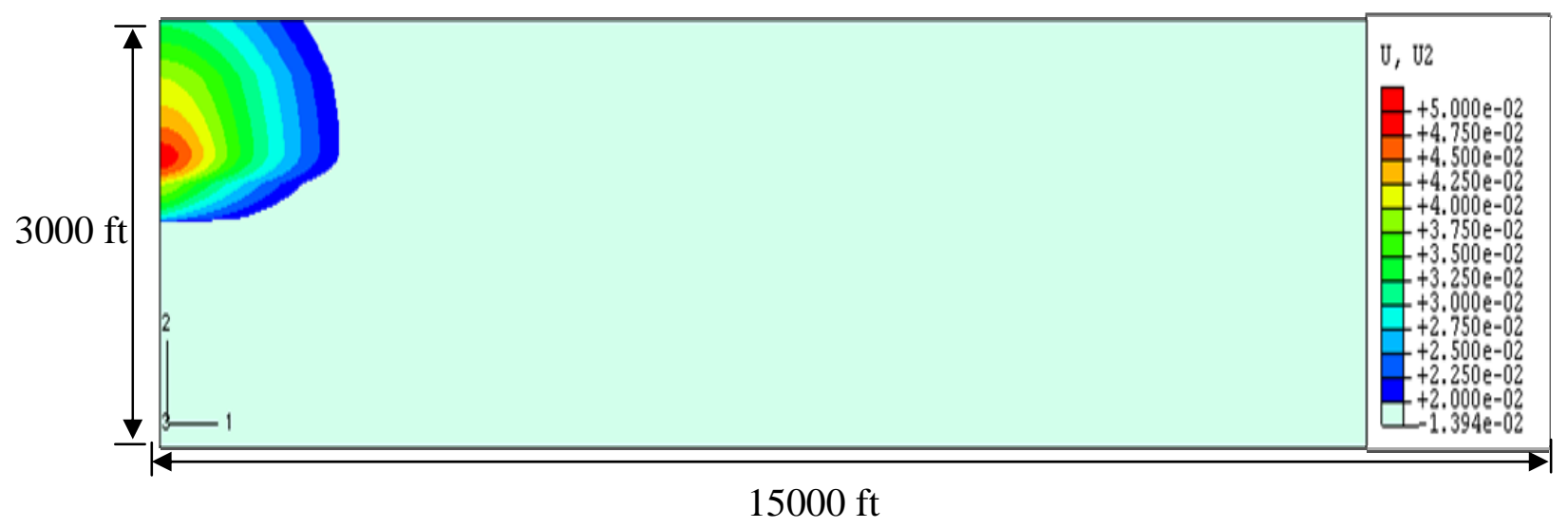

Figure A.3: Vertical displacement of the strata at the end of $\mathrm{CO}_{2}$ injection

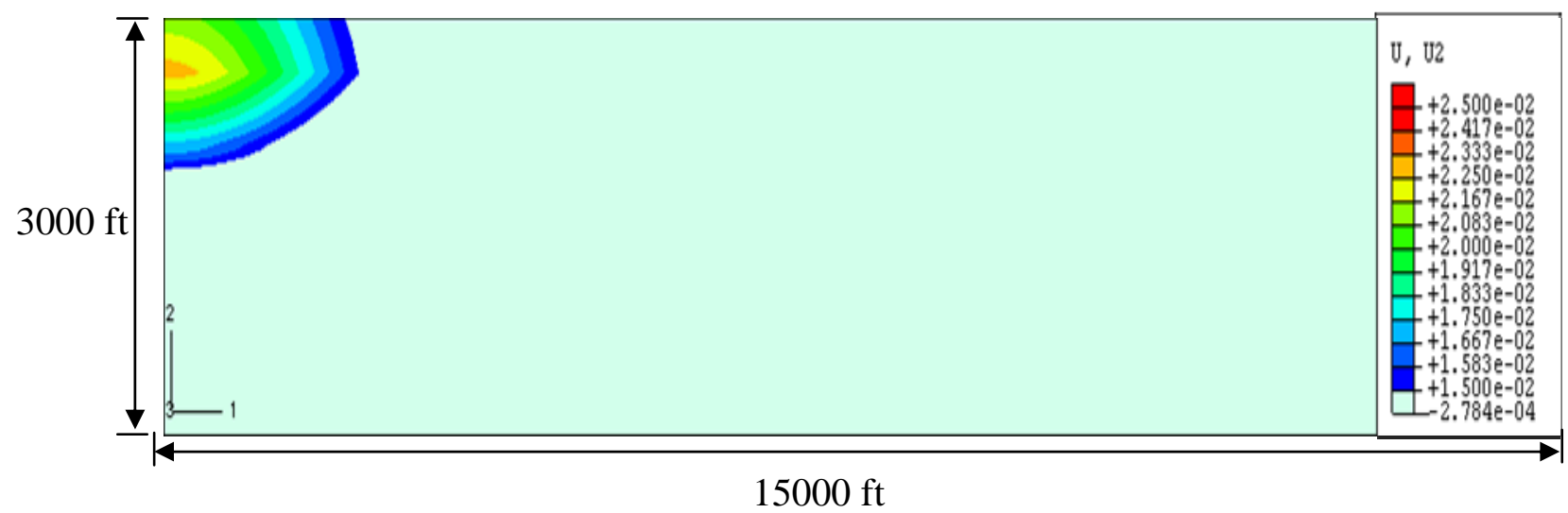

Figure A.4: Vertical displacement of the strata at the end of dissipation period 


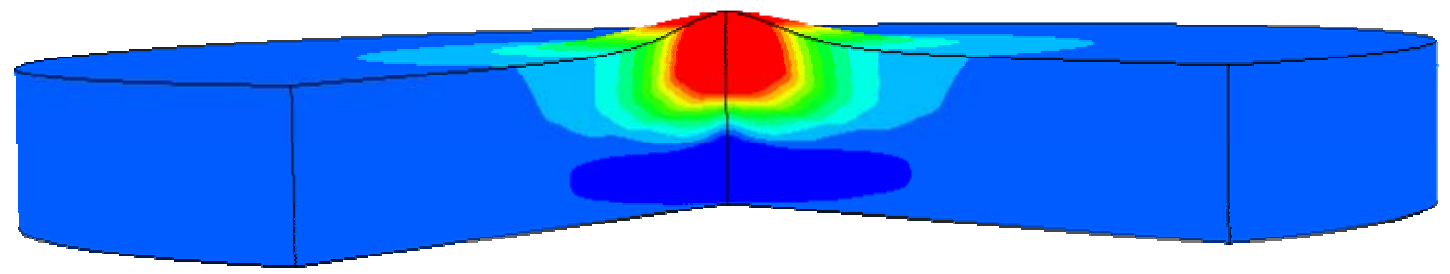

Figure A.5: 3-D view of the strata deformation at the end of $\mathrm{CO}_{2}$ injection 


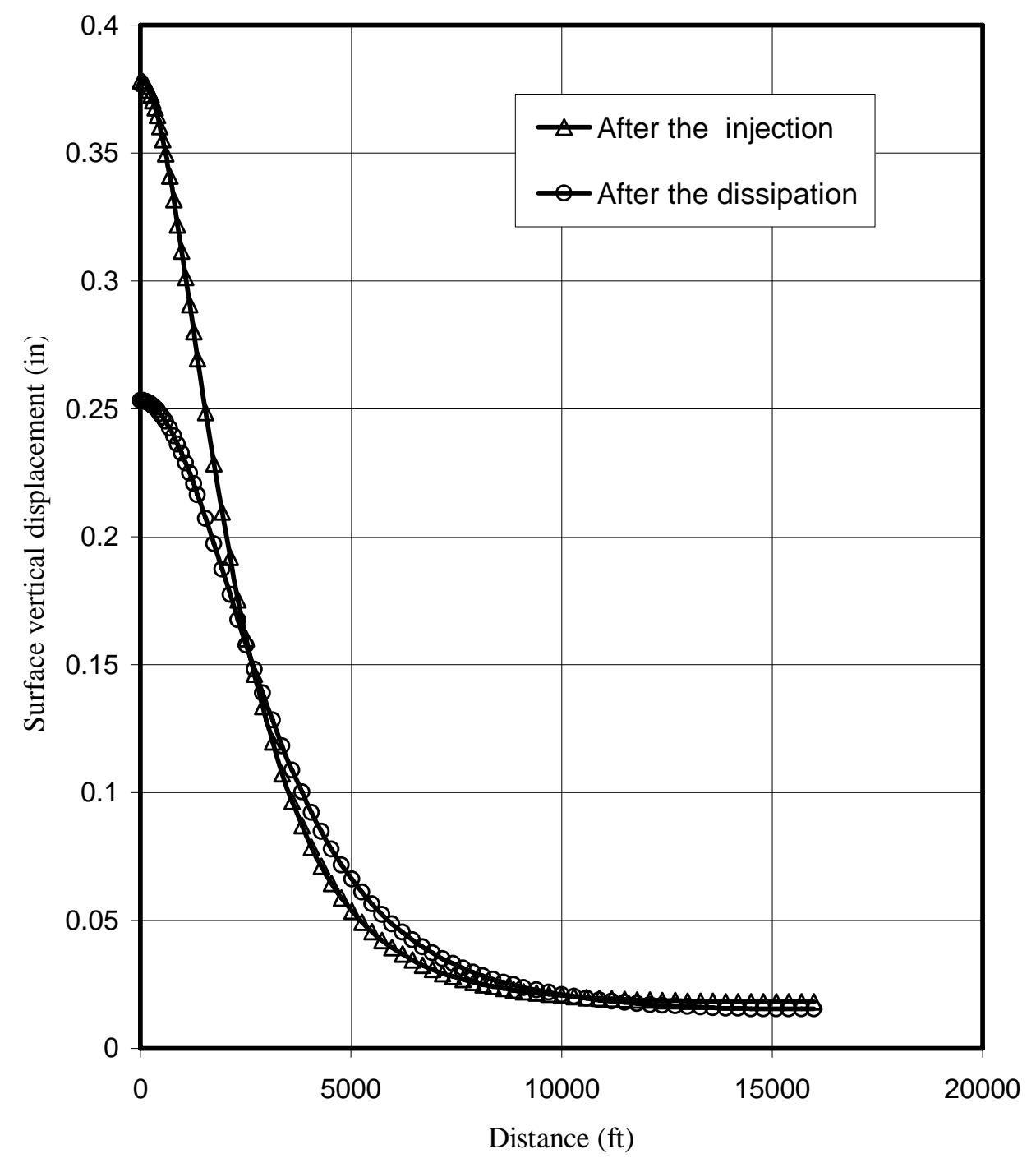

Figure A.6: vertical displacement at the ground surface at the Marshall county case 